\title{
Complex organic molecules in strongly UV-irradiated gas ${ }^{\star}$
}

\author{
S. Cuadrado ${ }^{1}$, J. R. Goicoechea ${ }^{1}$, J. Cernicharo ${ }^{1}$, A. Fuente ${ }^{2}$, J. Pety ${ }^{3,4}$, and B. Tercero ${ }^{1}$ \\ ${ }^{1}$ Grupo de Astrofísica Molecular. Instituto de Ciencia de Materiales de Madrid (CSIC), Sor Juana Inés de la Cruz 3 , \\ 28049 Cantoblanco, Madrid, Spain \\ e-mail: s.cuadrado@icmm.csic.es \\ 2 Observatorio Astronómico Nacional, Apdo. 112, 28803 Alcalá de Henares, Madrid, Spain \\ ${ }^{3}$ Institut de Radioastronomie Millimétrique (IRAM), 300 rue de la Piscine, 38406 Saint-Martin d'Hères, France \\ ${ }^{4}$ LERMA, Observatoire de Paris, CNRS UMR 8112, École Normale Supérieure, PSL research university, 24 rue Lhomond, \\ 75231 Paris Cedex 05, France
}

Received 18 January 2017 / Accepted 12 May 2017

\begin{abstract}
We investigate the presence of complex organic molecules (COMs) in strongly UV-irradiated interstellar molecular gas. We have carried out a complete millimetre $(\mathrm{mm})$ line survey using the IRAM $30 \mathrm{~m}$ telescope towards the edge of the Orion Bar photodissociation region (PDR), close to the $\mathrm{H}_{2}$ dissociation front, a position irradiated by a very intense far-UV (FUV) radiation field. These observations have been complemented with 8.5" resolution maps of the $\mathrm{H}_{2} \mathrm{CO} J_{K_{\mathrm{a}}, K_{\mathrm{c}}}=5_{1,5} \rightarrow 4_{1,4}$ and $\mathrm{C}^{18} \mathrm{O} J=3 \rightarrow 2 \mathrm{emission}$ at $0.9 \mathrm{~mm}$. Despite being a harsh environment, we detect more than 250 lines from COMs and related precursors: $\mathrm{H}_{2} \mathrm{CO}, \mathrm{CH}_{3} \mathrm{OH}, \mathrm{HCO}, \mathrm{H}_{2} \mathrm{CCO}$, $\mathrm{CH}_{3} \mathrm{CHO}, \mathrm{H}_{2} \mathrm{CS}, \mathrm{HCOOH}, \mathrm{CH}_{3} \mathrm{CN}, \mathrm{CH}_{2} \mathrm{NH}, \mathrm{HNCO}, \mathrm{H}_{2}^{13} \mathrm{CO}$, and $\mathrm{HC}_{3} \mathrm{~N}$ (in decreasing order of abundance). For each species, the large number of detected lines allowed us to accurately constrain their rotational temperatures $\left(T_{\text {rot }}\right)$ and column densities $(N)$. Owing to subthermal excitation and intricate spectroscopy of some COMs (symmetric- and asymmetric-top molecules such as $\mathrm{CH}_{3} \mathrm{CN}$ and $\mathrm{H}_{2} \mathrm{CO}$, respectively), a correct determination of $N$ and $T_{\text {rot }}$ requires building rotational population diagrams of their rotational ladders separately. The inferred column densities are in the $10^{11}-10^{13} \mathrm{~cm}^{-2}$ range. We also provide accurate upper limit abundances for chemically related molecules that might have been expected, but are not conclusively detected at the edge of the PDR (HDCO, $\mathrm{CH}_{3} \mathrm{O}, \mathrm{CH}_{3} \mathrm{NC}, \mathrm{CH}_{3} \mathrm{CCH}, \mathrm{CH}_{3} \mathrm{OCH}_{3}, \mathrm{HCOOCH}_{3}, \mathrm{CH}_{3} \mathrm{CH}_{2} \mathrm{OH}, \mathrm{CH}_{3} \mathrm{CH}_{2} \mathrm{CN}$, and $\mathrm{CH}_{2} \mathrm{CHCN}$ ). A non-thermodynamic equilibrium excitation analysis for molecules with known collisional rate coefficients suggests that some COMs arise from different PDR layers but we cannot resolve them spatially. In particular, $\mathrm{H}_{2} \mathrm{CO}$ and $\mathrm{CH}_{3} \mathrm{CN}$ survive in the extended gas directly exposed to the strong FUV flux $\left(T_{\mathrm{k}}=150-250 \mathrm{~K}\right.$ and $\left.T_{\mathrm{d}} \gtrsim 60 \mathrm{~K}\right)$, whereas $\mathrm{CH}_{3} \mathrm{OH}$ only arises from denser and cooler gas clumps in the more shielded PDR interior $\left(T_{\mathrm{k}}=40-50 \mathrm{~K}\right)$. The non-detection of HDCO towards the PDR edge is consistent with the minor role of pure gas-phase deuteration at very high temperatures. We find a $\mathrm{HCO} / \mathrm{H}_{2} \mathrm{CO} / \mathrm{CH}_{3} \mathrm{OH} \simeq 1 / 5 / 3$ abundance ratio. These ratios are different from those inferred in hot cores and shocks. Taking into account the elevated gas and dust temperatures at the edge of the Bar (mostly mantle-free grains), we suggest the following scenarios for the formation of COMs: (i) hot gas-phase reactions not included in current models; (ii) warm grain-surface chemistry; or (iii) the PDR dynamics is such that COMs or precursors formed in cold icy grains deeper inside the molecular cloud desorb and advect into the PDR.
\end{abstract}

Key words. astrochemistry - surveys - photon-dominated region (PDR) - ISM: molecules - ISM: abundances

\section{Introduction}

Almost 200 molecules have been detected in the interstellar medium (ISM) and circumstellar shells. A very large fraction of them are complex organic molecules (COMs). COMs are traditionally defined as carbon-based molecular species with more than six atoms in their structure (Herbst \& van Dishoeck 2009; Caselli \& Ceccarelli 2012). To date, the largest organic molecules detected in the ISM (excluding PAHs and fullerenes) are propyl cyanide $\left(\mathrm{C}_{3} \mathrm{H}_{7} \mathrm{CN}\right.$; Belloche et al. 2009, 2014) and benzene $\left(\mathrm{c}-\mathrm{C}_{6} \mathrm{H}_{6}\right.$; Cernicharo et al. 2001).

COMs have been detected in the ISM since the 1970s (e.g. $\mathrm{CH}_{3} \mathrm{CHO}$, Gottlieb 1973; or $\mathrm{HCOOCH}_{3}$, Brown et al. 1975). Most of the detections have been reported towards hot cores, that is, dense gas surrounding high-mass protostars in massive star-forming regions such as Sgr B2 and Orion KL (e.g.

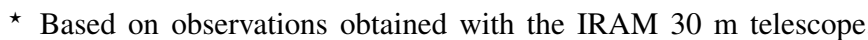
IRAM is supported by INSU/CNRS (France), MPG (Germany), and IGN (Spain).
}

Bisschop et al. 2007; Ziurys \& McGonagle 1993; Tercero et al. 2013, 2015; Ikeda et al. 2001), and towards hot corinos, that is, the low-mass analogs of hot cores such as IRAS 16293-2422 (Cazaux et al. 2003) and NGC 1333 IRAS 4A (Bottinelli et al. 2004). The high degree of chemical complexity (e.g. $\mathrm{C}_{2} \mathrm{H}_{5} \mathrm{CN}$, $\left.\mathrm{CH}_{3} \mathrm{CCH}, \mathrm{HCOOCH}_{3}, \mathrm{CH}_{3} \mathrm{OCH}_{3}, \ldots\right)$ found in these protostellar sources is thought to result from thermal desorption of the ice mantles coating dust grains. Herbst \& van Dishoeck (2009) have reviewed the subject. They classify the observed COMs towards protostars in three different generations depending on the time they are produced. The zeroth-generation species, such as $\mathrm{H}_{2} \mathrm{CO}$ and $\mathrm{CH}_{3} \mathrm{OH}$, are formed through grain-surface reactions in a previous cold interstellar phase in which icy mantles built up around granular cores of carbon and silicate grains. The firstgeneration species, such as $\mathrm{HCOOCH}_{3}$, are formed during the passive warm-up of the inner envelope of the protostar. During this phase, zeroth-generation species are photodissociated producing radicals such as $\mathrm{HCO}$ and $\mathrm{CH}_{3} \mathrm{O}$, which can associate through surface reactions to form larger molecules. Finally, the 
second-generation species are formed once the core has become a hot core or hot corino. The dust temperature at this stage is high enough $\left(T_{\mathrm{d}} \gtrsim 100 \mathrm{~K}\right)$ to sublimate the mantles completely, and new molecules are formed through warm gas-phase reactions (ion molecule and endothermic neutral-neutral reactions).

When protostellar outflows impact the ambient envelope material, grains can be eroded, and because of the high temperatures reached in shocks, icy mantles can sublimate. In sufficiently high-velocity shocks, ices can also be sputtered and directly injected into the gas phase (e.g. $v_{\mathrm{s}}>20-25 \mathrm{~km} \mathrm{~s}^{-1}$ for water ice, Draine et al. 1983). Several observations of the L1157 outflow have revealed the existence of $\mathrm{H}_{2} \mathrm{CO}, \mathrm{H}_{2} \mathrm{CS}$, $\mathrm{CH}_{3} \mathrm{OH}, \mathrm{HC}_{3} \mathrm{~N}, \mathrm{HNCO}, \mathrm{NH}_{2} \mathrm{CHO}$, and $\mathrm{CH}_{3} \mathrm{CHO}$ in shocked gas (Bachiller \& Pérez Gutiérrez 1997; Mendoza et al. 2014; Codella et al. 2015). In addition, Requena-Torres et al. (2006) have shown that the galactic centre contains dense clouds that are rich in $\mathrm{CH}_{3} \mathrm{OH}, \mathrm{HCOOCH}_{3}$, and $\mathrm{CH}_{3} \mathrm{OCH}_{3}$. Widespread shocks have been invoked to explain their abundance and extended spatial distribution. The relative importance of the gas-phase reactions immediately after ice mantle sublimation compared to a formation of COMs on the grain surfaces is however far from being understood.

Recent observations towards UV-shielded cold cores (e.g. TMC 1, L1689B, or Barnard 1-b) have revealed molecules once considered to be present only in hot molecular cores (e.g. Remijan et al. 2006; Bacmann et al. 2012; Cernicharo et al. 2012). In these cold environments, COMs are thought to form on the surface of grains and to be released through non-thermal desorption processes, chemical desorption, direct desorption by cosmic ray impacts, or secondary photon induced processes (Cernicharo et al. 2012). Finally, a number of organic species have been identified in circumstellar envelopes around evolved stars (e.g. IRC+10216, Cernicharo et al. 2000), towards extragalactic sources (e.g. Meier \& Turner 2005, 2012; Aladro et al. 2011), meteorites (e.g. Cronin \& Chang 1993), and comets (e.g. Bockelée-Morvan et al. 2004).

Studies of environments permeated by stellar far-UV (FUV) photons $(6.0 \mathrm{eV}<h v<13.6 \mathrm{eV})$ are more scarce. Guzmán et al. (2014) and Gratier et al. (2013) presented the unexpected detection of $\mathrm{HCOOH}, \mathrm{CH}_{2} \mathrm{CO}, \mathrm{CH}_{3} \mathrm{CN}, \mathrm{CH}_{3} \mathrm{OH}, \mathrm{CH}_{3} \mathrm{CHO}$, and $\mathrm{CH}_{3} \mathrm{CCH}$ in the Horsehead photodissociation region (PDR; a relatively low-FUV-flux dense PDR, $\chi \approx 60$ times the mean interstellar field in Draine units), finding enhanced abundances compared to a nearby cold and dense core shielded from external FUV radiation. Guzmán et al. (2014) proposed that owing to the cold grain temperatures, ice-mantle photodesorption processes dominate the formation of COMs in the Horsehead. In lower-density translucent clouds $(\chi \approx 1)$, only $\mathrm{H}_{2} \mathrm{CO}$ has been unambiguously detected (Liszt et al. 2006). These observations might suggest that, in FUV-irradiated environments, the presence of COMs diminishes as the $\chi / n_{\mathrm{H}}$ ratio increases. Thus, COMs might not be present in strongly FUV-irradiated gas.

In this work we test the above hypothesis and investigate the presence and abundances of COMs at the high FUV-illuminated edge of the Orion Bar, with an impinging radiation field of a few $10^{4}$ times the mean interstellar field (Marconi et al. 1998). Because of its proximity (414 \pm 7 pc, Menten et al. 2007) and nearly edge-on orientation, the Orion Bar provides an excellent template to determine the chemical content and also to investigate the structure and dynamics of strongly FUV-irradiated molecular gas (e.g. Tielens et al. 1993; Hogerheijde et al. 1995; Cuadrado et al. 2015, 2016; Goicoechea et al. 2016).

Multi-wavelength observations towards different positions of the Orion Bar have been historically used in the development of PDR models (e.g. Tielens \& Hollenbach 1985a,b) and today they are still used as a template to understand the unresolved emission from sources as different as the nuclei of distant starburst galaxies (e.g. Fuente et al. 2008) or the illuminated surfaces of protoplanetary disks (e.g. Agúndez et al. 2008). The transition from ionised to neutral gas in the Orion Bar has been extensively mapped, generally at low angular resolution, in various atomic and molecular tracers (see e.g. Tielens et al. 1993; Hogerheijde et al. 1995; van der Werf et al. 1996; Walmsley et al. 2000; Leurini et al. 2010; Ossenkopf et al. 2013). The detailed analysis of these observations suggested an inhomogeneous density distribution. The most commonly accepted scenario is that an extended gas component, with mean gas densities of $10^{4}-10^{5} \mathrm{~cm}^{-3}$, causes the chemical stratification seen perpendicular to the dissociation front as the FUV field is attenuated (Hogerheijde et al. 1995; Jansen et al. 1995; Simon et al. 1997; van der Wiel et al. 2009; Habart et al. 2010; van der Tak et al. 2013). In addition, another component of clumpy material with higher densities $\left(\gtrsim 10^{6} \mathrm{~cm}^{-3}\right)$ and more shielded from FUV radiation is embedded in the interclump gas (Burton et al. 1990; Parmar et al. 1991; Stoerzer et al. 1995; Young Owl et al. 2000; Lis \& Schilke 2003; Batrla \& Wilson 2003; Andree-Labsch et al. 2017). Previous observations of $\mathrm{H}_{2} \mathrm{CO}$ and $\mathrm{CH}_{3} \mathrm{OH}$ in the Orion Bar have shown that the two molecules trace these two different environments: $\mathrm{CH}_{3} \mathrm{OH}$, the denser and cooler clumps seen deeper inside the Bar, and $\mathrm{H}_{2} \mathrm{CO}$, the warmer interclump medium directly exposed to the strong FUV-field (Leurini et al. 2006, 2010).

We have performed a complete millimetre line survey using the IRAM $30 \mathrm{~m}$ telescope towards the edge of Orion Bar, a high FUV-illuminated position close to what Stoerzer et al. (1995) call the "CO${ }^{+}$peak", near the $\mathrm{H}_{2}$ dissociation front (see Fig. 1). This position shows a distinctive chemistry that can only be understood due to the presence of a strong flux of FUV photons (e.g. compared to that in the more shielded clumps deeper inside the Bar): enhanced abundances of simple reactive ions (e.g. $\mathrm{CH}^{+}, \mathrm{CO}^{+}$, and $\mathrm{HOC}^{+}$) and small hydrocarbon ions (e.g. $l-\mathrm{C}_{3} \mathrm{H}^{+}$) that are only abundant in the presence of $\mathrm{C}^{+}$; vibrationally excited $\mathrm{H}_{2}$; and high gas temperatures (e.g. Nagy et al. 2013; Guzmán et al. 2015; Cuadrado et al. 2015). Indeed, highangular resolution ALMA-ACA images do show that reactive ions such as $\mathrm{SH}^{+}$or $\mathrm{HOC}^{+}$do not emit from the more shielded clumps (Goicoechea et al. 2017). Therefore, their chemistry is different to that of the PDR edge observed in this work. Our survey covers $\sim 220 \mathrm{GHz}$ of bandwidth, between $80 \mathrm{GHz}$ and $360 \mathrm{GHz}$. These observations have been complemented with several 8.5" resolution maps of different molecules at $0.9 \mathrm{~mm}$ to put our line survey position in the context of the Bar large-scale emission. In this paper we focus on the detection of rotational lines from COMs and related precursors.

The paper is organised as follows. In Sect. 2 we describe the line survey and the mapping observations. In Sect. 3 we report the observational features of the detected organic molecules, while in Sect. 4 we present the $\mathrm{C}^{18} \mathrm{O}$ and $\mathrm{H}_{2} \mathrm{CO}$ integrated line intensity maps at $0.9 \mathrm{~mm}$. The data analysis is explained in Sect. 5. In Sect. 6 we discuss the results, and finally in Sect. 7 we summarise the main conclusions.

\section{Observations and data reduction}

\subsection{Line survey}

We performed a complete millimetre line survey towards the edge of Orion Bar using the IRAM 30 mtelescope. The target position is at $\alpha_{2000}=05^{\mathrm{h}} 35^{\mathrm{m}} 20.8^{\mathrm{s}}$, 

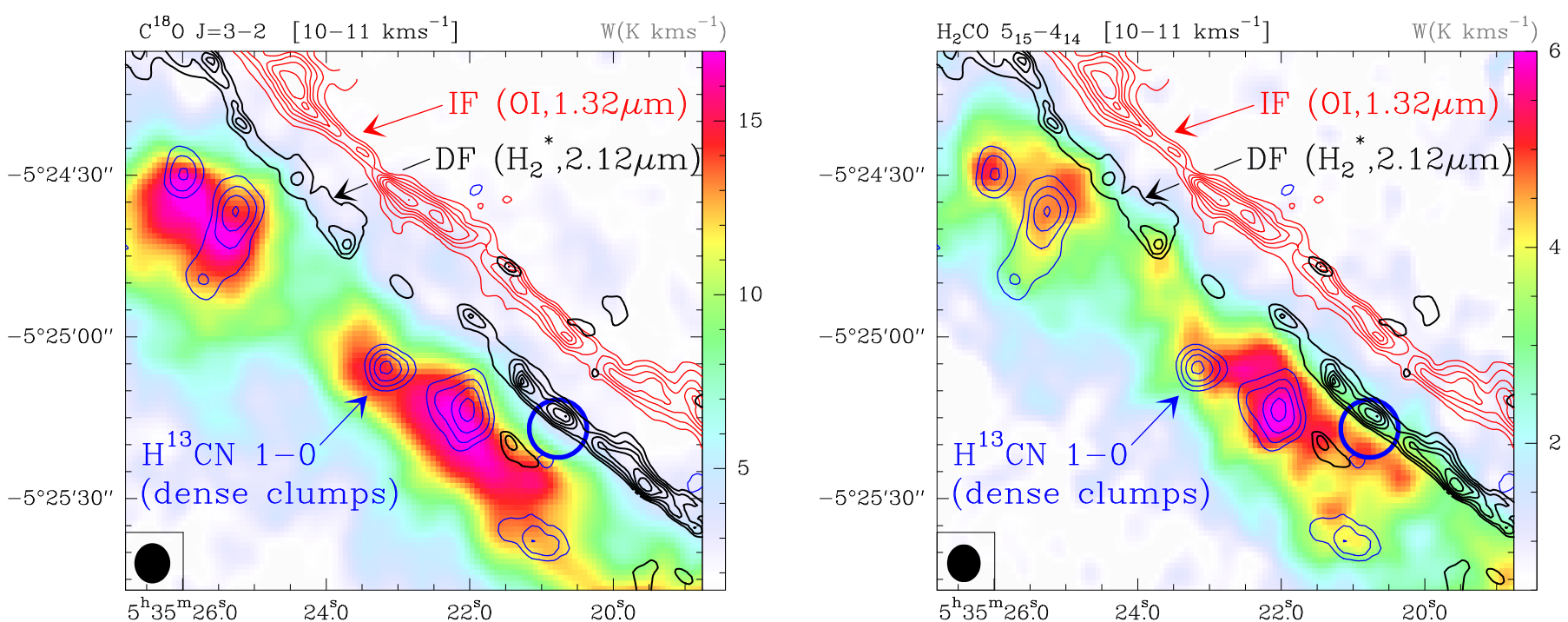

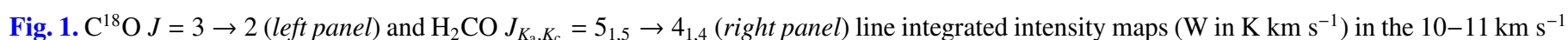
velocity interval observed with the IRAM $30 \mathrm{~m}$ telescope at $\sim 329 \mathrm{GHz}$ and $\sim 351 \mathrm{GHz}$, respectively (colour scale). Black contours are the $\mathrm{H}_{2}^{*} v=1 \rightarrow 0 S(1)$ emission delineating the $\mathrm{H}_{2}$ dissociation front (DF, Walmsley et al. 2000). The red contours represent the O I fluorescent line at $1.32 \mu \mathrm{m}$ (Walmsley et al. 2000) marking the position of the ionisation front (IF) that separates the H II region and the neutral cloud. The blue contours represent the $\mathrm{H}^{13} \mathrm{CN} J=1 \rightarrow 0$ emission tracing dense molecular clumps inside the Bar (Lis \& Schilke 2003). The target position of the Orion Bar survey, close to the DF, is indicated with a blue circle. The IRAM $30 \mathrm{~m}$ beam at $1 \mathrm{~mm}$ is plotted in the bottom left corner (black circle).

Table 1. Observed frequency ranges and telescope parameters.

\begin{tabular}{|c|c|c|c|c|c|}
\hline Rec..$^{a}$ & Backend & $\begin{array}{l}\text { Freq. }^{b} \\
{[\mathrm{GHz}]}\end{array}$ & $\begin{array}{c}\delta v^{c} \\
{\left[\mathrm{~km} \mathrm{~s}^{-1}\right]}\end{array}$ & $\eta_{\mathrm{MB}}{ }^{d}$ & $\begin{array}{l}\mathrm{HPBW}^{e} \\
{[\operatorname{arcsec}]}\end{array}$ \\
\hline E0 & FFTS & $80-117$ & $0.75-0.51$ & $0.87-0.82$ & $31-21$ \\
\hline E1 & WILMA & $128-176$ & $4.7-3.4$ & $0.80-0.74$ & $19-14$ \\
\hline E2 & FFTS & $202-275$ & $0.30-0.22$ & $0.70-0.56$ & $12-9$ \\
\hline \multirow{2}{*}{ E3 } & FFTS & $275-305$ & $0.22-0.20$ & $0.56-0.50$ & $9-8$ \\
\hline & FFTS & $328-359$ & $0.18-0.17$ & $0.46-0.40$ & $8-7$ \\
\hline
\end{tabular}

Notes. ${ }^{(a)}$ Emir receiver. ${ }^{(b)}$ Observed frequency range. ${ }^{(c)}$ Spectral resolution in velocity units $(\delta v)$ in the observed frequency ranges. ${ }^{(d)}$ Antenna efficiencies. ${ }^{(e)}$ The half power beam width can be well fitted by $\mathrm{HPBW}[\operatorname{arcsec}] \approx 2460 /$ Frequency $[\mathrm{GHz}]$.

$\delta_{2000}=-05^{\circ} 25^{\prime} 17.0^{\prime \prime}$, close to the dissociation front. This position is at $(\Delta \alpha, \Delta \delta)=\left(3^{\prime \prime},-3^{\prime \prime}\right)$ from the " $\mathrm{CO}^{+}$peak" of Stoerzer et al. (1995).

Our observations cover a total of $217 \mathrm{GHz}$ along 3, 2, 1, and $0.9 \mathrm{~mm}$ bands of the EMIR receivers using the WILMA ( $2 \mathrm{MHz}$ spectral resolution) and FTS (200 kHz spectral resolution) backends. The observing procedure was position switching (PSW) with the reference position located at an offset $\left(-600^{\prime \prime}, 00^{\prime \prime}\right)$ to avoid the extended molecular emission from the Orion Molecular Cloud (OMC-1). The antenna temperature, $T_{\mathrm{A}}^{*}$, was converted to the main beam temperature, $T_{\mathrm{MB}}$, through the $T_{\mathrm{MB}}=T_{\mathrm{A}}^{*} / \eta_{\mathrm{MB}}$ relation, where $\eta_{\mathrm{MB}}$ is the antenna efficiency. All intensities in tables and figures are in main beam temperature. A local standard of rest (LSR) of $10.7 \mathrm{~km} \mathrm{~s}^{-1}$ has been used in the line survey target position in the Orion Bar dissociation front. Table 1 shows an overview of the frequency ranges observed with each backend, the spectral resolution in velocity units $(\delta v)$ in the observed frequency ranges, as well as the variation in the telescope efficiencies, $\eta_{\mathrm{MB}}$, and the half power beam width (HPBW) across the covered frequency range.

In Appendix A we study the possible contamination of bright molecular line emission from the Orion $\mathrm{BN} / \mathrm{KL}$ region (located at a distance of $\sim 2^{\prime}$ ) through the beam side lobes (several arcmin, see Greve et al. 1998). Although the contribution to the detected power ranges from $\sim 12 \%(3 \mathrm{~mm})$ to $\sim 30 \%(0.8 \mathrm{~mm})$, most of the emission from the hot core region arises at different velocities $\left(\sim 8 \mathrm{~km} \mathrm{~s}^{-1}\right)$ than those of the Orion Bar $\left(\sim 10-11 \mathrm{~km} \mathrm{~s}^{-1}\right)$ and thus can be easily separated.

Data reduction and spectral analysis were done using the CLASS software of the GILDAS package ${ }^{1}$ developed by IRAM. Weighted spectra were averaged and calibrated, and a polynomial baseline of low order (typically second or third order) was subtracted from each $\sim 200 \mathrm{MHz}$ wide spectrum. Finally, Gaussian profiles were fitted to all the detected lines (Appendix B). The rms noise of our observations obtained after integration during $\sim 4 \mathrm{~h}$ ranges between $4 \mathrm{mK}$ and $20 \mathrm{mK}$ per resolution channel.

\subsection{Maps}

The $0.9 \mathrm{~mm}$ line emission from different molecules was mapped with the IRAM $30 \mathrm{~m}$ telescope in January 2014 under excellent winter conditions ( $<1 \mathrm{~mm}$ of precipitable water vapour). The E3 receiver and the FTS backend at $200 \mathrm{kHz}$ spectral resolution were used. On-the-fly (OTF) scans were obtained along and perpendicular to the Bar over a $170^{\prime \prime} \times 170^{\prime \prime}$ region, with an OFF position at $\left(-600^{\prime \prime}, 0^{\prime \prime}\right)$ relative to the map centre at $\alpha_{2000}=05^{\mathrm{h}} 35^{\mathrm{m}} 20.1^{\mathrm{s}}, \delta_{2000}=-05^{\circ} 25^{\prime} 07.0^{\prime \prime}$, which is slightly different from that of the line survey (see above). The HPBW at this frequency is $\sim 7^{\prime \prime}$. Data processing consisted in a linear baseline subtraction in each observed spectra. The resulting spectra were gridded to a data cube through convolution with a Gaussian kernel providing a final resolution of $8.5^{\prime \prime}$. The total integration

1 http://wWw.iram.fr/IRAMFR/GILDAS/ 
Table 2. Dipole moments $(\mu)$, number of detected lines of complex organic molecules and related organic precursors, and their corresponding Figure and Table numbers.

\begin{tabular}{lccccc}
\hline \hline Molecule & $\begin{array}{c}\text { No. of } \\
\text { lines }\end{array}$ & \multicolumn{2}{c}{$\mu$} & Fig. & Table \\
& [Debyes] & & \\
\hline $\mathrm{HCO}$ & 16 & $\mu_{a}=1.363$ & $\mu_{b}=0.700^{a}$ & 2 & $\mathrm{~B} .1$ \\
$\mathrm{H}_{2} \mathrm{CO}$ & 15 & $\mu_{a}=2.332^{b}$ & 3 & $\mathrm{~B} .2$ \\
$\mathrm{H}_{2}^{13} \mathrm{CO}$ & 8 & $\mu_{a}=2.332^{b}$ & 4 & $\mathrm{~B} .3$ \\
$\mathrm{H}_{2} \mathrm{CS}$ & 26 & $\mu_{a}=1.649^{b}$ & & 5 & $\mathrm{~B} .4$ \\
$\mathrm{HNCO}$ & 6 & $\mu_{a}=1.602$ & $\mu_{b}=1.350^{c}$ & 6 & $\mathrm{~B} .5$ \\
$\mathrm{CH}_{2} \mathrm{NH}$ & 6 & $\mu_{a}=1.340$ & $\mu_{b}=1.446^{d}$ & 7 & B.6 \\
$\mathrm{H}_{2} \mathrm{CCO}$ & 30 & $\mu_{a}=1.422^{b}$ & & 8 & B.7 \\
$\mathrm{HC}_{3} \mathrm{~N}$ & 11 & $\mu_{a}=3.732^{e}$ & & 9 & B.8 \\
$\mathrm{CH}_{3} \mathrm{CN}$ & 44 & $\mu_{a}=3.922^{f}$ & & 11 & B.9 \\
$\mathrm{CH}_{3} \mathrm{OH}$ & 55 & $\mu_{a}=0.896$ & $\mu_{b}=1.412^{g}$ & 12 & B.10 \\
$\mathrm{CH}_{3} \mathrm{CHO}$ & 36 & $\mu_{a}=2.423$ & $\mu_{b}=1.260^{h}$ & 13 & B.11 \\
\hline
\end{tabular}

References. (a) Blake et al. (1984); (b) Fabricant et al. (1977) (c) Hocking et al. (1975); (d) Allegrini et al. (1979); (e) DeLeon \& Muenter (1985); (f) Gadhi et al. (1995); (g) Sastry et al. (1981); (h) Kleiner et al. (1996).

time was approximately $6 \mathrm{~h}$, and the achieved rms noise is $\sim 1 \mathrm{~K}$ per $\sim 0.2 \mathrm{~km} \mathrm{~s}^{-1}$ channel. Figure 1 shows the $\mathrm{C}^{18} \mathrm{O} J=3 \rightarrow 2$ and $\mathrm{H}_{2} \mathrm{CO} J_{K_{\mathrm{a}}, K_{\mathrm{c}}}=5_{1,5} \rightarrow 4_{1,4}$ integrated line intensity maps in the range $v_{\mathrm{LSR}}=10-11 \mathrm{~km} \mathrm{~s}^{-1}$ in which the Orion Bar shows prominent emission. We note that van der Wiel et al. (2009) also presented a smaller $\mathrm{H}_{2} \mathrm{CO} J_{K_{\mathrm{a}}, K_{\mathrm{c}}}=5_{1,5} \rightarrow 4_{1,4}$ map at lower angular resolution (a factor of $\sim 2$ lower).

\section{Results: complex organic molecule detections}

We have identified more than 250 lines from COMs and related organic precursors. The detected lines are attributed to ten different molecules with up to seven atoms: $\mathrm{HCO}, \mathrm{HNCO}$, $\mathrm{H}_{2} \mathrm{CO}, \mathrm{H}_{2} \mathrm{CS}, \mathrm{CH}_{2} \mathrm{NH}, \mathrm{H}_{2} \mathrm{CCO}, \mathrm{HC}_{3} \mathrm{~N}, \mathrm{CH}_{3} \mathrm{OH}, \mathrm{CH}_{3} \mathrm{CN}$, and $\mathrm{CH}_{3} \mathrm{CHO}$. We also detect several lines of the isotopologue $\mathrm{H}_{2}^{13} \mathrm{CO}$. We note that among the organic molecules, we also identified several lines of formic acid, trans- and cis- $\mathrm{HCOOH}$, in the Orion Bar PDR. Cuadrado et al. (2016) have recently reported the first detection of the cis conformer of $\mathrm{HCOOH}$ in the interstellar medium as well as a detailed analysis of the detected lines of both $\mathrm{HCOOH}$ conformers in the $3 \mathrm{~mm}$ spectral band. Line profiles peak at $v_{\mathrm{LSR}}=10-11 \mathrm{~km} \mathrm{~s}^{-1}$, the velocity of the Bar, thus confirming their PDR origin. The detected organic molecules and their dipole moments are listed in Table 2.

Previous studies of the Orion Bar have already reported the presence of $\mathrm{HCO}, \mathrm{H}_{2} \mathrm{CO}$, and $\mathrm{CH}_{3} \mathrm{OH}$ in several positions close to the "CO ${ }^{+}$peak": (i) Schilke et al. (2001) detected one hyperfine component of HCO $N=1 \rightarrow 0$ using the IRAM $30 \mathrm{~m}$ telescope; (ii) Hogerheijde et al. (1995) detected nine lines of $\mathrm{H}_{2} \mathrm{CO}$ and three lines of $\mathrm{CH}_{3} \mathrm{OH}$ in several positions along the Bar using the JCMT, IRAM $30 \mathrm{~m}$, and CSO telescopes; (iii) Nagy et al. (2017) detected ten submm $\mathrm{H}_{2} \mathrm{CO}$ lines with Herschel/HIFI. In addition, $\mathrm{H}_{2} \mathrm{CO}, \mathrm{H}_{2}^{13} \mathrm{CO}, \mathrm{HDCO}, \mathrm{H}_{2} \mathrm{CS}$, and $\mathrm{CH}_{3} \mathrm{OH}$ have been detected towards the colder, denser, and more FUV-shielded clumps: (iv) Leurini et al. (2006) detected seven lines of $\mathrm{H}_{2} \mathrm{CO}$, four lines of $\mathrm{H}_{2} \mathrm{CS}$, and ten lines of $\mathrm{CH}_{3} \mathrm{OH}$ using APEX between $279 \mathrm{GHz}$ and $361.5 \mathrm{GHz}$ towards clump \#1 of Lis \& Schilke (2003); (v) Parise et al. (2009) also detected two isotopologues, one line of $\mathrm{H}_{2}^{13} \mathrm{CO}$ and one line of HDCO, towards clump \#3 of Lis \& Schilke (2003) using the IRAM $30 \mathrm{~m}$ telescope. To our knowledge, our work presents the first detection of $\mathrm{CH}_{2} \mathrm{NH}, \mathrm{H}_{2} \mathrm{CCO}, \mathrm{HC}_{3} \mathrm{~N}, \mathrm{CH}_{3} \mathrm{CN}$, and $\mathrm{CH}_{3} \mathrm{CHO}$ in the Orion Bar PDR.

Line assignment was carried out using J. Cernicharo's spectral catalogue (MADEX, Cernicharo 2012), and the JPL (Pickett et al. 1998) $^{2}$ and CDMS (Müller et al. 2001, 2005) ${ }^{3}$ public databases. Although some lines have peak intensities lower than $3 \sigma$ noise level, we included them in our results as tentative detections because other transitions from the same molecule are well detected in this survey, and these $3 \sigma$ limits are in agreement with our excitation models. Given their intricate spectroscopy, below we summarise the main spectroscopic information of the detected species.

\subsection{Formyl radical: $\mathrm{HCO}$}

The formyl radical, HCO, is a light asymmetric rotor with one unpaired electron and one non-zero nuclear spin. The quantum numbers designating the energy levels are $N, J$, and $F$. Spin doubling $(J=N+S)$ is produced by the coupling between the rotational angular momentum, $N$, and the unpaired electron spin, $S$, while the hyperfine structure $(F=J+I)$ is due to the coupling of the angular momentum, $J$, and the spin of the hydrogen nucleus, $I$. Each rotational level $N_{K_{\mathrm{a}}, K_{\mathrm{c}}}$ is split into a doublet by the spin-rotation interaction, the levels of which are further split into doublets by magnetic hyperfine interactions, with the final energy levels labelled by the quantum number $F=J \pm 1 / 2$ (e.g. Bowater et al. 1971; Saito 1972; Austin et al. 1974; Blake et al. 1984). $a$-type $\left(\Delta K_{a}=0, \pm 2, \ldots\right)$ and $b$-type $\left(\Delta K_{a}= \pm 1, \pm 3, \ldots\right)$ transitions are allowed, with a stronger dipole moment for the $a$-type transitions (see Table 2).

We identified a total of 16 lines of HCO. They consist of four sets of rotational transitions corresponding to the hyperfine splitting of the $N=1 \rightarrow 0$ to $4 \rightarrow 3$ transitions. All transitions observed here are $a$-type. The quantum numbers of the detected HCO transitions, their spectroscopic parameters, and the results from fitting the line profiles with Gaussians are listed in Table B.1. In Fig. 2 we present the spectra of the $N=1 \rightarrow 0$ to $4 \rightarrow 3$ rotational lines.

\subsection{Formaldehyde: $\mathrm{H}_{2} \mathrm{CO}$}

Formaldehyde, $\mathrm{H}_{2} \mathrm{CO}$, was the first polyatomic organic molecule found in the ISM (Snyder et al. 1969). It is a slightly asymmetric prolate rotor molecule with $K$-type doublets and an orthopara symmetry because of the two indiscernible off-axis hydrogen atoms. The ortho states are those with $K_{\mathrm{a}}$ odd, and the para states with $K_{\mathrm{a}}$ even. The nuclear spin weights are 3 and 1 for $\mathrm{o}-\mathrm{H}_{2} \mathrm{CO}$ and $\mathrm{p}-\mathrm{H}_{2} \mathrm{CO}$, respectively. The $K$-type doublets are the result of the slight asymmetry in the $\mathrm{H}_{2} \mathrm{CO}$ produced by the light $\mathrm{H}$ atoms. There are no line doublets in the $K_{\mathrm{a}}=0$ para state (e.g. Bocquet et al. 1996; Brünken et al. 2003; Eliet et al. 2012).

We detected nine lines of the ortho species (in the $K_{\mathrm{a}}=1$ and 3 ladders) with $E_{\mathrm{u}} / k \leq 125.8 \mathrm{~K}$, and six lines for the para species (in the $K_{\mathrm{a}}=0$ and 2 ladders) with $E_{\mathrm{u}} / k \leq 82.1 \mathrm{~K}$. Line profiles are shown in Fig. 3. Table B.2 gives the observed line parameters.

We also detected eight lines of $\mathrm{H}_{2}^{13} \mathrm{CO}$, consisting of six lines of ortho species and two lines of the para species, in the $K_{\mathrm{a}}=0$

\footnotetext{
2 http://spec.jpl.nasa.gov/

http://wWw . astro.uni-koeln.de/cdms/
} 


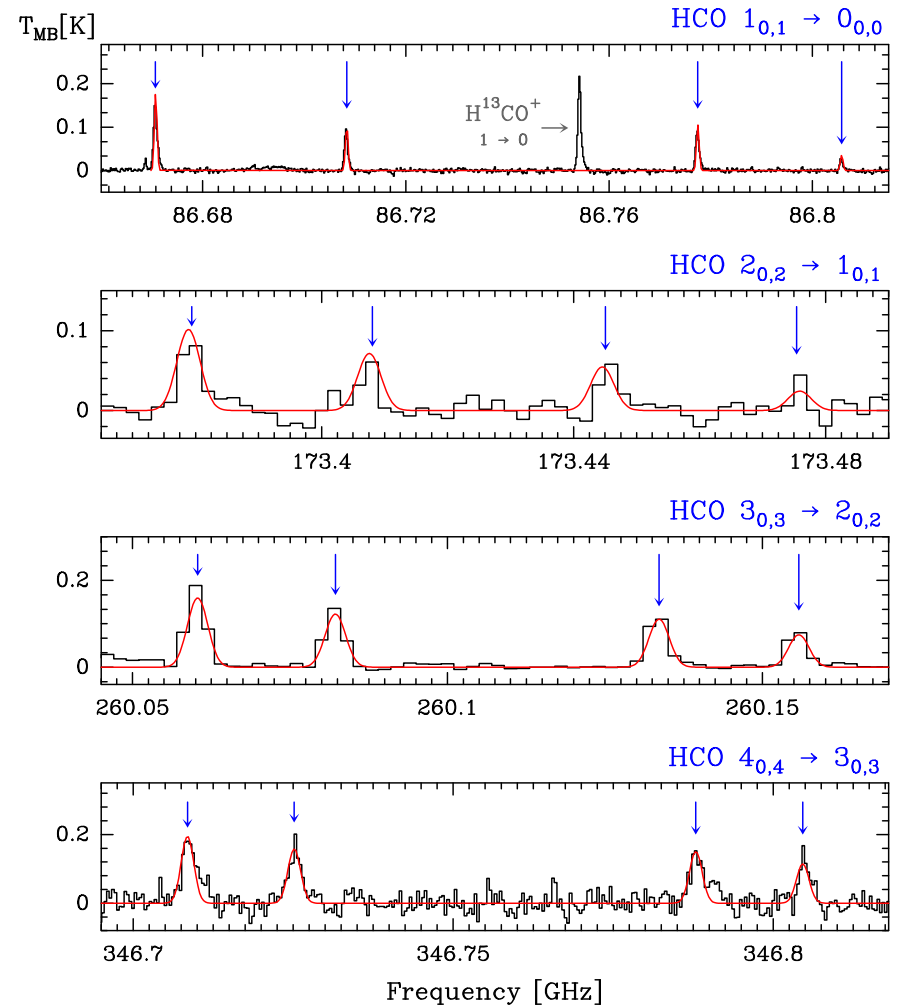

Fig. 2. Detected HCO hyperfine structure (HFS) lines of the $N=1 \rightarrow 0$, $2 \rightarrow 1,3 \rightarrow 2$, and $4 \rightarrow 3$ rotational transitions (black histogram spectra). A single excitation temperature model is shown overlaid in red (see Sect. 5.4). HFS lines are indicated by the blue arrows. The other spectral features appearing in the selected windows are labelled with their corresponding identification.

and 1 ladders, respectively $\left(E_{\mathrm{u}} / k \leq 34.0 \mathrm{~K}\right)$. Line profiles are shown in Fig. 4. Table B.3 gives the observed line parameters. No lines of deuterated formaldehyde were detected.

\subsection{Thioformaldehyde: $\mathrm{H}_{2} \mathrm{CS}$}

Thioformaldehyde, $\mathrm{H}_{2} \mathrm{CS}$, has a formaldehyde-like structure. It is a slightly asymmetric prolate rotor, with only $a$-type transitions and ortho-para symmetry (e.g. Johnson et al. 1971; Beers et al. 1972; Maeda et al. 2008).

We detected 15 lines of ortho species (in the $K_{\mathrm{a}}=1$ and 3 ladders) with $E_{\mathrm{u}} / k \leq 149.8 \mathrm{~K}$, and 11 lines of para species (in the $K_{\mathrm{a}}=0$ and 2 ladders) with $E_{\mathrm{u}} / k \leq 112.0 \mathrm{~K}$. Figure 5 shows a selection of ortho and para detected lines. Table B.4 gives the observed line parameters.

\subsection{Isocyanic acid: HNCO}

Isocyanic acid, $\mathrm{H}-\mathrm{N}=\mathrm{C}=\mathrm{O}$, is the simplest molecule containing carbon, hydrogen, oxygen, and nitrogen. It is a slightly asymmetric prolate rotor with $a$ - and $b$-type transitions. Its rotational levels are designated as $J_{K_{\mathrm{a}}, K_{\mathrm{c}}}$ (e.g. Kukolich et al. 1971; Hocking et al. 1975; Lapinov et al. 2007).

We detect six $a$-type transitions inside the $K_{a}=0$ rotational ladder $\left(E_{\mathrm{u}} / k \leq 96.0 \mathrm{~K}\right)$. The observed lines do not show evidence for hyperfine splittings. Line profiles are shown in Fig. 6. Table B.5 gives the observed line parameters.
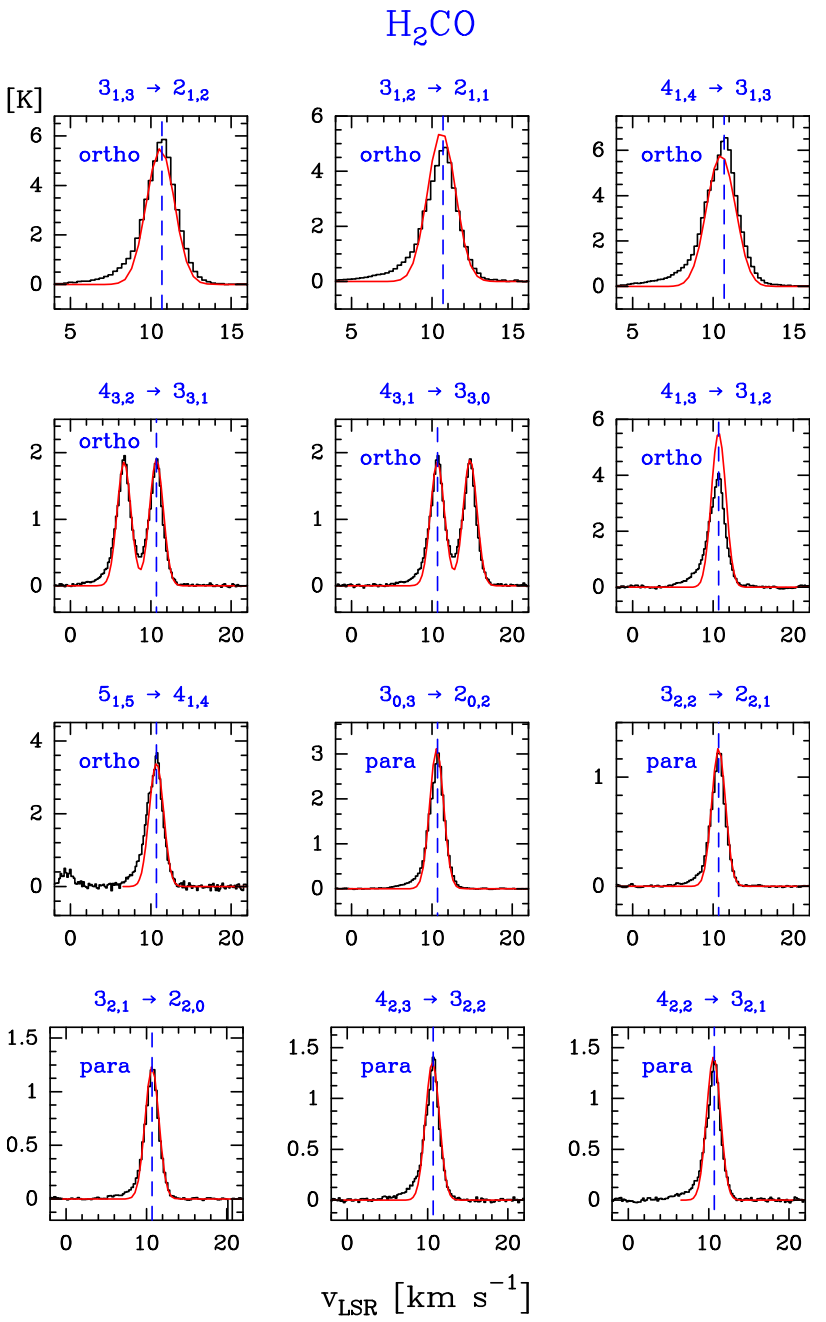

Fig. 3. Example of ortho- and para- $\mathrm{H}_{2} \mathrm{CO}$ lines (black histogram spectra). A non-LTE LVG model $\left(T_{\mathrm{k}} \simeq 200 \mathrm{~K}, n\left(\mathrm{H}_{2}\right) \simeq 1 \times 10^{6} \mathrm{~cm}^{-3}\right.$, $N\left(\mathrm{o}-\mathrm{H}_{2} \mathrm{CO}\right)=4.0 \times 10^{13} \mathrm{~cm}^{-2}$, and $\left.N\left(\mathrm{p}-\mathrm{H}_{2} \mathrm{CO}\right)=1.8 \times 10^{13} \mathrm{~cm}^{-2}\right)$ is shown overlaid in red (see Sect. 5.2). The dashed lines indicate the LSR velocity $\left(10.7 \mathrm{~km} \mathrm{~s}^{-1}\right)$ of the Orion Bar PDR.

$$
\mathrm{H}_{2}{ }^{13} \mathrm{CO}
$$
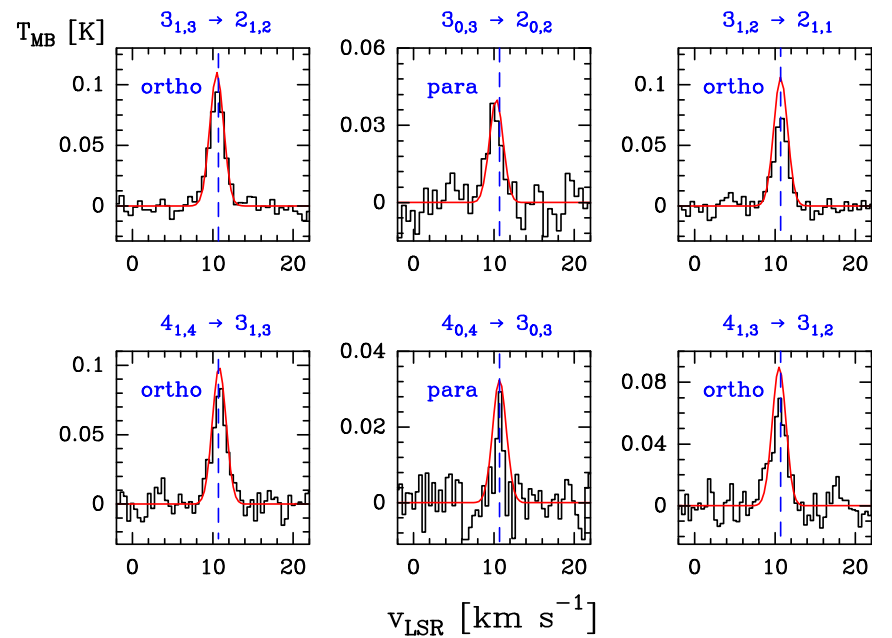

Fig. 4. Example of ortho- and para- $\mathrm{H}_{2}^{13} \mathrm{CO}$ lines (black histogram spectra). A non-LTE LVG model $\left(T_{\mathrm{k}} \simeq 200 \mathrm{~K}, n\left(\mathrm{H}_{2}\right) \simeq 1 \times 10^{6} \mathrm{~cm}^{-3}\right.$, $N\left(\mathrm{o}-\mathrm{H}_{2}^{13} \mathrm{CO}\right)=7.3 \times 10^{11} \mathrm{~cm}^{-2}$, and $\left.N\left(\mathrm{p}-\mathrm{H}_{2}^{13} \mathrm{CO}\right)=2.3 \times 10^{11} \mathrm{~cm}^{-2}\right)$ is shown overlaid in red (see Sect. 5.2). 


\section{$\mathrm{H}_{2} \mathrm{CS}$}
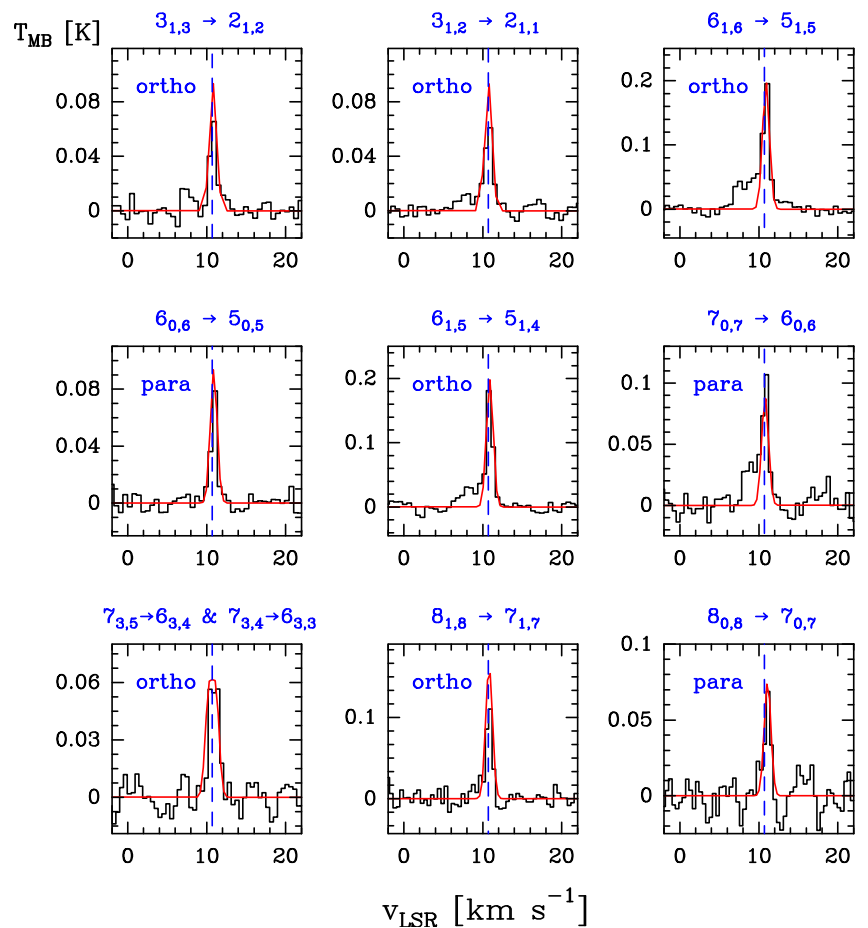

Fig. 5. Example of ortho- and para- $\mathrm{H}_{2} \mathrm{CS}$ lines (black histogram spectra). Single excitation temperature models are shown overlaid in red (see Sect. 5.4)

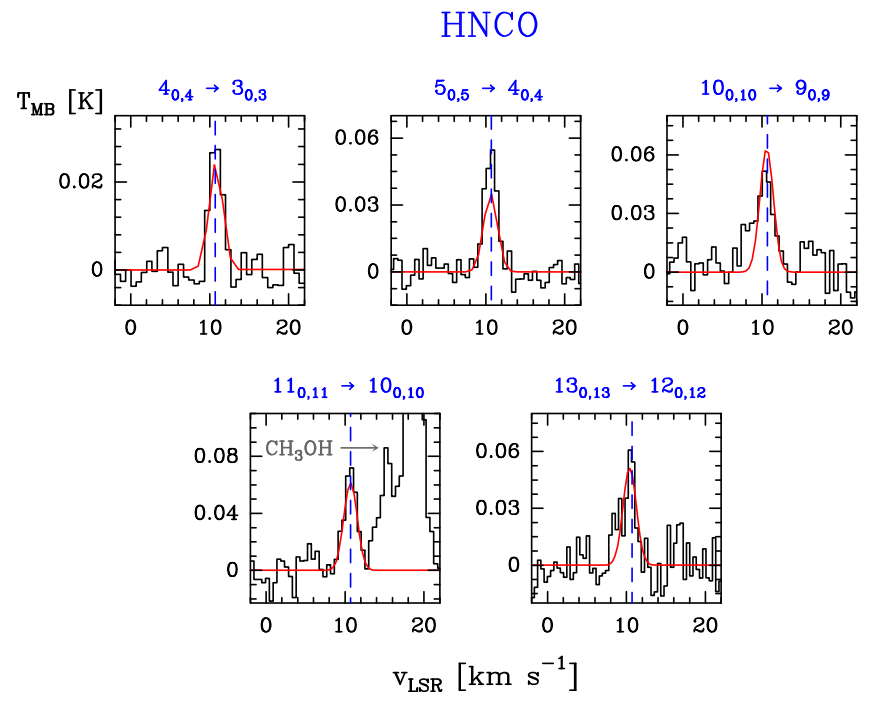

Fig. 6. Example of $\mathrm{HNCO}$ detected lines (black histogram spectra). A single excitation temperature model is shown overlaid in red (see Sect. 5.4).

\subsection{Methanimine: $\mathrm{CH}_{2} \mathrm{NH}$}

Methanimine is the simplest molecule containing a carbonnitrogen double bond $\left(\mathrm{H}_{2} \mathrm{C}=\mathrm{NH}\right)$. It is a planar molecule and a nearly prolate asymmetric rotor with components of the electric dipole moment along both the $a$ and $b$ molecular axes (e.g. Kirchhoff et al. 1973; Dore et al. 2010, 2012).

We detected six lines of $\mathrm{CH}_{2} \mathrm{NH}$ consisting of (i) three $a$-type transitions (in the $K_{\mathrm{a}}=0$ and 1 ladders) and (ii) three $b$-type transitions, with $E_{\mathrm{u}} / k \leq 64.1 \mathrm{~K}$. The observed lines do not show
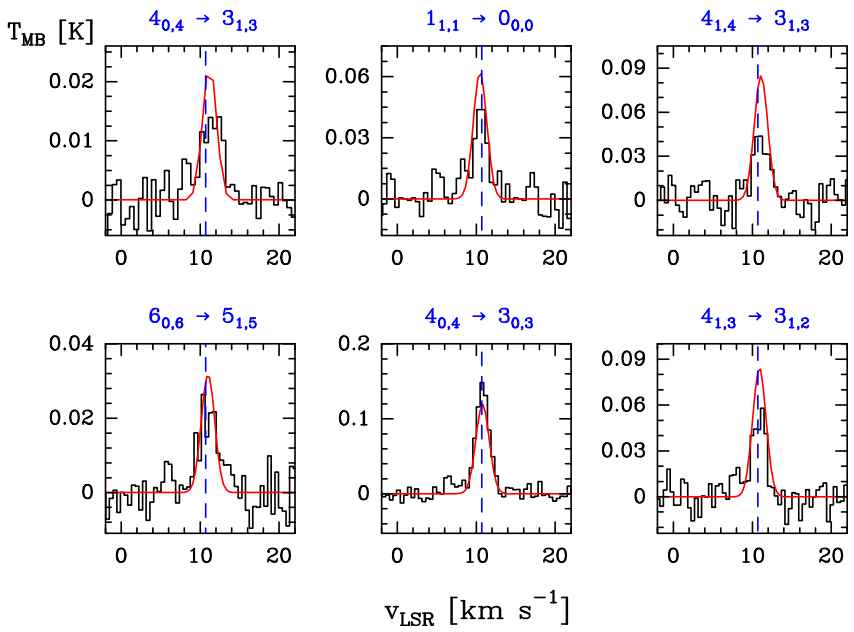

Fig. 7. $\mathrm{CH}_{2} \mathrm{NH}$ detected lines (black histogram spectra). A single excitation temperature model is shown overlaid in red (see Sect. 5.4).

evidence for hyperfine splittings. The line profiles are shown in Fig. 7. Table B.6 gives the observed line parameters.

\subsection{Ketene: $\mathrm{H}_{2} \mathrm{CCO}$}

Ketene, $\mathrm{H}_{2} \mathrm{C}=\mathrm{C}=\mathrm{O}$, is a slightly asymmetric prolate rotor with only $a$-type transitions and ortho-para symmetry (e.g. Johnson \& Strandberg 1952; Fabricant et al. 1977; Brown et al. 1990; Johns et al. 1992). We detected 20 lines of ortho species (in the $K_{\mathrm{a}}=1$ and 3 ladders) with $E_{\mathrm{u}} / k \leq 205.2 \mathrm{~K}$, and ten lines for the para species (in the $K_{\mathrm{a}}=0$ and 2 ladders) with $E_{\mathrm{u}} / k \leq 154 \mathrm{~K}$. Examples of the line profiles of ortho and para lines are shown in Fig. 8. Table B.7 gives the observed line parameters.

\subsection{Cyanoacetylene: $\mathrm{HC}_{3} \mathrm{~N}$}

Cyanoacetylene, $\mathrm{H}-\mathrm{C} \equiv \mathrm{C}-\mathrm{C} \equiv \mathrm{N}$, is a linear molecule with a large dipole moment of $\mu_{a}=3.732 \mathrm{D}$ (DeLeon \& Muenter 1985). It is the simplest example of cyanopolyynes, $\mathrm{HC}_{n} \mathrm{~N}$ (with $n=3,5$, 7, ...; see e.g. Turner 1971; Avery et al. 1976; Cernicharo et al. 1986). The rotational transitions show hyperfine splittings owing to the interaction of the electric-quadrupole moment of the nitrogen nuclear spin with the electronic-charge distribution (e.g. de Zafra 1971; Mbosei et al. 2000; Chen et al. 1991; Yamada et al. 1995; Thorwirth et al. 2000). This hyperfine splitting is only fully resolved in the lowest rotational transitions (e.g. Turner 1971; Dickinson 1972), therefore, $\mathrm{HC}_{3} \mathrm{~N}$ is described here by a simple rotational spectrum, with $J+1 \rightarrow J$ transitions.

We detected 11 lines of $\mathrm{HC}_{3} \mathrm{~N}$, from $J=9 \rightarrow 8$ to $24 \rightarrow 23$, with $E_{\mathrm{u}} / k \leq 131.0 \mathrm{~K}$. Figure 9 shows a selection of detected lines and Table B. 8 gives the observed line parameters.

\subsection{Methyl cyanide: $\mathrm{CH}_{3} \mathrm{CN}$}

Methyl cyanide, $\mathrm{CH}_{3} \mathrm{CN}$, is a strongly prolate symmetric rotor, therefore, the permitted radiative transitions are all $\Delta K=0$. The internal rotation of the methyl group gives rise to two non-interacting torsional substates, denoted $\mathrm{A}$ and $\mathrm{E}$. The A state levels are described by $K=3 n$, and those of $\mathrm{E}$ state by 

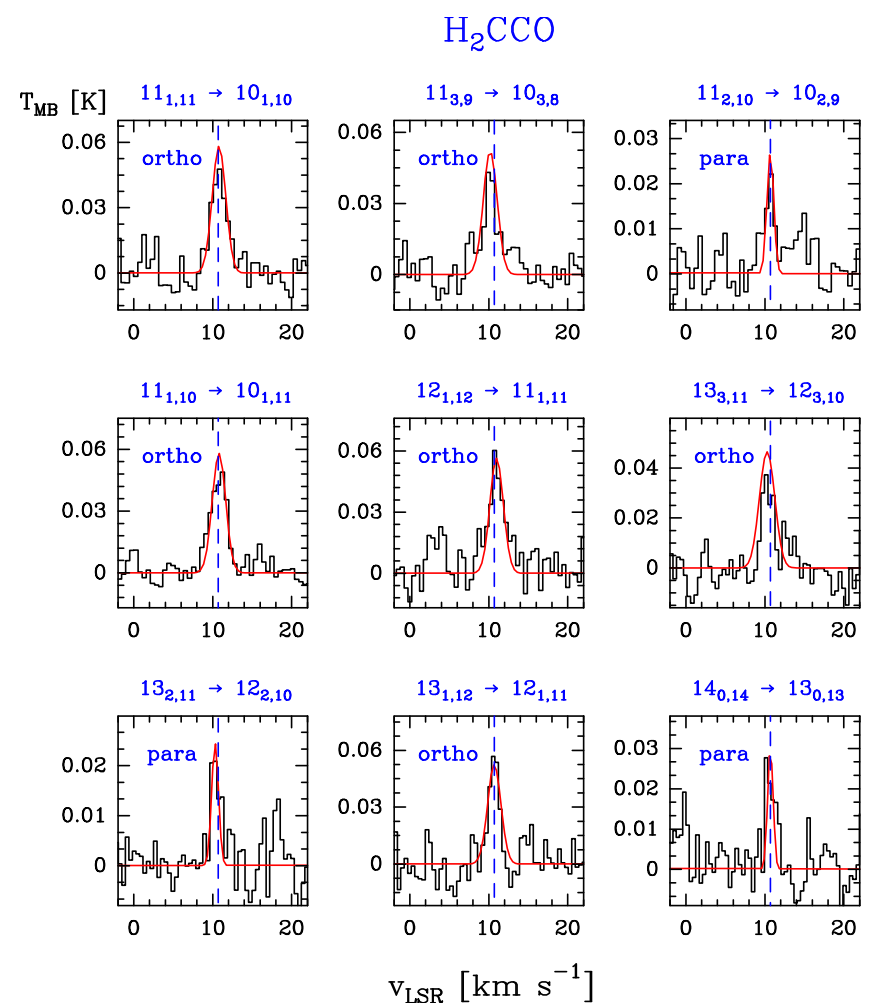

Fig. 8. Example of ortho- and para- $\mathrm{H}_{2} \mathrm{CCO}$ lines (black histogram spectra). Single excitation temperature models are shown overlaid in red (see Sect. 5.4)
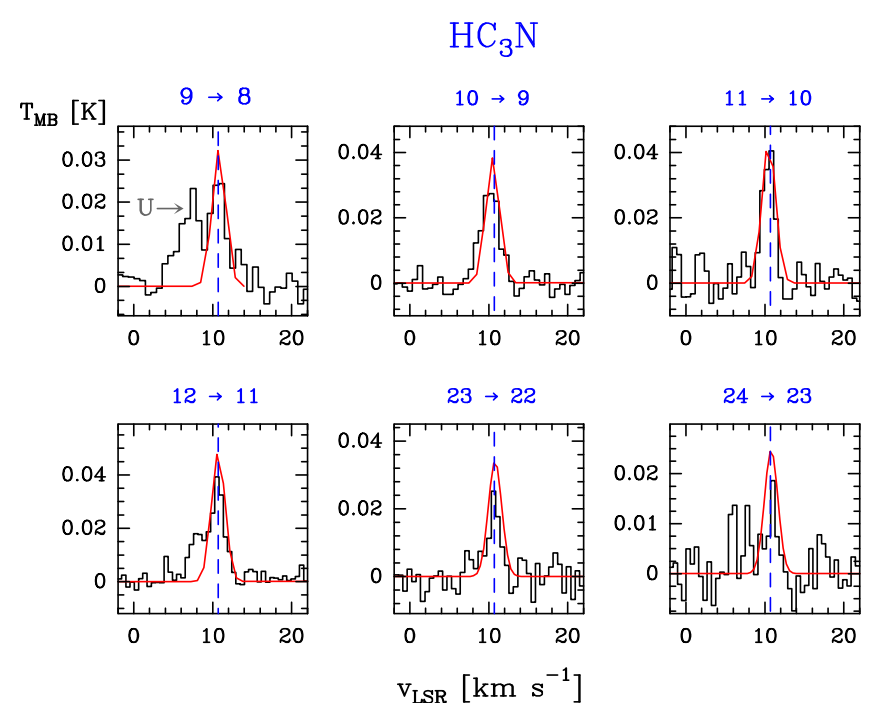

Fig. 9. Example of $\mathrm{HC}_{3} \mathrm{~N}$ detected lines (black histogram spectra). A non-LTE LVG model $\left(T_{\mathrm{k}} \simeq 80 \mathrm{~K}, n\left(\mathrm{H}_{2}\right) \simeq 1 \times 10^{6} \mathrm{~cm}^{-3}\right.$, $\left.N\left(\mathrm{HC}_{3} \mathrm{~N}\right)=4.0 \times 10^{11} \mathrm{~cm}^{-2}\right)$ is shown overlaid in red (see Sect. 5.2).

$K=3 n \pm 1$, with $n \geq 0$ (e.g. Kukolich et al. 1973; Kukolich 1982; Boucher et al. 1977; Anttila et al. 1993; Šimečková et al. 2004; Cazzoli \& Puzzarini 2006; Müller et al. 2009). Transitions with different $K$ but the same $J$ occur in narrow frequency regions but they have quite different energies (see Fig. 10).

We detected 18 lines of A-CH${ }_{3} \mathrm{CN}$ (in the $K=0$ and 3 ladders) with $E_{\mathrm{u}} / k \leq 184.4 \mathrm{~K}, 23$ lines for the $\mathrm{E}-\mathrm{CH}_{3} \mathrm{CN}$ (in the $K=1,2$, and 4 ladders) with $E_{\mathrm{u}} / k \leq 199.0 \mathrm{~K}$, and three lines corresponding to several fully overlapped A-E transitions. Examples of line profiles of $\mathrm{A}-$ and $\mathrm{E}-\mathrm{CH}_{3} \mathrm{CN}$ lines are shown in

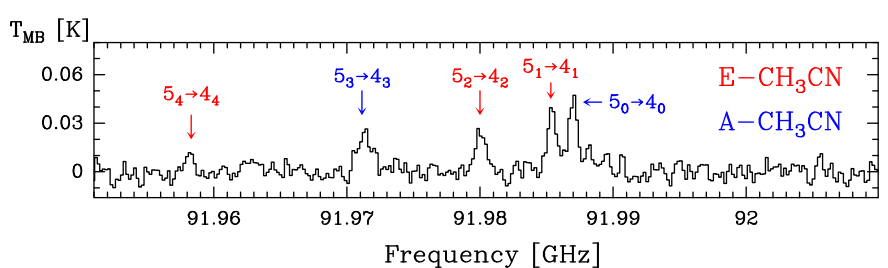

Fig. 10. Observed emission lines from the $J=5 \rightarrow 4$ transitions of $\mathrm{CH}_{3} \mathrm{CN}$. Transitions with different $K$ but the same $J$ occur in narrow frequency regions despite they have different level energies.

Fig. 11. Table B.9 gives the observed line parameters. We did not detect the $\mathrm{CH}_{3} \mathrm{NC}$ isomer (see Sect. 5.6).

\subsection{Methanol: $\mathrm{CH}_{3} \mathrm{OH}$}

Methanol, $\mathrm{CH}_{3} \mathrm{OH}$, is the simplest alcohol molecule. It is a slightly asymmetric rotor showing hindered internal rotation. Its energy levels are classified as a symmetric rotor with quantum number $J_{K}$ and a threefold barrier that causes two states in the molecule, A and E; the latter being doubly degenerate (e.g. Lees \& Baker 1968; Lees et al. 1973; Xu et al. 2008).

We detected 20 lines of $\mathrm{A}-\mathrm{CH}_{3} \mathrm{OH}$ (in the $|K|=0$ and 1 ladders) with $E_{\mathrm{u}} / k \leq 104.4 \mathrm{~K}, 33$ lines for the $\mathrm{E}-\mathrm{CH}_{3} \mathrm{OH}$ (in the $|\mathrm{K}|=1,2,3$, and 4 ladders) with $E_{\mathrm{u}} / k \leq 114.8 \mathrm{~K}$, and two lines corresponding to several fully overlapped A-E transitions. Examples of line profiles of A- and $\mathrm{E}-\mathrm{CH}_{3} \mathrm{OH}$ lines are shown in Fig. 12. Table B.10 gives the observed line parameters.

\subsection{Acetaldehyde: $\mathrm{CH}_{3} \mathrm{CHO}$}

Acetaldehyde, $\mathrm{CH}_{3} \mathrm{CHO}$, is an asymmetric-top molecule with $\mathrm{A}$ and $\mathrm{E}$ symmetry states and $a$ - and $b$-type transitions (e.g. Kleiner et al. 1996, and references therein).

We detected 18 lines of A- $\mathrm{CH}_{3} \mathrm{CHO}, 15$ lines of $\mathrm{E}-\mathrm{CH}_{3} \mathrm{CHO}$, and three lines corresponding to a fully overlapped A-E transition ( $a$-type transitions with $E_{\mathrm{u}} / k \leq 109.7 \mathrm{~K}$ ). Figure 13 shows a selection of detected lines and Table B.11 gives the observed line parameters.

\section{Spatial distribution of $\mathrm{C}^{18} \mathrm{O}$ and $\mathrm{H}_{2} \mathrm{CO}$}

Figure 1 shows the spatial distribution of the rotationally excited $\mathrm{C}^{18} \mathrm{O} J=3 \rightarrow 2\left(E_{\mathrm{u}} / k \simeq 32 \mathrm{~K}, A_{\mathrm{ul}} \simeq 2 \times 10^{-6} \mathrm{~s}^{-1}\right)$ and $\mathrm{H}_{2} \mathrm{CO} \quad J_{K_{\mathrm{a}}, K_{\mathrm{c}}}=5_{1,5} \rightarrow 4_{1,4} \quad\left(E_{\mathrm{u}} / k \simeq 47 \mathrm{~K}, \quad A_{\mathrm{ul}} \simeq 1 \times 10^{-3} \mathrm{~s}^{-1}\right)$ lines along the Bar. The molecular dissociation front (DF) is traced by the vibrationally excited $\mathrm{H}_{2} v=1 \rightarrow 0 \mathrm{~S}$ (1) line emission $\left(\mathrm{H}_{2}^{*}\right.$; black contours in Fig. 1; Walmsley et al. 2000). The red contours represent the OI fluorescent line at $1.32 \mu \mathrm{m}$ (Walmsley et al. 2000) marking the position of the ionisation front (IF) that separates the $\mathrm{H}$ II region and the neutral cloud. The blue contours represent the $\mathrm{H}^{13} \mathrm{CN} J=1 \rightarrow 0$ emission tracing dense molecular clumps inside the Bar (Lis \& Schilke 2003).

The emission from the Orion Bar can be distinguished from the extended OMC-1 cloud component by the emission LSR velocity. While OMC-1 is brighter in the $8-10 \mathrm{~km} \mathrm{~s}^{-1}$ velocity range, the Orion Bar emits predominantly in the $10-11 \mathrm{~km} \mathrm{~s}^{-1}$ range. The $\mathrm{C}^{18} \mathrm{O}$ and $\mathrm{H}_{2} \mathrm{CO}$ line emissions shown in Fig. 1 are integrated in this latter interval. In these maps, $\mathrm{H}_{2} \mathrm{CO}$ peaks at the position of the dense $\left(n\left(\mathrm{H}_{2}\right) \simeq 6 \times 10^{6} \mathrm{~cm}^{-3}\right)$ and lukewarm $\left(T_{\mathrm{k}} \simeq 50 \mathrm{~K}\right)$ clumps inside the Bar (Lis \& Schilke 2003). In addition, our maps reveal extended $\mathrm{H}_{2} \mathrm{CO}$ emission along the PDR and close to the DF. This conclusion was initially inferred 

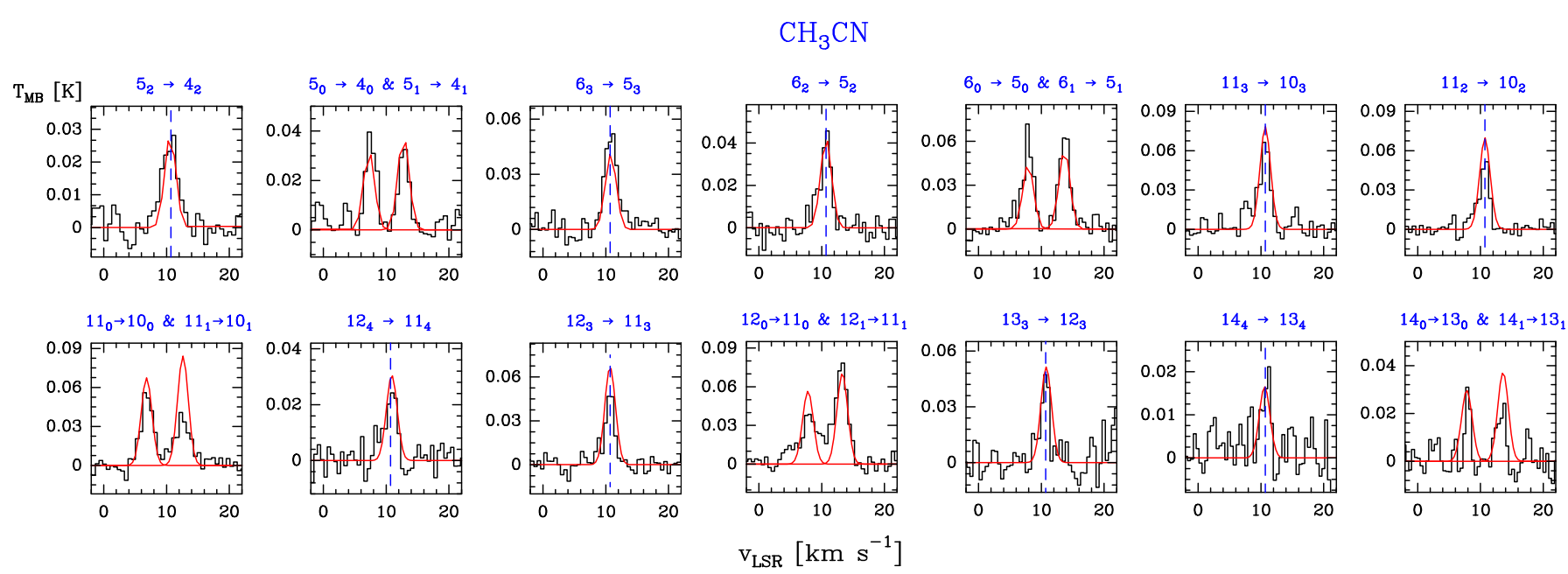

Fig. 11. Example of A- and $\mathrm{E}-\mathrm{CH}_{3} \mathrm{CN}$ lines (black histogram spectra). A non-LTE LVG model $\left(T_{\mathrm{k}} \simeq 150 \mathrm{~K}, n\left(\mathrm{H}_{2}\right) \simeq 1 \times 10^{6} \mathrm{~cm}^{-3}\right.$, $N\left(\mathrm{~A}-\mathrm{CH}_{3} \mathrm{CN}\right)=5 \times 10^{11} \mathrm{~cm}^{-2}$, and $\left.N\left(\mathrm{E}-\mathrm{CH}_{3} \mathrm{CN}\right)=6 \times 10^{11} \mathrm{~cm}^{-2}\right)$ is shown overlaid in red (see Sect. 5.2).
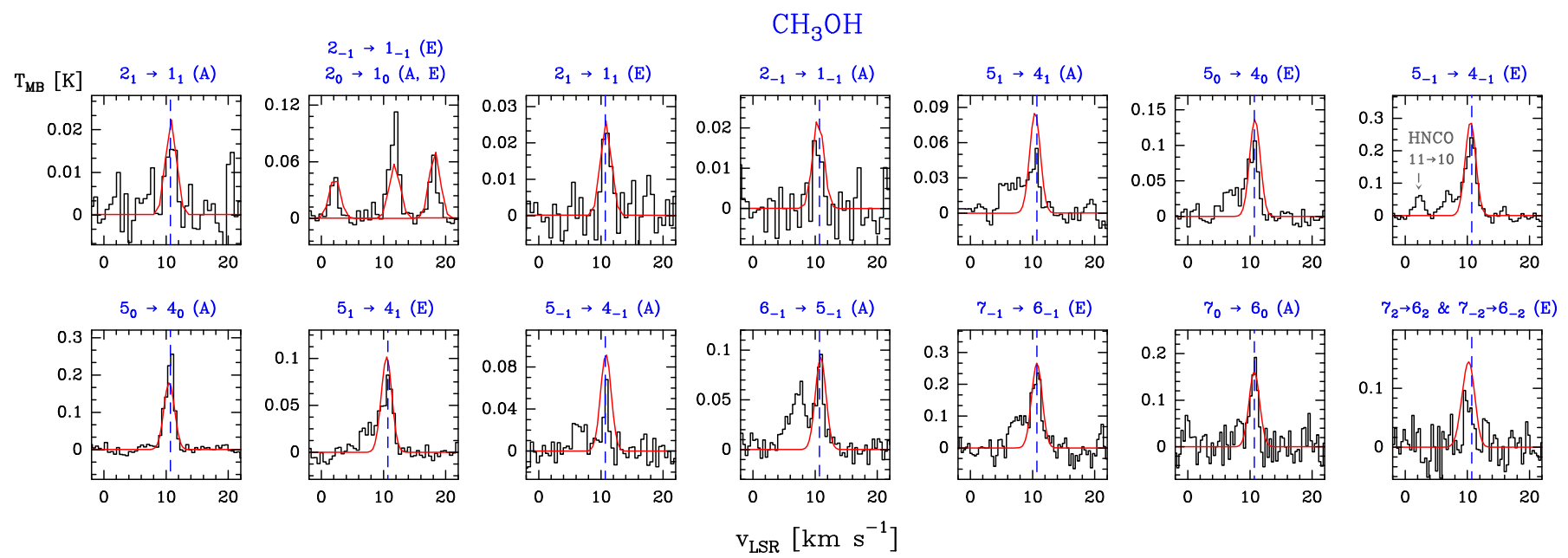

Fig. 12. Example of A- and $\mathrm{E}-\mathrm{CH}_{3} \mathrm{OH}$ lines (black histogram spectra). A non-LTE LVG model $\left(T_{\mathrm{k}} \simeq 40 \mathrm{~K}, n\left(\mathrm{H}_{2}\right) \simeq 3 \times 10^{7} \mathrm{~cm}^{-3}\right.$, $N\left(\mathrm{~A}-\mathrm{CH}_{3} \mathrm{OH}\right)=1.2 \times 10^{13} \mathrm{~cm}^{-2}$, and $\left.N\left(\mathrm{E}-\mathrm{CH}_{3} \mathrm{OH}\right)=1.9 \times 10^{13} \mathrm{~cm}^{-2}\right)$ is shown overlaid in red (see Sect. 5.2).

by Leurini et al. (2010) from $\sim 11^{\prime \prime}$ resolution observations of lower-excitation $\mathrm{H}_{2} \mathrm{CO}$ lines.

To investigate the chemical stratification as a function of FUV flux attenuation, we built averaged line intensity crosscuts perpendicular to the Bar. The maps were rotated by $50^{\circ}$ to bring the incident FUV radiation from left, and then, line intensities in the mapped area were averaged parallel to the IF. In Fig. 14 we plot the resulting normalised intensity cuts as a function of distance to the IF position. Distances are in arcseconds and increase with depth into the molecular cloud. Although these cuts do not represent true abundance variations (different lines have different excitation conditions), to first order they can be used to study the chemical stratification in the PDR. The $\mathrm{H}_{2}^{*}$ emission peak is at $\sim 15^{\prime \prime}$ (vertical dot-dashed line) from the IF, and shows a narrow emission profile. The $\mathrm{H}_{2} \mathrm{CO} J_{K_{\mathrm{a}}, K_{\mathrm{c}}}=5_{1,5} \rightarrow 4_{1,4}$ emission peak appears at $\sim 27^{\prime \prime}$, followed by $\mathrm{C}^{18} \mathrm{O} J=3 \rightarrow 2$ that peaks at $\sim 35^{\prime \prime}$.

We note that the different position of the emission peaks of the $\mathrm{C}^{18} \mathrm{O} J=3 \rightarrow 2$ and $\mathrm{H}_{2} \mathrm{CO} J_{K_{\mathrm{a}}, K_{\mathrm{c}}}=5_{1,5} \rightarrow 4_{1,4}$ lines shown in Fig. 14 could be related to a sharp thermal gradient in the region, with the gas temperature increasing from $\sim 50 \mathrm{~K}$ inside the dense clumps seen in the PDR interior (Lis \& Schilke 2003), to $\sim 300 \mathrm{~K}$ near the DF. The $\mathrm{H}_{2} \mathrm{CO} J_{K_{\mathrm{a}}, K_{\mathrm{c}}}=5_{1,5} \rightarrow 4_{1,4}$ line requires higher excitation conditions (higher temperature/density) and thus it would naturally peak closer to the DF than the $\mathrm{C}^{18} \mathrm{O} J=3 \rightarrow 2$ line, even for constant $\mathrm{H}_{2} \mathrm{CO}$ and $\mathrm{C}^{18} \mathrm{O}$ abundances throughout the PDR. Still, the main point is that observations show that $\mathrm{H}_{2} \mathrm{CO}$ is present in the warm interclump gas and close to the PDR edge where the FUV flux is strong.

\section{Analysis}

\subsection{Line parameter fitting procedure}

Detected lines show simple Gaussian line profiles centred at the Orion Bar LSR velocity and thus Gaussian profiles were fitted to all detected lines. For the resolved and unblended COM lines detected with significant $\mathrm{S} / \mathrm{N}$, the mean line width is $\Delta v=1.8 \mathrm{~km} \mathrm{~s}^{-1}$, with a standard deviation of $\sigma=0.6 \mathrm{~km} \mathrm{~s}^{-1}$.

The spectroscopic and observational line parameters of the detected lines are given in Tables B.1-B.11. We provide line frequencies (in $\mathrm{MHz}$ ), energy of the upper level of each transition $\left(E_{\mathrm{u}} / k\right.$ in $\left.\mathrm{K}\right)$, Einstein coefficient for spontaneous emission $\left(A_{\mathrm{ul}}\right.$ in $\left.\mathrm{s}^{-1}\right)$, intrinsic line strength $\left(S_{\mathrm{ul}}\right)$, and the level degeneracy $\left(g_{\mathrm{u}}\right)$ from the MADEX spectral catalogue, and the JPL and CDMS molecular databases. The velocity-integrated intensity $\left(\int T_{\mathrm{MB}} \mathrm{d} v\right.$ in $\left.\mathrm{mK} \mathrm{km} \mathrm{s}{ }^{-1}\right)$, LSR velocity $\left(v_{\mathrm{LSR}}\right.$ in $\left.\mathrm{km} \mathrm{s}^{-1}\right)$, FWHM 


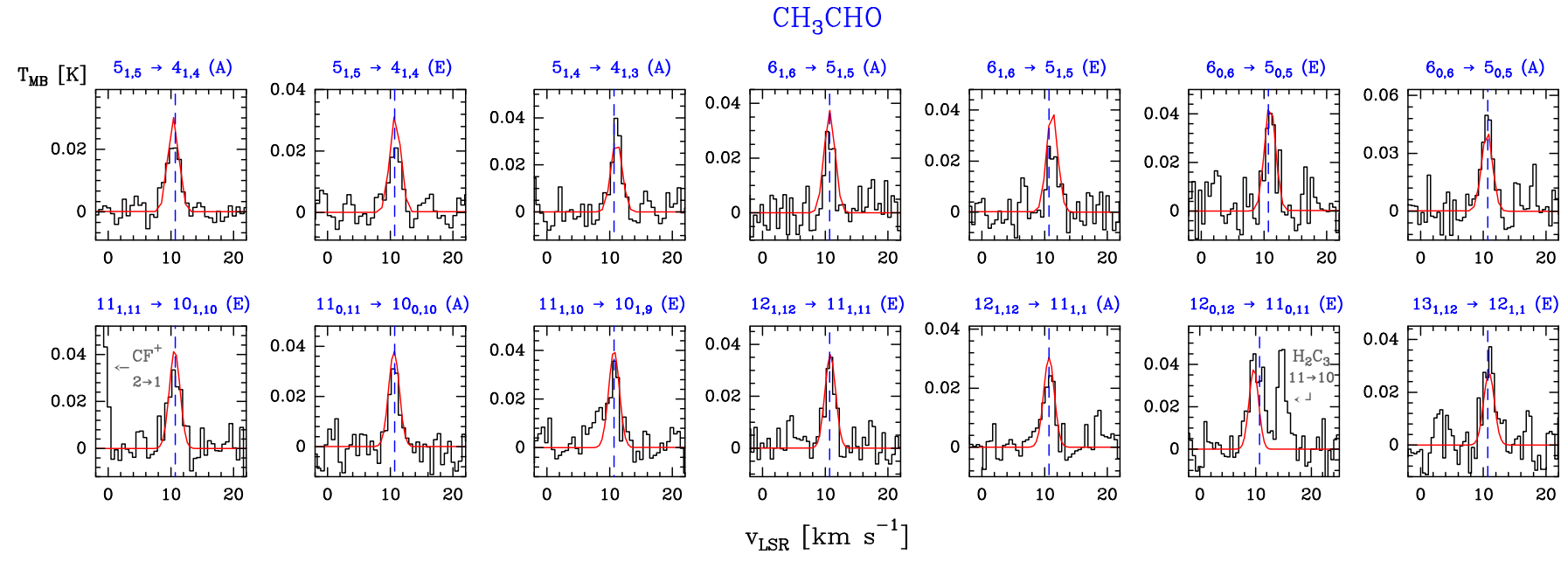

Fig. 13. Examples of A- and $\mathrm{E}-\mathrm{CH}_{3} \mathrm{CHO}$ lines (black histogram spectra). Single excitation temperature models are shown overlaid in red (see Sect. 5.4).

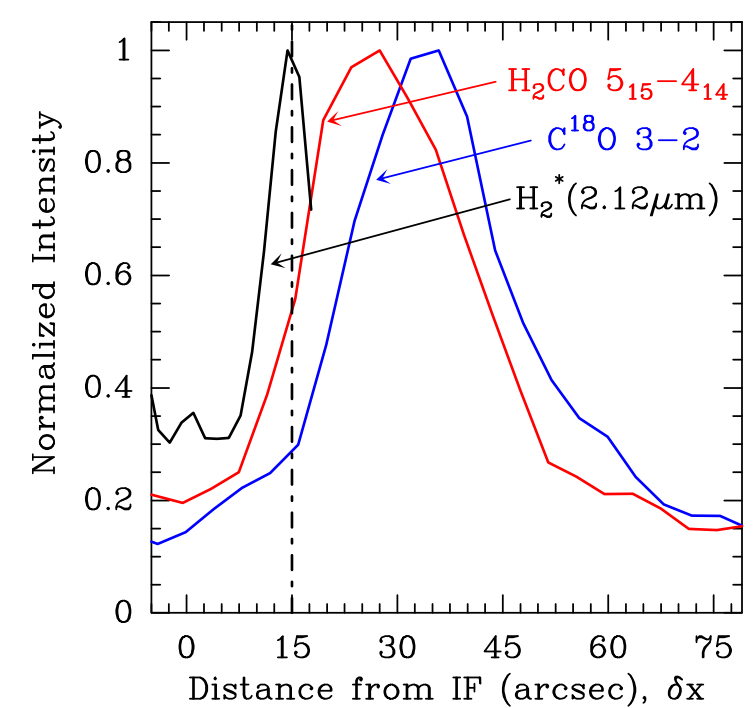

Fig. 14. Normalised intensity crosscuts for $\mathrm{C}^{18} \mathrm{O} J=3 \rightarrow 2$ (blue curve), $\mathrm{H}_{2} \mathrm{CO} J_{K_{\mathrm{a}}, K_{\mathrm{c}}}=5_{1,5} \rightarrow 4_{1,4}$ (red curve), and $\mathrm{H}_{2}^{*}$ (black curve) as a function of distance from the IF (in arcsec). The vertical dot-dashed line indicates the $\mathrm{H}_{2}$ dissociation front. FUV radiation comes from left.

(full width at half maximum) line width $\left(\Delta v\right.$ in $\left.\mathrm{km} \mathrm{s}^{-1}\right)$, and the line peak temperature $\left(T_{\mathrm{MB}}\right.$ in $\left.\mathrm{mK}\right)$ were obtained from Gaussian fits. Parentheses indicate the uncertainty. When two or more transitions were found to be overlapping, the total profile was fitted. Fully overlapping transitions are marked with connecting symbols in the tables.

\subsection{Non-LTE LVG excitation analysis: physical conditions}

We estimate the beam-averaged physical conditions towards the line survey position from non-LTE (local thermodynamic equilibrium) excitation models for molecules with known inelastic collisional rate coefficients $\left(\mathrm{H}_{2} \mathrm{CO}, \mathrm{HC}_{3} \mathrm{~N}, \mathrm{CH}_{3} \mathrm{CN}\right.$, and $\left.\mathrm{CH}_{3} \mathrm{OH}\right)^{4}$. In particular, we run a large grid of non-LTE excitation and radiative transfer models in which the statistical

4 We used $\left[\mathrm{H}_{2} \mathrm{CO}-\mathrm{H}_{2}\right]$ collisional rates for ortho and para $\mathrm{H}_{2} \mathrm{CO}$ (Green 1991), [A/E- $\left.\mathrm{CH}_{3} \mathrm{OH}-\mathrm{H}_{2}\right]$ for A- and $\mathrm{E}-\mathrm{CH}_{3} \mathrm{OH}$ (Rabli \& Flower 2010), [A/E-C $\left.\mathrm{CH}_{3} \mathrm{CN}-\mathrm{H}_{2}\right]$ for A- and $\mathrm{E}-\mathrm{CH}_{3} \mathrm{CN}$ (Green 1986), and $\left[\mathrm{HC}_{3} \mathrm{~N}-\mathrm{H}_{2}\right]$ for $\mathrm{HC}_{3} \mathrm{~N}$ (Wernli et al. 2007).
Table 3. Best fit LVG model parameters and comparison with the column density obtained with the rotational diagram (RD) analysis.

\begin{tabular}{|c|c|c|c|c|}
\hline & \multicolumn{3}{|c|}{ LVG calculations } & \multirow{2}{*}{$\begin{array}{c}\text { RD analysis* } \\
N(\mathrm{X})_{\mathrm{RD}} \\
{\left[\mathrm{cm}^{-2}\right]}\end{array}$} \\
\hline & $\begin{array}{c}T_{\mathrm{k}} \\
{[\mathrm{K}]}\end{array}$ & $\begin{array}{c}n\left(\mathrm{H}_{2}\right) \\
{\left[\mathrm{cm}^{-3}\right]}\end{array}$ & $\begin{array}{c}N(\mathrm{X})_{\mathrm{LVG}} \\
{\left[\mathrm{cm}^{-2}\right]}\end{array}$ & \\
\hline o- $\mathrm{H}_{2} \mathrm{CO}$ & $\sim 200$ & $\sim 10^{6}$ & $4.0 \times 10^{13}$ & $(4.4 \pm 0.6) \times 10^{13}$ \\
\hline $\mathrm{p}-\mathrm{H}_{2} \mathrm{CO}$ & $\sim 200$ & $\sim 10^{6}$ & $1.8 \times 10^{13}$ & $(1.6 \pm 0.1) \times 10^{13}$ \\
\hline $\mathrm{HC}_{3} \mathrm{~N}$ & $\sim 80$ & $\sim 10^{6}$ & $4.0 \times 10^{11}$ & $(4.2 \pm 0.3) \times 10^{11}$ \\
\hline $\mathrm{A}-\mathrm{CH}_{3} \mathrm{CN}$ & $\sim 150$ & $\sim 10^{6}$ & $5.0 \times 10^{11}$ & $(5.8 \pm 0.8) \times 10^{11}$ \\
\hline $\mathrm{E}-\mathrm{CH}_{3} \mathrm{CN}$ & $\sim 150$ & $\sim 10^{6}$ & $6.0 \times 10^{11}$ & $(5.7 \pm 0.7) \times 10^{11}$ \\
\hline $\mathrm{E}-\mathrm{CH}_{3} \mathrm{OH}$ & $\sim 40$ & $\sim 3 \times 10^{7}$ & $1.9 \times 10^{13}$ & $(1.9 \pm 0.2) \times 10^{13}$ \\
\hline
\end{tabular}

Notes. ${ }^{(*)}$ Rotational diagram analysis assuming uniform beam filling (see Sect. 5.4).

equilibrium equations are explicitly solved in the LVG (large velocity gradient) approximation using MADEX (Cernicharo 2012; see also Appendix A in Cuadrado et al. 2015).

We tested a broad range of column density $(N), \mathrm{H}_{2}$ density $\left(n\left(\mathrm{H}_{2}\right)=10^{3}-10^{9} \mathrm{~cm}^{-3}\right)$, and gas temperature $\left(T_{\mathrm{k}}=\right.$ $10-1000 \mathrm{~K})$ values. We adopted $\Delta v=2 \mathrm{~km} \mathrm{~s}^{-1}$ line widths. In order to constrain the physical conditions that reproduce the observed line intensities and line profiles towards the observed position, we compared the observed $\mathrm{H}_{2} \mathrm{CO}, \mathrm{CH}_{3} \mathrm{OH}, \mathrm{CH}_{3} \mathrm{CN}$, and $\mathrm{HC}_{3} \mathrm{~N}$ lines to synthetic lines obtained from the grid of LVG models. The best fit model (assuming uniform beam filling emission) was obtained by finding the minimum root mean square (rms); we refer to Cuadrado et al. (2015) for a detailed explanation. The range of column densities that we used as an input in the models is around the value derived from the rotational diagrams analysis (see Sect. 5.4). In fact, the best fit models have column densities within a factor of 2 (see Table 3 ) of the inferred value from the rotational diagram analysis (we note that in these models the observed lines are optically thin). Figure 15 represents the $\mathrm{rms}_{\min } / \mathrm{rms}$ ratio as a function of $T_{\mathrm{k}}$ and $n\left(\mathrm{H}_{2}\right)$ for a grid of excitation models trying to fit the observed lines towards the PDR position. 

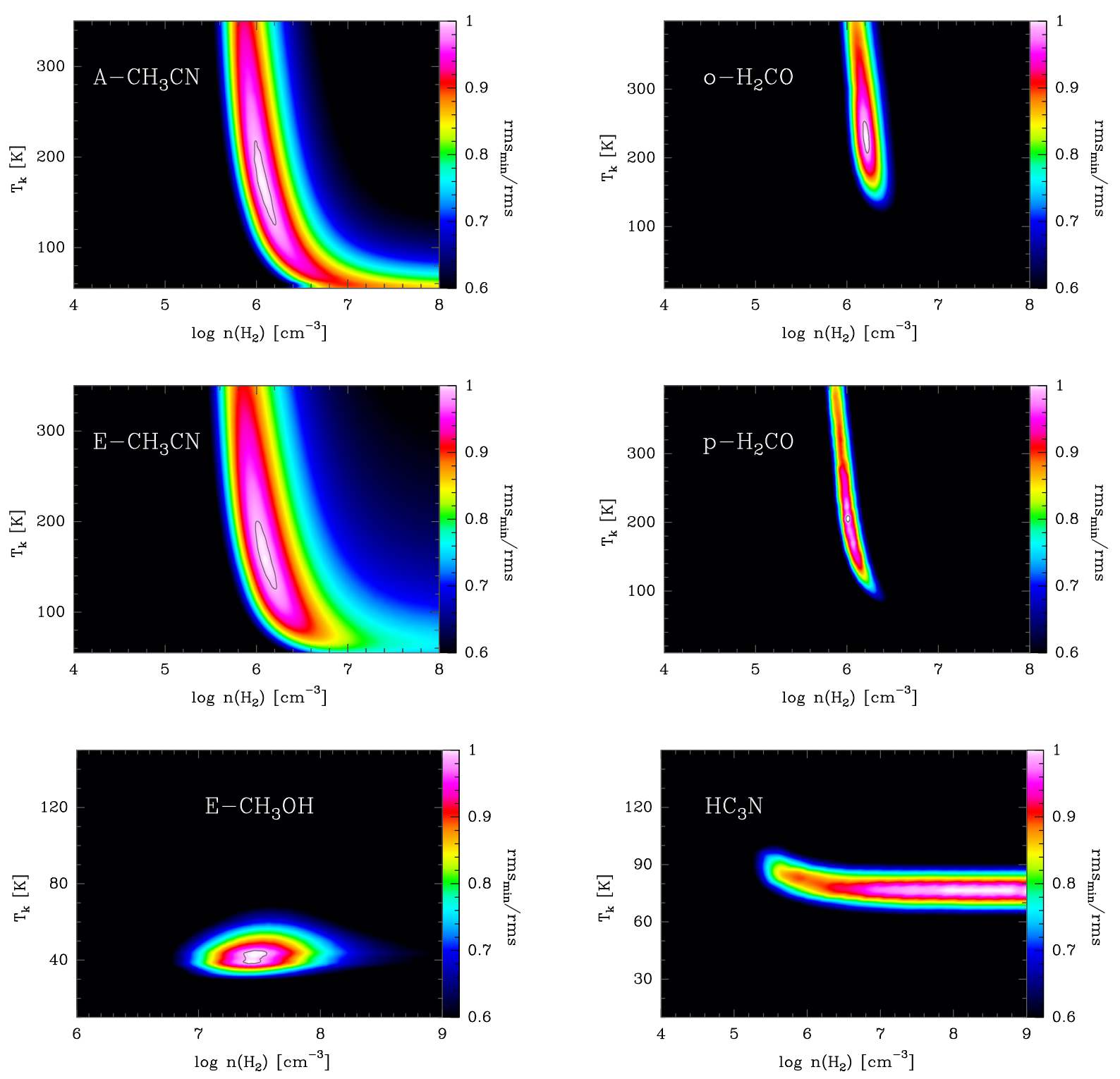

Fig. 15. Grid of LVG excitation and radiative transfer models for $\mathrm{CH}_{3} \mathrm{CN}, \mathrm{H}_{2} \mathrm{CO}, \mathrm{CH}_{3} \mathrm{OH}$, and $\mathrm{HC}_{3} \mathrm{~N}$ lines towards the PDR position assuming uniform beam filling and using column densities shown in Table 3 . The best fits are those with the higher $\mathrm{rms}_{\min } / \mathrm{rms}$ value.

From the excitation analysis it seems that not all COMs arise from the same PDR layers (i.e. same cloud depth). The set of beam-averaged physical conditions that best fit the $\mathrm{CH}_{3} \mathrm{CN}$ and $\mathrm{H}_{2} \mathrm{CO}$ lines lie within $T_{\mathrm{k}}=150-250 \mathrm{~K}$ and $n\left(\mathrm{H}_{2}\right)=(1-3) \times 10^{6} \mathrm{~cm}^{-3}$, similar (although slightly denser gas) to that obtained for $\mathrm{C}_{2} \mathrm{H}$ in Cuadrado et al. (2015). Figures 3 and 11 show the best fit models overlaid over the observed lines. The $\mathrm{HC}_{3} \mathrm{~N}$ detected lines (see Fig. 9) fit within $T_{\mathrm{k}}=70-90 \mathrm{~K}$ and $n\left(\mathrm{H}_{2}\right)>1 \times 10^{6} \mathrm{~cm}^{-3}$. The physical conditions that fit the $\mathrm{CH}_{3} \mathrm{OH}$ detected lines (see Fig. 12) are colder and denser $\left(T_{\mathrm{k}}=40-50 \mathrm{~K}\right.$ and $\left.n\left(\mathrm{H}_{2}\right) \simeq 5 \times 10^{7} \mathrm{~cm}^{-3}\right)$. The bestfit parameters $\left(n\left(\mathrm{H}_{2}\right), T_{\mathrm{k}}\right.$, and $\left.N\right)$ of the LVG models fitting the lines in Figs. 3, 9, 11, and 12 are shown in Table 3. We note, however, that the best fit gas density value depends on the assumed emission beam filling factor ${ }^{5}$ for each molecule. Lower densities (by a factor of up to $\sim 10$ ) would still be consistent with

\footnotetext{
5 Assuming that the emission source has a 2D Gaussian shape, the beam filling factor $\left(\eta_{\mathrm{bf}}\right)$ is equal to $\eta_{\mathrm{bf}}=\theta_{\mathrm{S}}^{2} /\left(\theta_{\mathrm{S}}^{2}+\theta_{\mathrm{B}}^{2}\right)$, with $\theta_{\mathrm{B}}$ the HPBW of the $30 \mathrm{~m}$ telescope (in arcsec) and $\theta_{\mathrm{S}}$ the diameter of
}

observations if one assumes a semi-extended emission source (i.e. more compact than the beam-size at each observed frequency; see Sect. 5.4).

Higher-angular-resolution maps are needed to spatially resolve the structures producing the molecular emission (Goicoechea et al. 2016). Either way, $\mathrm{CH}_{3} \mathrm{OH}$ and $\mathrm{HC}_{3} \mathrm{~N}$ seem to arise from a different, cooler component where the FUV flux has been attenuated. This scenario agrees with the different $\mathrm{H}_{2} \mathrm{CO}$ and $\mathrm{CH}_{3} \mathrm{OH}$ spatial distributions observed by Leurini et al. (2010) with the IRAM $30 \mathrm{~m}$ telescope and the PdB interferometer. In particular, Leurini et al. found that both species show different spatial distributions, with $\mathrm{CH}_{3} \mathrm{OH}$ only tracing the denser and cooler clumps seen deeper inside the Bar, whereas $\mathrm{H}_{2} \mathrm{CO}$ also traces the warmer extended (interclump) gas directly exposed to the strong FUV-field. Consistent with previous works (Goicoechea et al. 2011, 2016; Nagy et al. 2013),

the Gaussian source (also in arcsec). For the semi-extended emission we assumed that $\theta_{\mathrm{S}}=9^{\prime \prime}$ (see Sect. 5.4). 


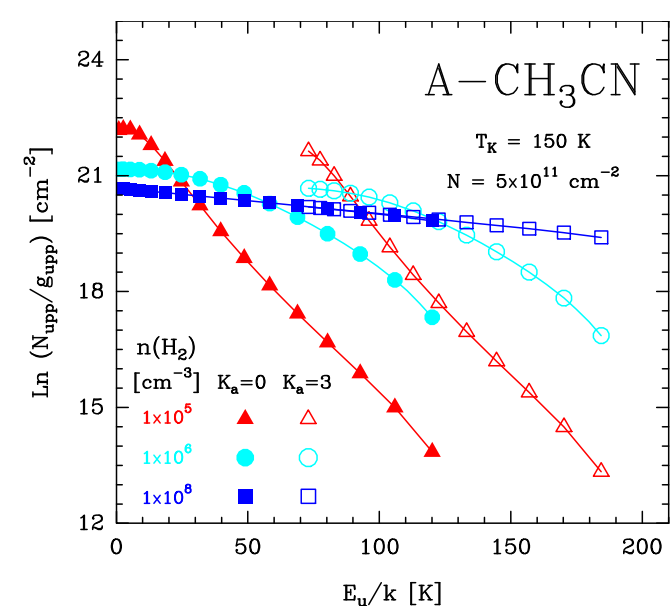

Fig. 16. Rotational population diagrams for $\mathrm{A}-\mathrm{CH}_{3} \mathrm{CN}$ computed with a non-LTE excitation code. All models adopt the same gas temperature $\left(T_{\mathrm{k}}=150 \mathrm{~K}\right)$ and column density $\left(N_{\text {tot }}=5 \times 10^{11} \mathrm{~cm}^{-2}\right)$, but three different $n\left(\mathrm{H}_{2}\right)$ values. For simplicity, only rotational transitions in the $K_{\mathrm{a}}=0$ (filled symbols) and 3 (empty symbols) ladders are shown.

we derive very high thermal gas pressures at the PDR edge $\left(P_{\mathrm{th}} / k=n_{\mathrm{H}} T_{\mathrm{K}} \gtrsim 10^{8} \mathrm{~K} \mathrm{~cm}^{-3}\right)$.

\subsection{Subthermal excitation effects on the rotational diagrams of symmetric- and asymmetric-top molecules}

In this section we show how subthermal excitation effects modify the resulting rotational population diagram of symmetric- and asymmetric-top molecules such as $\mathrm{CH}_{3} \mathrm{CN}$ and $\mathrm{H}_{2} \mathrm{CO}$, respectively. In particular we run a grid of LVG models for varying gas densities, but keeping the same gas temperature and column density. Figures 16 and 17 show model results in the form of population diagrams for $\mathrm{A}-\mathrm{CH}_{3} \mathrm{CN}$ transitions in the $K_{\mathrm{a}}=0$ and 3 rotational ladders $\left(T_{\mathrm{k}}=150 \mathrm{~K}\right.$ and $\left.N_{\text {tot }}=5 \times 10^{11} \mathrm{~cm}^{-2}\right)$, and for p- $\mathrm{H}_{2} \mathrm{CO}$ in the $K_{\mathrm{a}}=0$ and 2 rotational ladders $\left(T_{\mathrm{k}}=200 \mathrm{~K}\right.$ and $\left.N_{\text {tot }}=1.8 \times 10^{13} \mathrm{~cm}^{-2}\right)$. Only at very high gas densities, higher than the critical density for collisional excitation $\left(n \gg n_{\mathrm{cr}}\right)$, do inelastic collisions drive the level populations close to LTE ( $T_{\text {rot }} \simeq T_{\mathrm{k}}$ ). In a rotational diagram, the $K_{\mathrm{a}}$ ladders merge in a single straight line with a slope equal to $-1 / T_{\mathrm{k}}$. Owing to the high gas densities, this characteristic straight diagram is typically seen towards hot cores (e.g. Bisschop et al. 2007). As the gas density decreases, the excitation becomes subthermal $\left(T_{\text {rot }}<T_{\mathrm{k}}\right)$, and the rotational population diagram starts to show separate rotational ladders for each set of transitions with the same $K_{\mathrm{a}}$ quantum number. For very polar molecules such as $\mathrm{CH}_{3} \mathrm{CN}$ and $\mathrm{H}_{2} \mathrm{CO}$ (thus high $n_{\mathrm{cr}}$ ), subthermal excitation happens at relatively high densities. Therefore, accurate column densities and rotational temperatures from rotational diagrams can only be obtained if the individual column densities for each rotational ladder are computed independently. This likely explains the discrepancy with the high $T_{\text {rot }}$ obtained by Nagy et al. (2017) in the rotational diagram of their submm o- $\mathrm{H}_{2} \mathrm{CO}$ lines observed with Herschel/HIFI towards the Bar.

\subsection{Rotational diagrams and column-density determination}

We determined the beam-averaged column density $(N)$ and the rotational temperature $\left(T_{\text {rot }}\right)$ for each molecule found by building rotational diagrams (e.g. Goldsmith \& Langer 1999; Cuadrado et al. 2015). The large number of detected lines allows us to accurately determine rotational temperatures and column densities. Optically thin emission is assumed (consistent with

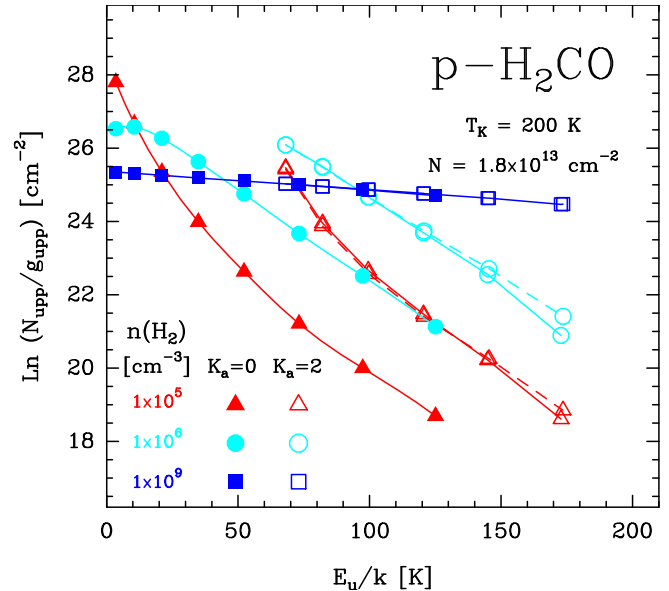

Fig. 17. Rotational population diagrams for $\mathrm{p}-\mathrm{H}_{2} \mathrm{CO}$ computed with a non-LTE excitation code. All models adopt the same gas temperature $\left(T_{\mathrm{k}}=200 \mathrm{~K}\right)$ and column density $\left(N_{\mathrm{tot}}=1.8 \times 10^{13} \mathrm{~cm}^{-2}\right)$, but three different $n\left(\mathrm{H}_{2}\right)$ values. For simplicity, only rotational transitions in the $K_{\mathrm{a}}=0$ (filled symbols) and 2 (empty symbols) ladders are shown. We note that at densities $<10^{8} \mathrm{~cm}^{-3}$, the set of transitions with the $K_{\mathrm{a}}=2$ number are also split into two components: (i) transitions with $K_{\mathrm{c}}=J-1$ (empty symbols connected with solid lines) and (ii) transitions with $K_{\mathrm{c}}=J-2$ (empty symbols connected with dashed lines).

our best LVG models of $\mathrm{H}_{2} \mathrm{CO}, \mathrm{HC}_{3} \mathrm{~N}, \mathrm{CH}_{3} \mathrm{CN}$, and $\mathrm{CH}_{3} \mathrm{OH}$ ). We note that owing to their specific spectroscopy and prevailing excitation conditions at the edge of the Bar (subthermal excitation), a correct determination of the rotational temperatures and column densities for species such as $\mathrm{H}_{2} \mathrm{CO}, \mathrm{H}_{2} \mathrm{CS}, \mathrm{H}_{2} \mathrm{CCO}$, $\mathrm{CH}_{3} \mathrm{OH}$, and $\mathrm{CH}_{3} \mathrm{CN}$ requires building specific diagrams for each rotational ladder (see Sect. 5.3). For the molecules with known collisional rates, we determine $N_{\mathrm{LVG}} \approx N_{\mathrm{RD}}$ (within a factor of 2). This comparison shows that the $N_{\mathrm{RD}}$ computed for the other molecules are accurate.

The rotational diagrams were built considering two limiting cases: (i) that the detected emission is extended (i.e. uniform beam filling), with $\eta_{\mathrm{bf}}=1$; and (ii) that the emission is semi-extended, assuming that $\theta_{\mathrm{s}}=9^{\prime \prime}$ (the typical beam of the IRAM $30 \mathrm{~m}$ telescope at $\sim 1 \mathrm{~mm})^{6}$. We only considered lines not blended with other transitions and detected above a $3 \sigma$ level. The resulting rotational diagrams are shown in Fig. 18. Rotational temperatures and column densities obtained by linear least squares fits are listed in Table 4. The uncertainties shown in Table 4 indicate the uncertainty obtained from the least squares fit to the rotational diagram. The uncertainty obtained in the determination of the line parameters with the Gaussian fitting programme are included in the uncertainty bars at each point of the rotational diagram.

For $\mathrm{H}_{2} \mathrm{CO}, \mathrm{H}_{2}^{13} \mathrm{CO}, \mathrm{H}_{2} \mathrm{CS}, \mathrm{H}_{2} \mathrm{CCO}, \mathrm{A}-\mathrm{CH}_{3} \mathrm{OH}, \mathrm{A}-\mathrm{CH}_{3} \mathrm{CN}$, and $\mathrm{E}-\mathrm{CH}_{3} \mathrm{CN}$ we have built specific rotational diagrams for different sets of transitions with the same $K_{a}$ quantum number value. The total column density of the molecule is obtained by adding the column density of each rotational ladder. For the other molecules, it is possible to fit the observed transitions by a single $T_{\text {rot }}$ and $N$, independently of the $K_{a}$ value. The cis- and trans-HCOOH rotational diagrams are shown in Cuadrado et al. (2016).

For molecules with hyperfine structure, like that of $\mathrm{HCO}$, each rotational transition was described without splits, only with a single rotational number $N$. For this purpose, the integrated intensity, $W$, level degeneracy, $g$, and line strength, $S$, of each transition was calculated as the sum of all allowed hyperfine 
Table 4. Rotational temperatures $\left(T_{\text {rot }}\right)$, column densities $(N)$, and abundances with respect to hydrogen nuclei inferred in the Orion Bar PDR.

\begin{tabular}{|c|c|c|c|c|c|c|}
\hline & \multicolumn{2}{|c|}{ Uniform beam filling } & \multicolumn{2}{|c|}{ Semi-extended source } & \multirow{3}{*}{ Abundance* } & \multirow{3}{*}{ Notes } \\
\hline & $T_{\text {rot }}$ & $N(\mathrm{X})$ & $T_{\text {rot }}$ & $N(\mathrm{X})$ & & \\
\hline & {$[\mathrm{K}]$} & {$\left[\mathrm{cm}^{-2}\right]$} & {$[\mathrm{K}]$} & {$\left[\mathrm{cm}^{-2}\right]$} & & \\
\hline HCO & $15 \pm 2$ & $(1.1 \pm 0.3) \times 10^{13}$ & $9 \pm 2$ & $(5.3 \pm 3.5) \times 10^{13}$ & $(1.7-8.4) \times 10^{-10}$ & $\mathrm{a}$ \\
\hline $\mathrm{o}-\mathrm{H}_{2} \mathrm{CO} K_{\mathrm{a}}=1$ & $17 \pm 2$ & $(3.7 \pm 0.6) \times 10^{13}$ & $12 \pm 1$ & $(1.1 \pm 0.3) \times 10^{14}$ & & $\mathrm{a}$ \\
\hline $\mathrm{o}-\mathrm{H}_{2} \mathrm{CO} K_{\mathrm{a}}=3$ & 17 & $(6.9 \pm 1.0) \times 10^{12}$ & 12 & $(1.1 \pm 0.2) \times 10^{13}$ & & $\mathrm{~b}, \mathrm{c}$ \\
\hline $\mathrm{p}-\mathrm{H}_{2} \mathrm{CO} K_{\mathrm{a}}=0$ & $16 \pm 2$ & $(9.8 \pm 1.4) \times 10^{12}$ & $9 \pm 1$ & $(3.9 \pm 0.6) \times 10^{13}$ & & $\mathrm{a}, \mathrm{c}$ \\
\hline $\mathrm{p}-\mathrm{H}_{2} \mathrm{CO} K_{\mathrm{a}}=2$ & $18 \pm 1$ & $(6.2 \pm 0.2) \times 10^{12}$ & $13 \pm 1$ & $(1.3 \pm 0.1) \times 10^{13}$ & & $\mathrm{a}, \mathrm{c}$ \\
\hline$\left[(\mathbf{o}+\mathbf{p})-\mathrm{H}_{2} \mathrm{CO}\right]$ & - & $(6.0 \pm 0.6) \times 10^{13}$ & - & $(1.7 \pm 0.3) \times 10^{14}$ & $(0.9-2.7) \times 10^{-9}$ & $\mathrm{~d}$ \\
\hline $\mathrm{o}-\mathrm{H}_{2}^{13} \mathrm{CO}$ & $15 \pm 3$ & $(7.3 \pm 2.4) \times 10^{11}$ & $10 \pm 2$ & $(3.0 \pm 1.1) \times 10^{12}$ & & $\mathrm{a}$ \\
\hline $\mathrm{p}-\mathrm{H}_{2}^{13} \mathrm{CO}$ & $9 \pm 1$ & $(2.3 \pm 0.4) \times 10^{11}$ & $7 \pm 1$ & $(8.0 \pm 1.2) \times 10^{11}$ & & $\mathrm{a}, \mathrm{c}$ \\
\hline$\left[(\mathbf{o}+\mathbf{p})-\mathrm{H}_{2}^{13} \mathbf{C O}\right]$ & - & $(9.6 \pm 2.4) \times 10^{11}$ & - & $(3.8 \pm 1.1) \times 10^{12}$ & $(1.5-6.0) \times 10^{-11}$ & d \\
\hline $\mathrm{o}-\mathrm{H}_{2} \mathrm{CS} K_{\mathrm{a}}=1$ & $30 \pm 3$ & $(3.1 \pm 0.5) \times 10^{12}$ & $19 \pm 1$ & $(1.3 \pm 0.2) \times 10^{13}$ & & $\mathrm{a}$ \\
\hline $\mathrm{o}-\mathrm{H}_{2} \mathrm{CS} K_{\mathrm{a}}=3$ & 30 & $(6.7 \pm 1.9) \times 10^{11}$ & 19 & $(2.7 \pm 0.4) \times 10^{12}$ & & $\mathrm{e}, \mathrm{c}$ \\
\hline $\mathrm{p}-\mathrm{H}_{2} \mathrm{CS} K_{\mathrm{a}}=0$ & $29 \pm 6$ & $(5.0 \pm 1.4) \times 10^{11}$ & $16 \pm 2$ & $(2.6 \pm 1.0) \times 10^{12}$ & & $\mathrm{a}$ \\
\hline $\mathrm{p}-\mathrm{H}_{2} \mathrm{CS} K_{\mathrm{a}}=2$ & $35 \pm 8$ & $(7.8 \pm 4.4) \times 10^{11}$ & $15 \pm 3$ & $(2.6 \pm 1.9) \times 10^{12}$ & & $\mathrm{a}$ \\
\hline$\left[(\mathbf{o}+\mathbf{p})-\mathrm{H}_{2} \mathbf{C S}\right]$ & - & $(5.0 \pm 0.7) \times 10^{12}$ & - & $(2.1 \pm 0.3) \times 10^{13}$ & $(0.8-3.3) \times 10^{-10}$ & $\mathrm{~d}$ \\
\hline HNCO & $51 \pm 7$ & $(1.0 \pm 0.1) \times 10^{12}$ & $26 \pm 3$ & $(5.6 \pm 1.3) \times 10^{12}$ & $(1.6-8.9) \times 10^{-11}$ & $\mathrm{a}$ \\
\hline $\mathrm{CH}_{2} \mathrm{NH}$ & $28 \pm 7$ & $(1.1 \pm 0.4) \times 10^{12}$ & $27 \pm 7$ & $(2.4 \pm 1.0) \times 10^{12}$ & $(1.7-3.8) \times 10^{-11}$ & $\mathrm{a}$ \\
\hline $\mathrm{o}-\mathrm{H}_{2} \mathrm{CCO} K_{\mathrm{a}}=1$ & $55 \pm 2$ & $(3.0 \pm 0.1) \times 10^{12}$ & $30 \pm 2$ & $(1.3 \pm 0.2) \times 10^{13}$ & & $\mathrm{a}$ \\
\hline $\mathrm{o}-\mathrm{H}_{2} \mathrm{CCO} K_{\mathrm{a}}=3$ & $64 \pm 6$ & $(1.3 \pm 0.3) \times 10^{12}$ & $34 \pm 1$ & $(4.2 \pm 0.7) \times 10^{12}$ & & $\mathrm{a}$ \\
\hline $\mathrm{p}-\mathrm{H}_{2} \mathrm{CCO} K_{\mathrm{a}}=0$ & $57 \pm 4$ & $(4.8 \pm 0.6) \times 10^{11}$ & $42 \pm 3$ & $(1.3 \pm 0.2) \times 10^{12}$ & & $\mathrm{a}$ \\
\hline $\mathrm{p}-\mathrm{H}_{2} \mathrm{CCO} K_{\mathrm{a}}=2$ & $54 \pm 3$ & $(1.1 \pm 0.1) \times 10^{12}$ & $29 \pm 2$ & $(6.1 \pm 1.8) \times 10^{12}$ & & $\mathrm{a}$ \\
\hline$\left[(\mathbf{o}+\mathbf{p})-\mathrm{H}_{2} \mathrm{CCO}\right]$ & - & $(5.9 \pm 0.3) \times 10^{12}$ & - & $(2.5 \pm 0.3) \times 10^{13}$ & $(0.9-4.0) \times 10^{-10}$ & d \\
\hline $\mathbf{H C}_{3} \mathbf{N}$ & $43 \pm 2$ & $(4.2 \pm 0.3) \times 10^{11}$ & $27 \pm 1$ & $(3.2 \pm 0.3) \times 10^{12}$ & $(0.7-5.1) \times 10^{-11}$ & $\mathrm{a}$ \\
\hline cis-HCOOH & $23 \pm 4$ & $(4.6 \pm 0.7) \times 10^{11}$ & $21 \pm 4$ & $(4.2 \pm 0.6) \times 10^{12}$ & & $\mathrm{f}$ \\
\hline trans-HCOOH $K_{\mathrm{a}}=0$ & $12 \pm 2$ & $(3.5 \pm 0.5) \times 10^{11}$ & $6 \pm 1$ & $(4.1 \pm 0.6) \times 10^{12}$ & & $\mathrm{f}$ \\
\hline trans-HCOOH $K_{\mathrm{a}}=1$ & $12 \pm 3$ & $(3.3 \pm 1.3) \times 10^{11}$ & $6 \pm 1$ & $(3.6 \pm 2.1) \times 10^{12}$ & & $\mathrm{f}$ \\
\hline trans-HCOOH $K_{\mathrm{a}}=2$ & $13 \pm 3$ & $(6.3 \pm 2.8) \times 10^{11}$ & $7 \pm 1$ & $(5.0 \pm 2.4) \times 10^{12}$ & & $\mathrm{f}$ \\
\hline$[($ cis+trans $)-\mathrm{HCOOH}]$ & - & $(1.8 \pm 0.3) \times 10^{12}$ & - & $(1.7 \pm 0.3) \times 10^{13}$ & $(0.3-2.7) \times 10^{-10}$ & $\mathrm{~g}$ \\
\hline $\mathrm{A}-\mathrm{CH}_{3} \mathrm{CN} K_{\mathrm{a}}=0$ & $26 \pm 2$ & $(2.8 \pm 0.5) \times 10^{11}$ & $19 \pm 1$ & $(1.9 \pm 0.6) \times 10^{12}$ & & a \\
\hline $\mathrm{A}-\mathrm{CH}_{3} \mathrm{CN} K_{\mathrm{a}}=3$ & $30 \pm 1$ & $(3.0 \pm 0.6) \times 10^{11}$ & $21 \pm 1$ & $(1.5 \pm 0.6) \times 10^{12}$ & & $\mathrm{a}$ \\
\hline $\mathrm{E}-\mathrm{CH}_{3} \mathrm{CN} K_{\mathrm{a}}=1$ & $28 \pm 2$ & $(2.9 \pm 0.5) \times 10^{11}$ & $20 \pm 1$ & $(1.8 \pm 0.4) \times 10^{12}$ & & a \\
\hline E- $\mathrm{CH}_{3} \mathrm{CN} K_{\mathrm{a}}=2$ & $31 \pm 1$ & $(1.7 \pm 0.2) \times 10^{11}$ & $22 \pm 1$ & $(1.0 \pm 0.3) \times 10^{12}$ & & $\mathrm{a}$ \\
\hline $\mathrm{E}-\mathrm{CH}_{3} \mathrm{CN} K_{\mathrm{a}}=4$ & $26 \pm 1$ & $(1.1 \pm 0.4) \times 10^{11}$ & $18 \pm 1$ & $(6.7 \pm 3.2) \times 10^{11}$ & & $\mathrm{a}$ \\
\hline$\left[(\mathrm{A}+\mathrm{E})-\mathrm{CH}_{3} \mathrm{CN}\right]$ & - & $(1.2 \pm 0.1) \times 10^{12}$ & - & $(6.9 \pm 1.0) \times 10^{12}$ & $(0.2-1.1) \times 10^{-10}$ & $\mathrm{~h}$ \\
\hline $\mathrm{A}-\mathrm{CH}_{3} \mathrm{OH} K_{\mathrm{a}}=0$ & $34 \pm 2$ & $(8.0 \pm 0.6) \times 10^{12}$ & $18 \pm 2$ & $(5.3 \pm 1.1) \times 10^{13}$ & & $\mathrm{a}$ \\
\hline $\mathrm{A}-\mathrm{CH}_{3} \mathrm{OH} K_{\mathrm{a}}= \pm 1$ & $26 \pm 2$ & $(3.5 \pm 0.9) \times 10^{12}$ & $14 \pm 1$ & $(2.8 \pm 0.7) \times 10^{13}$ & & $\mathrm{a}$ \\
\hline $\mathrm{E}-\mathrm{CH}_{3} \mathrm{OH}$ & $36 \pm 3$ & $(1.9 \pm 0.2) \times 10^{13}$ & $26 \pm 3$ & $(6.5 \pm 1.4) \times 10^{13}$ & & $\mathrm{a}$ \\
\hline$\left[(\mathrm{A}+\mathrm{E})-\mathrm{CH}_{3} \mathrm{OH}\right]$ & - & $(3.1 \pm 0.2) \times 10^{13}$ & - & $(1.5 \pm 0.2) \times 10^{14}$ & $(0.5-2.4) \times 10^{-9}$ & $\mathrm{~h}$ \\
\hline $\mathrm{A}-\mathrm{CH}_{3} \mathrm{CHO}$ & $31 \pm 2$ & $(2.3 \pm 0.3) \times 10^{12}$ & $20 \pm 1$ & $(1.2 \pm 0.2) \times 10^{13}$ & & $\mathrm{a}$ \\
\hline $\mathrm{E}-\mathrm{CH}_{3} \mathrm{CHO}$ & $33 \pm 3$ & $(2.6 \pm 0.4) \times 10^{12}$ & $21 \pm 1$ & $(1.2 \pm 0.2) \times 10^{13}$ & & $\mathrm{a}$ \\
\hline$\left[(\mathrm{A}+\mathrm{E})-\mathrm{CH}_{3} \mathrm{CHO}\right]$ & - & $(4.9 \pm 0.5) \times 10^{12}$ & - & $(2.4 \pm 0.3) \times 10^{13}$ & $(0.8-3.8) \times 10^{-10}$ & $\mathrm{~h}$ \\
\hline
\end{tabular}

Notes. ${ }^{(*)}$ The abundance of each species with respect to $\mathrm{H}$ nuclei is given by $\frac{N(X)}{N_{H}}=\frac{N(X)}{N(H)+2 N\left(H_{2}\right)}$, with $N\left(\mathrm{H}_{2}\right) \simeq 3 \times 10^{22} \mathrm{~cm}^{-2}$ and $N(\mathrm{H}) \simeq 3 \times 10^{21} \mathrm{~cm}^{-2}$ (van der Werf et al. 2013). (a) $T_{\text {rot }}$ and $N$ from rotational diagram analysis. (b) Only two lines detected with the same $E_{\mathrm{u}} / k$. $N$ calculated assuming the same $T_{\text {rot }}$ that $\mathrm{o}-\mathrm{H}_{2} \mathrm{CO} K_{\mathrm{a}}=1$. (c) $\Delta N$ estimated assuming a $15 \%$ of the calculated $N$. (d) Total $N$ calculated as the sum of the ortho and para species. (e) Only two lines detected with upper level energies of $138.3 \mathrm{~K}$ and $149.8 \mathrm{~K}$. They are too similar for an accurate estimation of $T_{\text {rot }}$ and $N$ from a rotational diagram analysis. $N$ calculated assuming the same $T_{\text {rot }}$ that o- $\mathrm{H}_{2} \mathrm{CS} K_{\mathrm{a}}=1$. (f) From Cuadrado et al. (2016). (g) Total $N$ calculated as the sum of the cis and trans species. (h) Total $N$ calculated as the sum of the A and E species. 
S. Cuadrado et al.: Complex organic molecules in strongly UV-irradiated gas
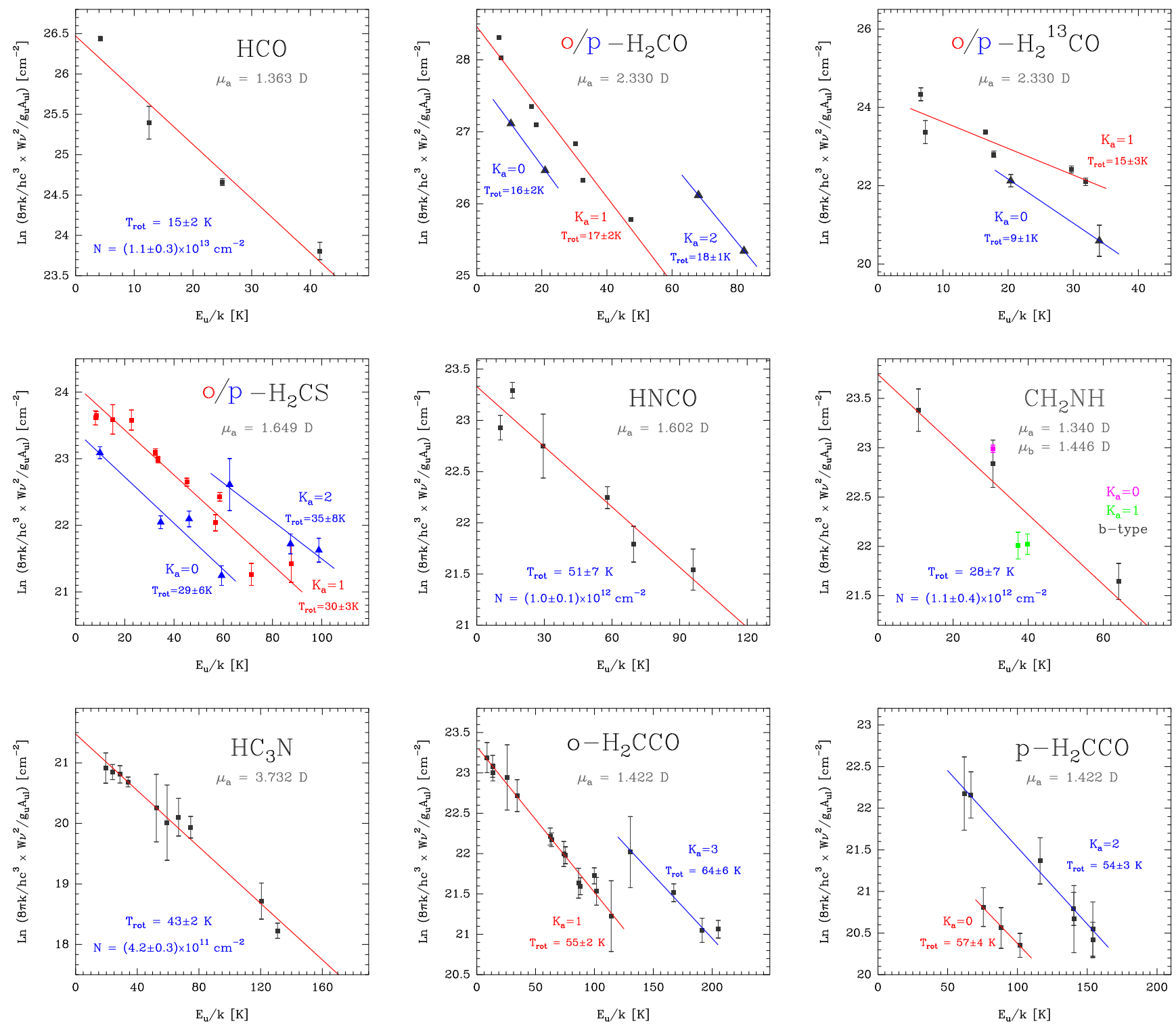

Fig. 18. Rotational diagrams of the detected complex molecules in the Orion Bar PDR (assuming uniform beam filling). Fitted values of the rotational temperature, $T_{\text {rot }}$, column density, $N$, and their respective uncertainties are also indicated for each molecule.

components of each $N+1 \rightarrow N$ transition. The characteristic frequency, $v$, was determined using the weighted average with the relative strength of each line as weight, and the Einstein coefficient, $A$, was calculated using the weighted values in the usual relation.

Comparing the resulting rotational diagrams, we see that: (i) $\mathrm{H}_{2} \mathrm{CO}$ and $\mathrm{CH}_{3} \mathrm{OH}$ are, by far, the most abundant organic molecules (by a factor of $\gtrsim 5$ ), followed by $\mathrm{HCO}, \mathrm{H}_{2} \mathrm{CCO}$, $\mathrm{CH}_{3} \mathrm{CHO}, \mathrm{H}_{2} \mathrm{CS}, \mathrm{HCOOH}, \mathrm{CH}_{3} \mathrm{CN}, \mathrm{CH}_{2} \mathrm{NH}, \mathrm{HNCO}, \mathrm{H}_{2}^{13} \mathrm{CO}$, and $\mathrm{HC}_{3} \mathrm{~N}$ (in decreasing order of abundance); (ii) the orthoto-para (OTP) ratios obtained from the $\mathrm{H}_{2} \mathrm{CO}, \mathrm{H}_{2}^{13} \mathrm{CO}, \mathrm{H}_{2} \mathrm{CS}$, $\mathrm{H}_{2} \mathrm{CCO}$ column densities are $\sim 3$, as expected at high gas temperature; (iii) we obtain similar rotational temperatures for orthopara and A-E species; (iv) and the inferred $\left[\mathrm{H}_{2} \mathrm{CO}\right] /\left[\mathrm{H}_{2}^{13} \mathrm{CO}\right]$ ratio is $63 \pm 3$, similar to the ${ }^{12} \mathrm{C} /{ }^{13} \mathrm{C} \approx 67$ isotopic ratio in Orion (Langer \& Penzias 1990). Hence, this confirms that even lines from the most abundant organic species studied in this work, are optically thin.

In order to confirm the correct line identification and possible line blendings, we have modelled the spectrum of each molecule using the MADEX radiative transfer code assuming a Boltzmann distribution and a single excitation temperature for the rotational levels population (we recall that for the observed set of lines/ladders of a given molecule, we infer a single temperature component from the rotational diagrams). Figures 2, and 5-8, and 13 show the observational spectra (black histograms) and the modelled spectra (red lines) of each molecule. The obtained fits agree very well with the observations and rotational diagrams.

\subsection{Abundances}

In order to determine molecular abundances with respect to hydrogen nuclei ${ }^{6}$ towards the line survey position, we derived the beam-averaged $\mathrm{H}_{2}$ column density from our observations of the optically thin $\mathrm{C}^{18} \mathrm{O}$ lines $(J=1 \rightarrow 0,2 \rightarrow 1$, and $3 \rightarrow 2$ transitions) assuming ${ }^{16} \mathrm{O} /{ }^{18} \mathrm{O} \approx 500$ (Wilson \& Rood 1994) and

6 The molecular abundance with respect to hydrogen nuclei is given by $\frac{N(X)}{N(H)+2 N\left(H_{2}\right)}$. 

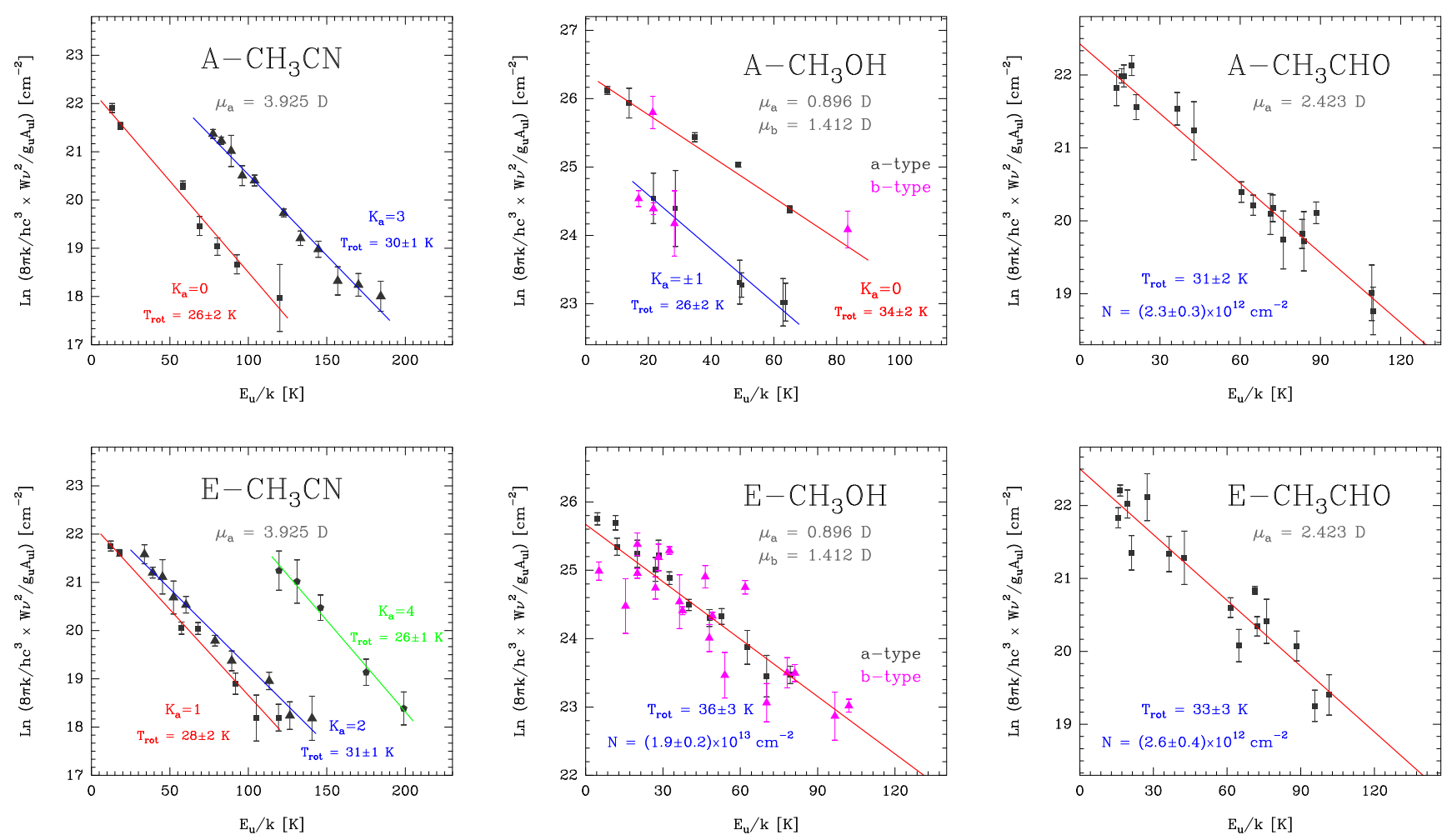

Fig. 18. continued.

a $[\mathrm{CO}] /\left[\mathrm{H}_{2}\right]$ abundance of $\sim 10^{-4}$ (lower than the canonical value due to photodissociation). The resulting $\mathrm{H}_{2}$ column density, $N\left(\mathrm{H}_{2}\right) \simeq 3 \times 10^{22} \mathrm{~cm}^{-2}$, is in good agreement with previous estimations of $N\left(\mathrm{H}_{2}\right)$ close to the dissociation front (see e.g. Hogerheijde et al. 1995). A hydrogen atom column density, $N(\mathrm{H})$, of $\sim 3 \times 10^{21} \mathrm{~cm}^{-2}$ has been inferred from H I observations towards the edge of the Orion Bar (van der Werf et al. 2013). Molecular abundances with respect to hydrogen nuclei are listed in Table 4. The abundances of the detected species range from $10^{-9}$ to $10^{-11}$.

\subsection{Undetected complex organic molecules and precursors}

The broadband frequency coverage of the survey allowed us to obtain upper limits for other chemically interesting organic molecules that have not been detected towards the edge of the PDR, but could have been expected. In particular, we searched for $\mathrm{HDCO}, \mathrm{CH}_{3} \mathrm{O}, \mathrm{CH}_{3} \mathrm{NC}, \mathrm{CH}_{3} \mathrm{CCH}, \mathrm{CH}_{3} \mathrm{OCH}_{3}, \mathrm{HCOOCH}_{3}$, $\mathrm{CH}_{3} \mathrm{CH}_{2} \mathrm{OH}, \mathrm{CH}_{2} \mathrm{CHCN}$, and $\mathrm{CH}_{3} \mathrm{CH}_{2} \mathrm{CN}$, because they have been detected in other PDRs and star-forming regions (e.g. Horsehead, Orion KL, Barnard 1-b, or IRAS 16293-2422; see Table 6 for references). The $\mathrm{CH}_{3} \mathrm{O}$ radical is thought to be an important intermediary for the $\mathrm{H}_{2} \mathrm{CO}$ and $\mathrm{CH}_{3} \mathrm{OH}$ chemistry but so far, has only been detected in cold and dense gas (Cernicharo et al. 2012; Bacmann \& Faure 2016). HDCO has been detected by Parise et al. (2009) towards the lukewarm, dense and more FUV-shielded clump \#3 of Lis \& Schilke (2003), but it is not detected towards the warmer and high FUVilluminated line survey position, near the dissociation front.

First, we estimated $3 \sigma$ line intensities using the relation

$\int T_{\mathrm{MB}} \mathrm{d} v=3 \sigma \sqrt{2 \delta v \Delta v} \quad\left[\mathrm{Kkm} \mathrm{s}^{-1}\right]$
Table 5. Upper limits for undetected COMs.

\begin{tabular}{lcc}
\hline \hline Molecule & $N(\mathrm{X})\left[\mathrm{cm}^{-2}\right]$ & Abundance $^{a}$ \\
\hline $\mathrm{HDCO}^{b}$ & $(1.3-1.5) \times 10^{11}$ & $(2.1-2.4) \times 10^{-12}$ \\
$\mathrm{CH}_{3} \mathrm{O}$ & $(2.0-4.0) \times 10^{12}$ & $(3.2-6.3) \times 10^{-11}$ \\
$\mathrm{CH}_{3} \mathrm{NC}$ & $(5.0-8.0) \times 10^{10}$ & $(0.8-1.3) \times 10^{-12}$ \\
$\mathrm{CH}_{3} \mathrm{CCH}$ & $(5.0-8.0) \times 10^{12}$ & $(0.8-1.3) \times 10^{-10}$ \\
$\mathrm{CH}_{3} \mathrm{OCH}_{3}$ & $(7.0-9.0) \times 10^{12}$ & $(1.1-1.4) \times 10^{-10}$ \\
$\mathrm{HCOOCH}_{3}$ & $(9.0-9.5) \times 10^{12}$ & $(1.4-1.5) \times 10^{-10}$ \\
$\mathrm{CH}_{3} \mathrm{CH}_{2} \mathrm{OH}$ & $(1.0-1.2) \times 10^{12}$ & $(1.6-1.9) \times 10^{-11}$ \\
$\mathrm{CH}_{2} \mathrm{CHCN}$ & $(9.0-9.5) \times 10^{12}$ & $(1.4-1.5) \times 10^{-10}$ \\
$\mathrm{CH}_{3} \mathrm{CH}_{2} \mathrm{CN}$ & $(7.0-5.0) \times 10^{11}$ & $(1.1-0.8) \times 10^{-11}$ \\
\hline
\end{tabular}

Notes. ${ }^{(a)}$ The abundance of each species with respect to $\mathrm{H}$ nuclei (see Sect. 5.5). ${ }^{(b)}$ Detected by Parise et al. (2009) towards clump \#3 (Lis \& Schilke 2003) of the Orion Bar.

where $\sigma$ is the rms of the observations per resolution channel $[\mathrm{K}], \delta v$ is the velocity spectral resolution $\left[\mathrm{km} \mathrm{s}^{-1}\right]$, and $\Delta v$ is the assumed line widths $\left(\sim 2 \mathrm{~km} \mathrm{~s}^{-1}\right)$. Second, we used MADEX to create synthetic models that simulate the line emission to constrain their column densities. The column densities and $3 \sigma$ upper limit abundances assuming $T_{\text {rot }}=20-30 \mathrm{~K}$ are listed in Table 5 . We also provide the following abundance ratio upper limits: $[\mathrm{HDCO}] /\left[\mathrm{H}_{2} \mathrm{CO}\right]<0.003$ and $\left[\mathrm{CH}_{3} \mathrm{NC}\right] /\left[\mathrm{CH}_{3} \mathrm{CN}\right]<0.1$. Parise et al. (2009) estimated an abundance ratio of $[\mathrm{HDCO}] /\left[\mathrm{H}_{2} \mathrm{CO}\right]>0.006$ towards clump \#3, which suggests that the deuteration diminishes from the lukewarm and shielded clumps to the warmer and more FUVirradiated cloud edge. 
Table 6. Abundances relative to $\mathrm{H}_{2}$ in different environments (in units of $10^{-10}$ ).

\begin{tabular}{|c|c|c|c|c|c|c|c|c|}
\hline \multirow[t]{2}{*}{ Molecule } & \multirow{2}{*}{$\begin{array}{c}\text { Orion } \mathrm{Bar}^{1 *} \\
\text { PDR }\end{array}$} & \multicolumn{2}{|c|}{ Horsehead } & \multicolumn{2}{|c|}{ Orion KL } & \multirow{2}{*}{$\begin{array}{c}\text { L1157-B17 } \\
\text { Outflow }\end{array}$} & \multirow{2}{*}{$\begin{array}{c}\text { IRAS } 16293-2422^{8} \\
\text { Hot corino }\end{array}$} & \multirow{2}{*}{$\begin{array}{c}\text { B1- } b^{9} \\
\text { Dense core }\end{array}$} \\
\hline & & $\mathrm{PDR}^{2 *}$ & Core $^{3 *}$ & $\mathrm{HC}^{4}$ & $\mathrm{CR}^{5}$ & & & \\
\hline $\mathrm{HCO}$ & 1.7 & $8.4^{\mathrm{b}}$ & $<0.8^{\mathrm{b}}$ & - & $<0.3^{6, \mathrm{~g}}$ & - & $<2.0$ & $0.2^{\mathrm{n}}$ \\
\hline HNCO & 0.2 & - & - & $780^{\mathrm{h}}$ & - & $605^{\mathrm{k}}$ & 1.7 & $0.7^{\mathrm{p}}$ \\
\hline $\mathrm{H}_{2} \mathrm{CO}$ & 9.0 & $2.9^{c}$ & $2.0^{c}$ & $1200^{\mathrm{h}}$ & $440^{\mathrm{h}}$ & $4000^{1}$ & 7.0 & $4.6^{\mathrm{q}}$ \\
\hline $\mathrm{H}_{2} \mathrm{CS}$ & 0.8 & - & - & $150^{\mathrm{h}}$ & $74^{\mathrm{h}}$ & $1100^{1}$ & - & $0.9^{\mathrm{q}}$ \\
\hline $\mathrm{t}-\mathrm{HCOOH} \dagger$ & $0.2^{\mathrm{a}}$ & $0.5^{\mathrm{d}}$ & $0.1^{\mathrm{d}}$ & $800^{\mathrm{i}}$ & - & - & $<3.0$ & $0.1^{\mathrm{n}}$ \\
\hline $\mathrm{CH}_{2} \mathrm{NH}$ & 0.2 & - & - & $42^{\mathrm{h}}$ & - & - & $<5.0$ & - \\
\hline $\mathrm{H}_{2} \mathrm{CCO}$ & 0.9 & $1.5^{\mathrm{d}}$ & $0.5^{\mathrm{d}}$ & - & $51^{\mathrm{h}}$ & - & 1.8 & $0.2^{\mathrm{n}}$ \\
\hline $\mathrm{HC}_{3} \mathrm{~N}$ & 0.07 & $0.06^{\mathrm{e}}$ & $0.08^{\mathrm{e}}$ & $81^{\mathrm{h}}$ & - & $100^{1}$ & 0.3 & $3.1^{\mathrm{r}}$ \\
\hline $\mathrm{CH}_{3} \mathrm{OH}$ & 5.0 & $1.2^{\mathrm{f}}$ & $2.3^{\mathrm{f}}$ & $22000^{\mathrm{h}}$ & $12000^{\mathrm{h}}$ & $115000^{1}$ & 44 & $31^{\mathrm{r}, \mathrm{s}}$ \\
\hline $\mathrm{CH}_{3} \mathrm{CN}$ & 0.2 & $2.5^{\mathrm{e}}$ & $0.08^{\mathrm{e}}$ & $300^{\mathrm{h}}$ & $120^{\mathrm{h}}$ & - & 1.5 & $0.4^{\mathrm{r}}$ \\
\hline $\mathrm{CH}_{3} \mathrm{CHO}$ & 0.8 & $0.7^{\mathrm{d}}$ & $0.2^{\mathrm{d}}$ & $9.5^{\mathrm{i}}$ & - & $250^{\mathrm{m}}$ & 1.0 & $0.1^{\mathrm{n}}$ \\
\hline $\mathrm{CH}_{3} \mathrm{CCH}$ & $<1.0$ & $4.4^{\mathrm{d}}$ & $3.0^{\mathrm{d}}$ & $24^{\mathrm{i}}$ & $133^{6, \mathrm{i}}$ & - & 6.5 & $5.0^{\mathrm{r}}$ \\
\hline
\end{tabular}

Notes. ${ }^{*}$ A bundances with respect to total hydrogen nuclei. $\dagger$ To date, the cis conformer of HCOOH has only been detected towards the Orion Bar PDR (Cuadrado et al. 2016), therefore, we only provide the abundances of the trans conformer. ${ }^{(1)}$ This work. Abundances calculated assuming uniform beam filling. References: (a) Cuadrado et al. (2016). ${ }^{(2)}$ Low-UV field Horsehead PDR $\left(\chi \approx 60 ; N_{\mathrm{H}}=3.8 \times 10^{22} \mathrm{~cm}^{-2}\right)$ and (3) condensation shielded from the UV field (dense core, $N_{\mathrm{H}}=6.4 \times 10^{22} \mathrm{~cm}^{-2}$ ) behind the Horsehead PDR edge. Ref.: ${ }^{(\mathrm{b})} \mathrm{Gerin}$ et al. (2009), (c) Guzmán et al. (2011), ${ }^{(\mathrm{d})}$ Guzmán et al. (2014), ${ }^{(\mathrm{e})}$ Gratier et al. (2013), ${ }^{(\mathrm{f})}$ Guzmán et al. (2013). ${ }^{(4)}$ Orion KL Hot Core (HC); and ${ }^{(5)}$ Orion KL Compact Ridge (CR). ${ }^{\left({ }^{6}\right)}$ Abundances calculated for the Extended Ridge. Ref.: ${ }^{(g)}$ Blake et al. (1987), ${ }^{\text {(h) }}$ Crockett et al. (2014), ${ }^{\text {(i) }}$ B. Tercero, priv. comm.. ${ }^{(7)}$ Peak B1 in the blue lobe of the L1157. Ref.: ${ }^{(\mathrm{k})}$ Mendoza et al. (2014), ${ }^{(1)}$ Bachiller \& Pérez Gutiérrez (1997), ${ }^{(\mathrm{m})}$ Codella et al. (2015). (8) Low-mass protostar (hot corino) IRAS 16293-2422. The abundances are computed for a $N\left(\mathrm{H}_{2}\right)=2 \times 10^{23} \mathrm{~cm}^{-2}$. Abundances averaged over a $\sim 20^{\prime \prime}$ beam (van Dishoeck et al. 1995). ${ }^{(9)}$ Quiescent dark core Barnard 1-b (B1-b), $N\left(\mathrm{H}_{2}\right)=1.3 \times 10^{23} \mathrm{~cm}^{-2}$ (see e.g. Hirano et al. 1999; Lis et al. 2002). Ref.: ${ }^{(\mathrm{n})}$ Cernicharo et al. (2012), ${ }^{(\mathrm{p})}$ Marcelino et al. (2009), ${ }^{(\mathrm{q})}$ Marcelino et al. (2005), ${ }^{(\mathrm{r})}$ N. Marcelino, priv. comm., ${ }^{(\mathrm{s})}$ see also Öberg et al. (2010).

\section{Discussion}

In order to shed more light on the possible chemical formation routes of COMs in strongly FUV-irradiated gas from an observational perspective, we compare the observed abundances of several COMs and precursors in different environments (see Table 6). In addition to the Orion Bar, we consider the Horsehead PDR (a low-FUV-flux PDR) and a nearby cold core also in the Horsehead nebula, the Orion KL hot core and compact ridge (warm dense gas at roughly the same distance to the Bar), the L1157 outflow (shocked gas), the low-mass protostar IRAS 16293-2422 (hot corino), and the quiescent dark cloud Barnard 1-b (B1-b).

\subsection{COMs in different environments}

Figure 19 shows a comparison between the abundances of 12 organic molecules detected in the above sources. As expected for widespread interstellar molecules, abundant $\mathrm{H}_{2} \mathrm{CO}$ and $\mathrm{CH}_{3} \mathrm{OH}$ are found in all sources $\left(N(\mathrm{X}) / N\left(\mathrm{H}_{2}\right)>10^{-10}\right)$. In diffuse and translucent clouds $\left(n\left(\mathrm{H}_{2}\right) \simeq 10^{2}-10^{3} \mathrm{~cm}^{-3}\right)$, only $\mathrm{H}_{2} \mathrm{CO}$ has been detected so far (Liszt et al. 2006), suggesting that the formation of COMs is more efficient in dense gas.

In general, the abundances of $\mathrm{COMs}$, and $\mathrm{CH}_{3} \mathrm{OH}$ in particular, are much higher towards Orion KL (hot core and compact ridge) and towards the L1157-B1 outflow. This translates into low $\left[\mathrm{X}_{\mathrm{COM}}\right] /\left[\mathrm{CH}_{3} \mathrm{OH}\right] \ll 1$ abundance ratios in those environments. The Horsehead PDR, however, shows $\left[\mathrm{X}_{\mathrm{COM}}\right] /\left[\mathrm{CH}_{3} \mathrm{OH}\right]>1$ ratios for $\mathrm{X}_{\mathrm{COM}}=\mathrm{HCO}, \mathrm{H}_{2} \mathrm{CO}, \mathrm{H}_{2} \mathrm{CCO}$, $\mathrm{CH}_{3} \mathrm{CN}$, and $\mathrm{CH}_{3} \mathrm{CCH}$ abundances. The Orion $\mathrm{KL}$ hot core and compact ridge show enhanced COM abundances. Owing to the very high dust temperatures $\left(T_{\mathrm{d}}>100 \mathrm{~K}\right)$, ice sublimation and subsequent warm gas-phase chemistry dominates (e.g. Blake et al. 1987). On the other hand, the abundances inferred in the hot corino IRAS 16293-2422 (lower dust temperatures) are more similar to those in the Orion Bar PDR and Horsehead. Interestingly, the L1157 outflow shows the highest abundances of $\mathrm{CH}_{3} \mathrm{OH}, \mathrm{H}_{2} \mathrm{CO}, \mathrm{H}_{2} \mathrm{CS}, \mathrm{HC}_{3} \mathrm{~N}$, and $\mathrm{CH}_{3} \mathrm{CHO}$. This suggests that the combined effects of ice mantle sublimation, grain sputtering, and hot gas-phase chemistry in shocks results in a very efficient COM formation.

Among the studied species, only the HCO radical and cis-HCOOH (Cuadrado et al. 2016) are more abundant in PDRs. This enhancement is thus a characteristic feature of FUVilluminated gas. Figure 20 shows normalised abundances with respect to the abundances in $\mathrm{B} 1-\mathrm{b}$ (cold and gas shielded from strong FUV radiation). $\mathrm{HCO}, \mathrm{CH}_{3} \mathrm{CHO}, \mathrm{H}_{2} \mathrm{CCO}, \mathrm{H}_{2} \mathrm{CO}$, and trans- $\mathrm{HCOOH}$ are a factor of $\sim 2-10$ more abundant in the PDRs than in the cold core.

Guzmán et al. (2014) observed two positions of the Horsehead, the moderately warm PDR $\left(T_{\mathrm{k}} \simeq 60 \mathrm{~K}\right)$ and a cold core behind the PDR and shielded from stellar FUV field. Interestingly, they found enhanced COM abundances in the PDR compared to the core. Given the low-FUV field in the Horsehead, dust grains are relatively cold even at the PDR edge $\left(T_{\mathrm{d}} \lesssim 30 \mathrm{~K}\right.$, Goicoechea et al. 2009). These dust temperatures are significantly below the sublimation temperatures of abundant interstellar ices (Gibb et al. 2000) such as $\mathrm{H}_{2} \mathrm{O}(\sim 100 \mathrm{~K}), \mathrm{CH}_{3} \mathrm{OH}$ $(\sim 100 \mathrm{~K})$, and even $\mathrm{H}_{2} \mathrm{CO}(\sim 40 \mathrm{~K})$. Hence, grains must be coated with mantles, even in the Horsehead PDR, and photodesorption can be efficient, either desorbing specific COMs or their gas-phase precursors (Guzmán et al. 2014). Indeed, PDR models 


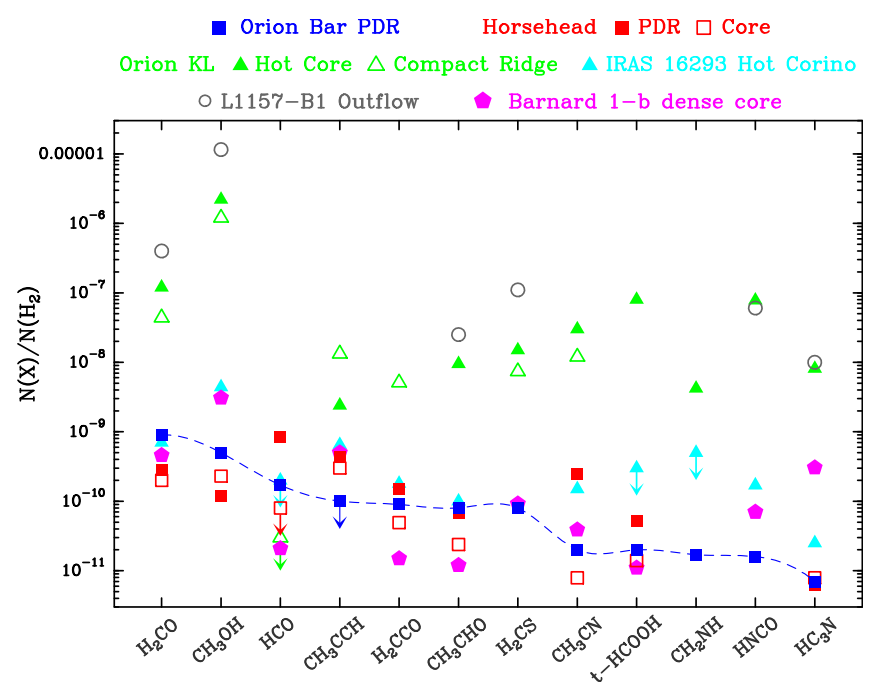

Fig. 19. Molecular abundances with respect to $\mathrm{H}_{2}$ in several sources. In the Orion Bar PDR, blue points represent the molecular abundance assuming uniform beam filling.

adapted to the Horsehead and including grain surface reactions and ice photodesorption were invoked to explain the observed gas-phase $\mathrm{CH}_{3} \mathrm{OH}$ and $\mathrm{H}_{2} \mathrm{CO}$ abundances (Guzmán et al. 2013). In addition, the low $\mathrm{H}_{2} \mathrm{CO}$ ortho-to-para ratio of two in the PDR (Guzmán et al. 2011) might support a cold surface origin for $\mathrm{H}_{2} \mathrm{CO}$. However, those Horsehead models required relatively high photodesorption yields (several $10^{-4}$ to $10^{-3}$ molecules per photon) that are apparently not supported by recent laboratory experiments of methanol photodesorption. In fact, little $\mathrm{CH}_{3} \mathrm{OH}$ is actually seen to desorb in $\mathrm{CH}_{3} \mathrm{OH}$ ice irradiation experiments (Bertin et al. 2016; Cruz-Diaz et al. 2016).

Also in the Horsehead, $\mathrm{CH}_{3} \mathrm{CN}$ is 30 times more abundant in the PDR than in the shielded core (Gratier et al. 2013). $\mathrm{CH}_{3} \mathrm{CN}$ is also an order of magnitude more abundant in the Horsehead than in the Orion Bar PDR. Given the high binding energy of $\mathrm{CH}_{3} \mathrm{CN}$ ice (similar to $\mathrm{CH}_{3} \mathrm{OH}$, Collings et al. 2004) this result is quite surprising (methanol is more abundant than $\mathrm{CH}_{3} \mathrm{CN}$ in the Bar). In addition, Gratier et al. (2013) detected $\mathrm{CH}_{3} \mathrm{NC}$ towards the Horsehead PDR, with an isomeric ratio of $\left[\mathrm{CH}_{3} \mathrm{NC}\right] /\left[\mathrm{CH}_{3} \mathrm{CN}\right]=0.15$, higher than our upper limit. These authors suggested that photodesorption triggers the $\mathrm{CH}_{3} \mathrm{CN}$ abundance in the Horsehead. Therefore, photodesorption seems to enhance the gas-phase $\mathrm{CH}_{3} \mathrm{CN}$ and $\mathrm{CH}_{3} \mathrm{NC}$ abundances, but not that of $\mathrm{CH}_{3} \mathrm{OH}$. This suggests that photodesorption is a very selective process and thus, should be studied molecule by molecule in representative ISM ice analogs. In addition, gas phase reactions may allow the enhancement of $\mathrm{CH}_{3} \mathrm{CN}$ with respect to $\mathrm{CH}_{3} \mathrm{OH}$.

In the Orion Bar, a much more strongly FUV-irradiated PDR, gas and dust grains are warmer (from $T_{\mathrm{d}} \simeq 40$ to $80 \mathrm{~K}$; Arab et al. 2012). Thus, ice mantle abundances must be small close to the cloud edge. Interestingly, we find higher $\mathrm{H}_{2} \mathrm{CO}$ and $\mathrm{CH}_{3} \mathrm{OH}$ abundances in the Bar than in the Horsehead PDR (but not $\mathrm{HCO}$ ). In addition, $\mathrm{H}_{2} \mathrm{CO}$ is detected close to the irradiated edge of the Orion Bar and we determine a $\mathrm{H}_{2} \mathrm{CO}$ ortho-to-para ratio of approximately three (consistent with the high temperature limit). Finally, we determine a $\mathrm{HCO} / \mathrm{H}_{2} \mathrm{CO} / \mathrm{CH}_{3} \mathrm{OH} \simeq 1 / 5 / 3$ abundance ratio, whereas a 7/2/1 ratio is found in the Horsehead PDR (Gerin et al. 2009; Guzmán et al. 2013). The ratios typically inferred in cold dense gas are $\sim 1 / 10 / 10$ (Bacmann \& Faure 2016). Although HCO is

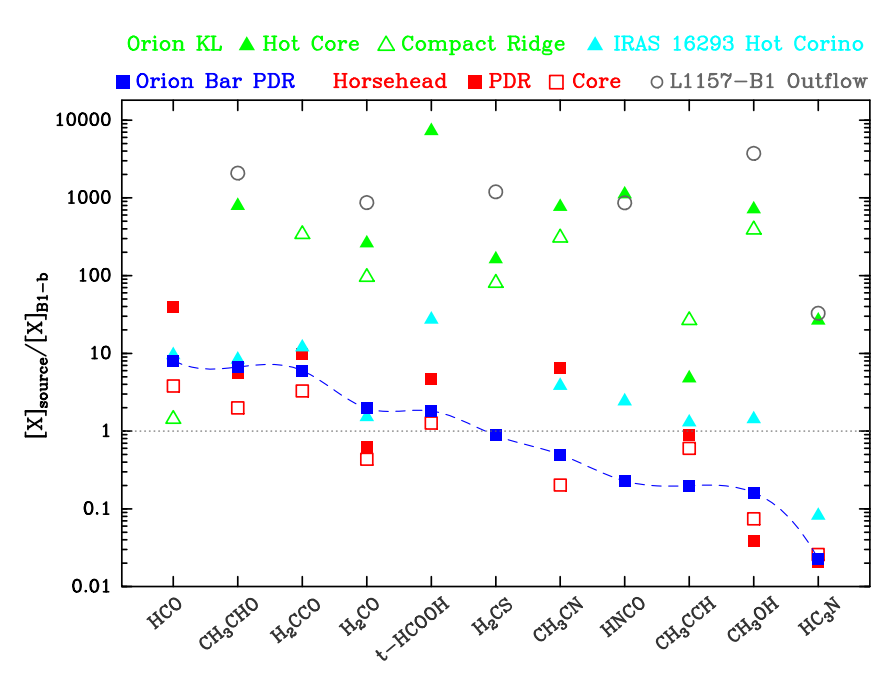

Fig. 20. Comparison of the abundance ratios with respect to $B 1-b$ in several sources.

approximately five times more abundant in the Horsehead, both PDRs show $\left[\mathrm{CH}_{3} \mathrm{OH}\right] /\left[\mathrm{H}_{2} \mathrm{CO}\right]<1$ abundance ratios. We note that $\mathrm{H}_{2} \mathrm{CO}$ is also a product of photodissociation of $\mathrm{CH}_{3} \mathrm{OH}$. In warm but FUV-shielded environments (hot cores and shocks), $\mathrm{CH}_{3} \mathrm{OH}$ is much more abundant than in PDRs and cold cores.

\subsection{Limits to steady-state PDR gas-phase chemistry}

In order to explore the gas-phase production of $\mathrm{HCO}, \mathrm{H}_{2} \mathrm{CO}$, and $\mathrm{CH}_{3} \mathrm{OH}$, we show PDR model results adapted to the illumination conditions in the Bar using the Meudon PDR code (e.g. Le Petit et al. 2006; Goicoechea \& Le Bourlot 2007). This is a model of a high gas-pressure isobaric PDR with $\chi=2 \times 10^{4}$ and $P_{\mathrm{th}} / k=10^{8} \mathrm{~K} \mathrm{~cm}^{-3}$. Only $\mathrm{H}_{2} \mathrm{O}, \mathrm{CO}$, and atoms are allowed to deplete from the gas following their adsorption energies (e.g. Hollenbach et al. 2009). However, we do not include surface chemistry (e.g. water ice only forms through water vapour freeze-out and desorbs thermally or by photodesorption; we refer to Cuadrado et al. 2015, for details). Figure 21 shows the abundance profiles as a function of cloud depth. Although the dust temperature is never low enough to allow $\mathrm{CO}$ ice-mantle formation, water ice starts to be very abundant at $A_{\mathrm{V}} \gtrsim 5$ (a similar behaviour can be expected for $\mathrm{CH}_{3} \mathrm{OH}$ ice). We note that the typical gas temperature inferred from our observations towards the line survey position $\left(T_{\mathrm{k}} \approx 150 \mathrm{~K}\right)$ corresponds to $A_{\mathrm{V}} \approx 1.5-2.0 \mathrm{mag}$ and $T_{\mathrm{d}} \approx 60 \mathrm{~K}$ in this model. Hence, we expect mostly bare grains at the edge of the PDR, only coated with a few monolayers of very polar ices such as water (with high adsorption energies).

The model shown in Fig. 21 roughly reproduces the HCO abundance enhancement at the PDR edge (driven by reaction $\mathrm{O}+\mathrm{CH}_{2} \rightarrow \mathrm{HCO}+\mathrm{H}$ ), but underpredicts the observed $\mathrm{H}_{2} \mathrm{CO}$ and $\mathrm{CH}_{3} \mathrm{OH}$ abundances. In these models, the $\mathrm{H}_{2} \mathrm{CO}$ formation at $A_{\mathrm{V}} \approx 1.5-2.0 \mathrm{mag}$ is largely dominated by reaction $\mathrm{O}+\mathrm{CH}_{3} \rightarrow \mathrm{H}_{2} \mathrm{CO}+\mathrm{H}$. This comparison suggests either the gas-phase model misses important formation routes (or rates) in hot molecular gas, or that (nearly bare) grain surface formation and subsequent desorption is important. Esplugues et al. (2016) have shown PDR models including surface chemistry on grains with different ice content. In their models, chemical/reactive desorption (the surface reaction exothermicity is used to break 
the adsorbate-surface bond, e.g. Herbst 2015; Minissale et al. 2016), can dominate over photodesorption for some species (e.g. methanol). Nevertheless, the $\mathrm{H}_{2} \mathrm{CO}$ and $\mathrm{CH}_{3} \mathrm{OH}$ abundances predicted by Esplugues et al. (2016) in a PDR with high FUV fluxes are still lower than our observed values. Hence, at present, no model seems to reproduce the inferred abundances of molecules such as $\mathrm{H}_{2} \mathrm{CO}$ and $\mathrm{CH}_{3} \mathrm{OH}$ towards the Bar.

All these models, however, simulate a static PDR in which steady-state has been reached. A real PDR is likely to be more dynamic (Goicoechea et al. 2016). Time-dependent flows of molecular gas and icy grains might advect from inside the cold molecular cloud to the warm PDR edge. There they can be reprocessed by the combination of high temperatures and the presence of a strong FUV photon flux for some time before photodissociation. Thus, time-dependent desorption and advection of COMs (or gas-phase precursors) from the molecular cloud interior to the PDR may contribute to enhance their abundances.

The non-detection of HDCO at the illuminated edge of the Bar $\left([\mathrm{HDCO}] /\left[\mathrm{H}_{2} \mathrm{CO}\right]<3 \times 10^{-3}\right)$, and also in the Horsehead PDR (Guzmán et al. 2011), shows that pure gas-phase $\mathrm{H}_{2} \mathrm{CO}$ deuteration is not efficient at high gas temperatures. However, HDCO has been detected towards the lukewarm $\left(T_{\mathrm{k}} \lesssim 70 \mathrm{~K}\right)$, dense and more FUV-shielded clump \#3 by Parise et al. (2009). This agrees with specific chemical models in which pure gas-phase deuteration is efficient in gas below $T_{\mathrm{k}} \lesssim 70 \mathrm{~K}$ (Roueff et al. 2007). Time-dependent gas-phase models show that the $[\mathrm{HDCO}] /\left[\mathrm{H}_{2} \mathrm{CO}\right]$ abundance ratio is particularly low at early cloud times (Treviño-Morales et al. 2014). In hot cores where high abundances of COMs have been detected, the gas deuteration is very high as well. Both effects are related to the sublimation of ice mantles formed and deuterated in a previous cold cloud stage. In the context of a dynamic PDR, deuterated species could desorb from grain surfaces and advect to the PDR edge as well. The very low $[\mathrm{HDCO}] /\left[\mathrm{H}_{2} \mathrm{CO}\right]$ upper limit abundance towards the edge of the Bar suggests that this mechanism is not efficient for deuterated molecules, and that the gas temperature is too high to enhance the deuterium fractionation by pure gas-phase reactions alone.

\section{3. $\mathrm{CH}_{3} \mathrm{CCH}$ non detection}

$\mathrm{CH}_{3} \mathrm{CCH}$ is a widespread hydrocarbon present in the Horsehead PDR $\left(\sim 4.4 \times 10^{-10}\right)$ and cold core $\left(\sim 3 \times 10^{-10}\right)$, the extended ridge of Orion KL $\left(\sim 1 \times 10^{-8}\right)$, the hot corino IRAS 16293$2422\left(\sim 7 \times 10^{-10}\right)$, the Monoceros R2 ultra-compact H II region $\left(\sim 2 \times 10^{-9}\right.$; Ginard et al. 2012), and even the nucleus of the starburst galaxy M $82\left(\sim 1 \times 10^{-8}\right.$; Fuente et al. 2005; Aladro et al. 2011). Unexpectedly, $\mathrm{CH}_{3} \mathrm{CCH}$ lines are not bright towards the Bar edge. A few $2 \sigma$ line features seen in the $1 \mathrm{~mm}$ range coincide with the expected frequencies of $\mathrm{CH}_{3} \mathrm{CCH}$. However, the detection cannot be confirmed with confidence at the sensitivity level of our line survey. Based on the tentative $2 \sigma$ features, we estimate an upper limit abundance of $\left[\mathrm{CH}_{3} \mathrm{CCH}\right]<(0.8-1.3) \times 10^{-10}$. The unattenuated $\mathrm{CH}_{3} \mathrm{CCH}$ photodissociation rate is high (several $10^{-9} \mathrm{~s}^{-1}$ for $\chi=1$ ) and $\mathrm{CH}_{3} \mathrm{CCH}$ reacts with $\mathrm{C}^{+}$ions relatively fast (e.g. Wakelam et al. 2012). Both the FUV photon flux and the $\mathrm{C}^{+}$column density are particularly high towards the observed position at the edge of the Bar (Ossenkopf et al. 2013; Goicoechea et al. 2015). This combination likely explains the reduced $\mathrm{CH}_{3} \mathrm{CCH}$ abundance. Indeed, in our PDR models, $\mathrm{CH}_{3} \mathrm{CCH}$ only reaches detectable abundances at $A_{\mathrm{V}}>8$ (Cuadrado et al. 2015).

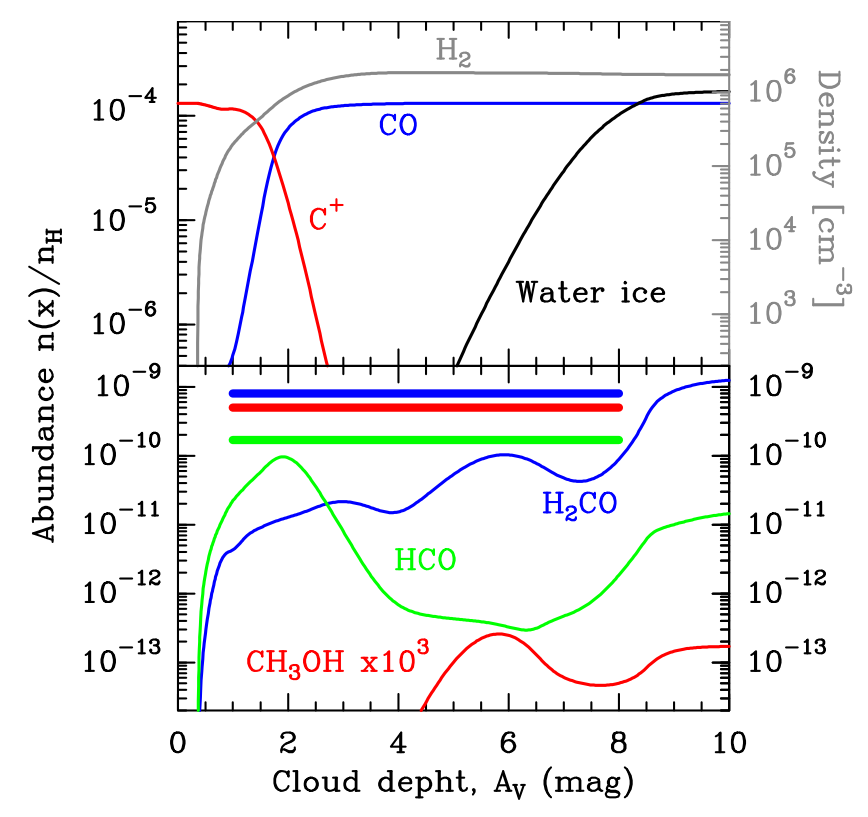

Fig. 21. Isobaric PDR model for the Orion Bar with $P_{\mathrm{th}} / k=10^{8} \mathrm{~K} \mathrm{~cm}^{-3}$ and $\chi=2 \times 10^{4}$. The thick horizontal bars show the inferred abundances of $\mathrm{HCO}, \mathrm{H}_{2} \mathrm{CO}$, and $\mathrm{CH}_{3} \mathrm{OH}$ towards the PDR edge. In this model, these molecules are formed only through gas-phase reactions.

\section{Summary and conclusions}

We have investigated the presence and abundance of complex organic molecules in the strongly FUV-irradiated edge of the Orion Bar PDR, near the $\mathrm{H}_{2}$ dissociation front. We used the IRAM $30 \mathrm{~m}$ telescope to carry out a millimetre line survey, complemented with $8.5^{\prime \prime}$ resolution maps of the molecular line emission at $0.9 \mathrm{~mm}$. Despite being a very harsh environment, our observations show a relatively rich spectrum, with more than 250 lines arising from COMs and related organic precursors with up to seven atoms: $\mathrm{H}_{2} \mathrm{CO}, \mathrm{CH}_{3} \mathrm{OH}, \mathrm{HCO}, \mathrm{H}_{2} \mathrm{CCO}, \mathrm{CH}_{3} \mathrm{CHO}$, $\mathrm{H}_{2} \mathrm{CS}, \mathrm{HCOOH}, \mathrm{CH}_{3} \mathrm{CN}, \mathrm{CH}_{2} \mathrm{NH}, \mathrm{HNCO}, \mathrm{H}_{2}^{13} \mathrm{CO}$, and $\mathrm{HC}_{3} \mathrm{~N}$ (in decreasing order of abundance). In particular, we obtained the following results:

- The abundance of the detected species range from $10^{-9}$ to $10^{-11} ; \mathrm{H}_{2} \mathrm{CO}$ being the most abundant. The inferred rotational temperatures range from $\sim 10$ to $\sim 55 \mathrm{~K}$, significantly lower than the gas temperature and thus consistent with subthermal excitation. $\mathrm{H}_{2}^{13} \mathrm{CO}$ and $\mathrm{H}_{2} \mathrm{CCO}$ have the lowest and the highest rotational temperatures, respectively. We obtain similar rotational temperatures for the ortho-para and A-E species, and ortho-to-para ratios of approximately three.

- For some molecules, we constrain the beam-averaged physical conditions from LVG excitation models. As shown by previous works (e.g. Leurini et al. 2006, 2010), we conclude that not all COMs arise from the same PDR layer. In particular, while $\mathrm{CH}_{3} \mathrm{OH}$ only arises from dense gas in the more shielded PDR interior $\left(T_{\mathrm{k}}=40-50 \mathrm{~K}\right), \mathrm{CH}_{3} \mathrm{CN}$ and $\mathrm{H}_{2} \mathrm{CO}$ also trace warmer gas layers $\left(T_{\mathrm{k}}=150-250 \mathrm{~K}\right)$, more exposed to a strong FUV-field.

- We determine a $\mathrm{HCO} / \mathrm{H}_{2} \mathrm{CO} / \mathrm{CH}_{3} \mathrm{OH} \simeq 1 / 5 / 3$ abundance ratio. Such relative abundances are not inferred in environments dominated by ice-mantle thermal desorption or grain sputtering. Overall, pure gas-phase models have difficulty reproducing the observed $\mathrm{H}_{2} \mathrm{CO}$ and especially $\mathrm{CH}_{3} \mathrm{OH}$ abundances in PDRs. Taking into account the elevated gas and dust temperatures at the edge of the $\operatorname{Bar}\left(T_{\mathrm{d}} \simeq 60 \mathrm{~K}\right)$, 
we suggest the following scenarios for the formation of COMs: (i) hot gas reactions not included in current models; (ii) COMs are produced in the warm grain surfaces of nearly bare grains; or (iii) the PDR dynamics is such that COMs or specific precursors formed in cold icy grains deeper inside the molecular cloud desorb and advect into the PDR.

The presence of COMs in the interstellar medium is more widespread that initially expected. It includes very harsh environments such as shocked gas and now strongly FUV-irradiated gas. COM formation reflects the complicated interplay between gas and grain surface chemistry in different environments. However, the specific formation pathways are not fully clear and may even not be the same in different environments. More laboratory experiments to study different grain surface processes and to investigate the products and rates of different desorption mechanisms (photodesorption, sublimation, chemical desorption, etc.) are needed to distinguish between the different possible scenarios. The census of increasingly complex organic molecule detections will obviously increase in the years to come.

Acknowledgements. We thank our referee for pointing us towards several missing references in an earlier version of the manuscript. We thank Nuria Marcelino for sharing the column densities of different COMs inferred towards Barnard 1-b. We are very grateful to the IRAM staff for their help during the observations. This work has been partially funded by MINECO grants (CSD2009-00038 and AYA2012-32032). We thank the ERC for support under grant ERC-2013-Syg610256-NANOCOSMOS.

\section{References}

Agúndez, M., Cernicharo, J., \& Goicoechea, J. R. 2008, A\&A, 483, 831 Aladro, R., Martín, S., Martín-Pintado, J., et al. 2011, A\&A, 535, A84

Allegrini, M., Johns, J. W. C., \& McKellar, A. R. W. 1979, J. Chem. Phys., 70, 2829

Andree-Labsch, S., Ossenkopf-Okada, V., \& Röllig, M. 2017, A\&A, 598, A2

Anttila, R., Horneman, V. M., Koivusaari, M., \& Paso, R. 1993, J. Mol. Spectr. 157, 198

Arab, H., Abergel, A., Habart, E., et al. 2012, A\&A, 541, A19

Austin, J. A., Levy, D. H., Gottlieb, C. A., \& Radford, H. E. 1974, J. Chem. Phys., 60, 207

Avery, L. W., Broten, N. W., MacLeod, J. M., Oka, T., \& Kroto, H. W. 1976, ApJ, 205, L173

Bachiller, R., \& Pérez Gutiérrez, M. 1997, ApJ, 487, L93

Bacmann, A., \& Faure, A. 2016, A\&A, 587, A130

Bacmann, A., Taquet, V., Faure, A., Kahane, C., \& Ceccarelli, C. 2012, A\&A, 541, L12

Batrla, W., \& Wilson, T. L. 2003, A\&A, 408, 231

Beers, Y., Klein, G. P., Kirchhoff, W. H., \& Johnson, D. R. 1972, J. Mol. Spectr., 44, 553

Belloche, A., Garrod, R. T., Müller, H. S. P., et al. 2009, A\&A, 499, 215

Belloche, A., Garrod, R. T., Müller, H. S. P., \& Menten, K. M. 2014, Science, 345,1584

Bertin, M., Romanzin, C., Doronin, M., et al. 2016, ApJ, 817, L12

Bisschop, S. E., Jørgensen, J. K., van Dishoeck, E. F., \& de Wachter, E. B. M. 2007, A\&A, 465, 913

Blake, G. A., Sastry, K. V. L. N., \& de Lucia, F. C. 1984, J. Chem. Phys., 80, 95 Blake, G. A., Sutton, E. C., Masson, C. R., \& Phillips, T. G. 1987, ApJ, 315, 621

Bockelée-Morvan, D., Crovisier, J., Mumma, M. J., \& Weaver, H. A. 2004, The composition of cometary volatiles, Comets II (University of Arizona Press), 391

Bocquet, R., Demaison, J., Poteau, L., et al. 1996, J. Mol. Spectr., 177, 154

Bottinelli, S., Ceccarelli, C., Lefloch, B., et al. 2004, ApJ, 615, 354

Boucher, D., Burie, J., Demaison, J., et al. 1977, J. Mol. Spectr., 64, 290

Bowater, I. C., Brown, J. M., \& Carrington, A. 1971, J. Chem. Phys., 54, 4957

Brown, R. D., Crofts, J. G., Godfrey, P. D., et al. 1975, ApJ, 197, L29

Brown, R. D., Godfrey, P. D., McNaughton, D., Pierlot, A. P., \& Taylor, W. H 1990, J. Mol. Spectr., 140, 340

Brünken, S., Müller, H. S. P., Lewen, F., \& Winnewisser, G. 2003, Phys. Chem. Chem. Phys. (Incorporating Faraday Transactions), 5

Burton, M. G., Hollenbach, D. J., \& Tielens, A. G. G. M. 1990, ApJ, 365, 620

Caselli, P., \& Ceccarelli, C. 2012, A\&ARv, 20, 56

Cazaux, S., Tielens, A. G. G. M., Ceccarelli, C., et al. 2003, ApJ, 593, L51
Cazzoli, G., \& Puzzarini, C. 2006, J. Mol. Spectr., 240, 153

Cernicharo, J. 2012, in EAS Pub. Ser., 58, 251

Cernicharo, J., Bachiller, R., \& Duvert, G. 1986, A\&A, 160, 181

Cernicharo, J., Guélin, M., \& Kahane, C. 2000, A\&AS, 142, 181

Cernicharo, J., Heras, A. M., Tielens, A. G. G. M., et al. 2001, ApJ, 546, L123

Cernicharo, J., Marcelino, N., Roueff, E., et al. 2012, ApJ, 759, L43

Cernicharo, J., Kisiel, Z., Tercero, B., et al. 2016, A\&A, 587, L4

Chen, W., Bocquet, R., Wlodarczak, G., \& Boucher, D. 1991, International Journal of Infrared and Millimeter Waves, 12, 987

Codella, C., Fontani, F., Ceccarelli, C., et al. 2015, MNRAS, 449, L11

Collings, M. P., Anderson, M. A., Chen, R., et al. 2004, MNRAS, 354, 1133

Creswell, R. A., Winnewisser, G., \& Gerry, M. C. L. 1977, J. Mol. Spectr., 65, 420

Crockett, N. R., Bergin, E. A., Neill, J. L., et al. 2014, ApJ, 787, 112

Cronin, J. R., \& Chang, S. 1993, in NATO Advanced Science Institutes (ASI)

Series C, eds. J. M. Greenberg, C. X. Mendoza-Gómez, \& V. Pirronello, 416, 209

Cruz-Diaz, G. A., Muñoz Caro, G. M., Martín-Doménech, R., \& Chen, Y.-J. 2016, A\&A, 592, A68

Cuadrado, S., Goicoechea, J. R., Pilleri, P., et al. 2015, A\&A, 575, A82

Cuadrado, S., Goicoechea, J. R., Roncero, O., et al. 2016, A\&A, 596, L1

DeLeon, R. L., \& Muenter, J. S. 1985, J. Chem. Phys., 82, 1702

de Zafra, R. L. 1971, ApJ, 170, 165

Dickinson, D. F. 1972, Astrophys. Lett., 12, 235

Dore, L., Bizzocchi, L., Degli Esposti, C., \& Gauss, J. 2010, J. Mol. Spectr., 263, 44

Dore, L., Bizzocchi, L., \& Degli Esposti, C. 2012, A\&A, 544, A19

Draine, B. T., Roberge, W. G., \& Dalgarno, A. 1983, ApJ, 264, 485

Eliet, S., Cuisset, A., Guinet, M., et al. 2012, J. Mol. Spectr., 279, 12

Esplugues, G. B., Cazaux, S., Meijerink, R., Spaans, M., \& Caselli, P. 2016, A\&A, 591, A52

Fabricant, B., Krieger, D., \& Muenter, J. S. 1977, J. Chem. Phys., 67, 1576

Fuente, A., García-Burillo, S., Gerin, M., et al. 2005, ApJ, 619, L155

Fuente, A., García-Burillo, S., Usero, A., et al. 2008, A\&A, 492, 675

Gadhi, J., Lahrouni, A., Legrand, J., \& Demaison, J. 1995, J. Chim. Phys., 92, 1984

Gerin, M., Goicoechea, J. R., Pety, J., \& Hily-Blant, P. 2009, A\&A, 494, 977

Gibb, E. L., Whittet, D. C. B., Schutte, W. A., et al. 2000, ApJ, 536, 347

Ginard, D., González-García, M., Fuente, A., et al. 2012, A\&A, 543, A27

Goicoechea, J. R., \& Le Bourlot, J. 2007, A\&A, 467, 1

Goicoechea, J. R., Compiègne, M., \& Habart, E. 2009, ApJ, 699, L165

Goicoechea, J. R., Joblin, C., Contursi, A., et al. 2011, A\&A, 530, L16

Goicoechea, J. R., Teyssier, D., Etxaluze, M., et al. 2015, ApJ, 812, 75

Goicoechea, J. R., Pety, J., Cuadrado, S., et al. 2016, Nature, 537, 207

Goicoechea, J. R., Cuadrado, S., Pety, J., et al. 2017, A\&A, 601, L9

Goldsmith, P. F., \& Langer, W. D. 1999, ApJ, 517, 209

Gottlieb, C. A. 1973, in Molecules in the Galactic Environment, eds. M. A. Gordon, \& L. E. Snyder, 181

Gratier, P., Pety, J., Guzmán, V., et al. 2013, A\&A, 557, A101

Green, S. 1986, ApJ, 309, 331

Green, S. 1991, ApJS, 76, 979

Greve, A., Kramer, C., \& Wild, W. 1998, A\&AS, 133, 271

Guzmán, V., Pety, J., Goicoechea, J. R., Gerin, M., \& Roueff, E. 2011, A\&A, 534, A49

Guzmán, V. V., Goicoechea, J. R., Pety, J., et al. 2013, A\&A, 560, A73

Guzmán, V. V., Pety, J., Gratier, P., et al. 2014, Faraday Discussions, 168, 103

Guzmán, V. V., Pety, J., Goicoechea, J. R., et al. 2015, ApJ, 800, L33

Habart, E., Dartois, E., Abergel, A., et al. 2010, A\&A, 518, L116

Herbst, E. 2015, in EPJ Web Conf., 84, 06002

Herbst, E., \& van Dishoeck, E. F. 2009, ARA\&A, 47, 427

Hirano, N., Kamazaki, T., Mikami, H., Ohashi, N., \& Umemoto, T. 1999, in Star Formation 1999, ed. T. Nakamoto, 181

Hocking, W. H., Gerry, M. C. L., \& Winnewisser, G. 1975, Can. J. Phys., 53, 1869

Hogerheijde, M. R., Jansen, D. J., \& van Dishoeck, E. F. 1995, A\&A, 294, 792

Hollenbach, D., Kaufman, M. J., Bergin, E. A., \& Melnick, G. J. 2009, ApJ, 690, 1497

Ikeda, M., Ohishi, M., Nummelin, A., et al. 2001, ApJ, 560, 792

Jansen, D. J., Spaans, M., Hogerheijde, M. R., \& van Dishoeck, E. F. 1995, A\&A, 303,541

Johns, J. W. C., Nemes, L., Yamada, K. M. T., et al. 1992, J. Mol. Spectr., 156, 501

Johnson, H. R., \& Strandberg, M. W. P. 1952, J. Chem. Phys., 20, 687

Johnson, D. R., Powell, F. X., \& Kirchhoff, W. H. 1971, J. Mol. Spectr., 39, 136

Kirchhoff, W. H., Johnson, D. R., \& Lovas, F. J. 1973, J. Phys. Chem. Ref. Data, 2,1

Kleiner, I., Lovas, F. J., \& Godefroid, M. 1996, J. Phys. Chem. Ref. Data, 25, 1113 
Kukolich, S. G. 1982, J. Chem. Phys., 76, 97

Kukolich, S., Nelson, A., \& Yamanashi, B. 1971, J. Am. Chem. Soc., 93, 6769

Kukolich, S. G., Ruben, D. J., Wang, J. H. S., \& Williams, J. R. 1973, J. Chem. Phys., 58, 3155

Langer, W. D., \& Penzias, A. A. 1990, ApJ, 357, 477

Lapinov, A. V., Golubiatnikov, G. Y., Markov, V. N., \& Guarnieri, A. 2007, Astron. Lett., 33, 121

Le Petit, F., Nehmé, C., Le Bourlot, J., \& Roueff, E. 2006, ApJS, 164, 506

Lees, R. M., \& Baker, J. G. 1968, J. Chem. Phys., 48, 5299

Lees, R. M., Lovas, F. J., Kirchhoff, W. H., \& Johnson, D. R. 1973, J. Phys. Chem. Ref. Data, 2, 205

Leurini, S., Rolffs, R., Thorwirth, S., et al. 2006, A\&A, 454, L47

Leurini, S., Parise, B., Schilke, P., Pety, J., \& Rolffs, R. 2010, A\&A, 511, A82

Lis, D. C., \& Schilke, P. 2003, ApJ, 597, L145

Lis, D. C., Roueff, E., Gerin, M., et al. 2002, ApJ, 571, L55

Liszt, H. S., Lucas, R., \& Pety, J. 2006, A\&A, 448, 253

Maeda, A., Medvedev, I. R., Winnewisser, M., et al. 2008, ApJS, 176, 543

Marcelino, N., Cernicharo, J., Roueff, E., Gerin, M., \& Mauersberger, R. 2005, ApJ, 620, 308

Marcelino, N., Cernicharo, J., Tercero, B., \& Roueff, E. 2009, ApJ, 690, L27

Marconi, A., Testi, L., Natta, A., \& Walmsley, C. M. 1998, A\&A, 330, 696

Mbosei, L., Fayt, A., Dréan, P., \& Cosléou, J. 2000, J. Mol. Structure, 517, 271

Meier, D. S., \& Turner, J. L. 2005, ApJ, 618, 259

Meier, D. S., \& Turner, J. L. 2012, ApJ, 755, 104

Mendoza, E., Lefloch, B., López-Sepulcre, A., et al. 2014, MNRAS, 445, 151

Menten, K. M., Reid, M. J., Forbrich, J., \& Brunthaler, A. 2007, A\&A, 474, 515

Minissale, M., Moudens, A., Baouche, S., Chaabouni, H., \& Dulieu, F. 2016, MNRAS, 458, 2953

Müller, H. S. P., Gendriesch, R., Margulès, L., et al. 2000, Phys. Chem. Chem. Phys. (Incorporating Faraday Transactions), 2

Müller, H. S. P., Thorwirth, S., Roth, D. A., \& Winnewisser, G. 2001, A\&A, 370, L49

Müller, H. S. P., Schlöder, F., Stutzki, J., \& Winnewisser, G. 2005, J. Mol. Structure, 742, 215

Müller, H. S. P., Drouin, B. J., \& Pearson, J. C. 2009, A\&A, 506, 1487

Nagy, Z., Van der Tak, F. F. S., Ossenkopf, V., et al. 2013, A\&A, 550, A96

Nagy, Z., Choi, Y., Ossenkopf-Okada, V., et al. 2017, A\&A, 599, A22

Öberg, K. I., Bottinelli, S., Jørgensen, J. K., \& van Dishoeck, E. F. 2010, ApJ, 716,825

Ossenkopf, V., Röllig, M., Neufeld, D. A., et al. 2013, A\&A, 550, A57

Parise, B., Leurini, S., Schilke, P., et al. 2009, A\&A, 508, 737

Parmar, P. S., Lacy, J. H., \& Achtermann, J. M. 1991, ApJ, 372, L25

Pavone, F. S., Zink, L. R., Prevedelli, M., Inguscio, M., \& Fusina, L. 1990, J. Mol. Spectr., 144, 45

Pickett, H. M., Poynter, R. L., Cohen, E. A., et al. 1998, J. Quant. Spectr. Rad. Transf., 60, 883
Rabli, D., \& Flower, D. R. 2010, MNRAS, 406, 95

Remijan, A. J., Hollis, J. M., Snyder, L. E., Jewell, P. R., \& Lovas, F. J. 2006 ApJ, 643, L37

Requena-Torres, M. A., Martín-Pintado, J., Rodríguez-Franco, A., et al. 2006, A\&A, 455, 971

Roueff, E., Parise, B., \& Herbst, E. 2007, A\&A, 464, 245

Saito, S. 1972, ApJ, 178, L95

Sastry, K. V. L. N., Lees, R. M., \& Van der Linde, J. 1981, J. Mol. Spectr., 88, 228

Schilke, P., Pineau des Forêts, G., Walmsley, C. M., \& Martín-Pintado, J. 2001, A\&A, 372, 291

Simon, R., Stutzki, J., Sternberg, A., \& Winnewisser, G. 1997, A\&A, 327, L9

Snyder, L. E., Buhl, D., Zuckerman, B., \& Palmer, P. 1969, Phys. Rev. Lett., 22, 679

Stoerzer, H., Stutzki, J., \& Sternberg, A. 1995, A\&A, 296, L9

Tercero, B., Cernicharo, J., Pardo, J. R., \& Goicoechea, J. R. 2010, A\&A, 517, A96

Tercero, B., Kleiner, I., Cernicharo, J., et al. 2013, ApJ, 770, L13

Tercero, B., Cernicharo, J., López, A., et al. 2015, A\&A, 582, L1

Thorwirth, S., Müller, H. S. P., \& Winnewisser, G. 2000, J. Mol. Spectr., 204, 133

Tielens, A. G. G. M., \& Hollenbach, D. 1985a, ApJ, 291, 747

Tielens, A. G. G. M., \& Hollenbach, D. 1985b, ApJ, 291, 722

Tielens, A. G. G. M., Meixner, M. M., van der Werf, P. P., et al. 1993, Science, 262, 86

Treviño-Morales, S. P., Pilleri, P., Fuente, A., et al. 2014, A\&A, 569, A19

Turner, B. E. 1971, ApJ, 163, L35

Šimečková, M., Urban, Š., Fuchs, U., et al. 2004, J. Mol. Spectr., 226, 123

van der Tak, F. F. S., Nagy, Z., Ossenkopf, V., et al. 2013, A\&A, 560, A95

van der Werf, P. P., Stutzki, J., Sternberg, A., \& Krabbe, A. 1996, A\&A, 313 633

van der Werf, P. P., Goss, W. M., \& O'Dell, C. R. 2013, ApJ, 762, 101

van der Wiel, M. H. D., van der Tak, F. F. S., Ossenkopf, V., et al. 2009, A\&A, 498, 161

van Dishoeck, E. F., Blake, G. A., Jansen, D. J., \& Groesbeck, T. D. 1995, ApJ, 447,760

Wakelam, V., Herbst, E., Loison, J.-C., et al. 2012, ApJS, 199, 21

Walmsley, C. M., Natta, A., Oliva, E., \& Testi, L. 2000, A\&A, 364, 301

Wernli, M., Wiesenfeld, L., Faure, A., \& Valiron, P. 2007, A\&A, 464, 1147

Wilson, T. L., \& Rood, R. 1994, ARA\&A, 32, 191

Xu, L.-H., Fisher, J., Lees, R. M., et al. 2008, J. Mol. Spectr., 251, 305

Yamada, K. M. T., Moravec, A., \& Winnewisser, G. 1995, Zeitschrift Naturforschung Teil A, 50, 1179

Young Owl, R. C., Meixner, M. M., Wolfire, M., Tielens, A. G. G. M., \& Tauber, J. 2000, ApJ, 540, 886

Ziurys, L. M., \& McGonagle, D. 1993, ApJS, 89, 155 


\section{Appendix A: Possible line emission contamination from the telescope side lobes}

In order to determine whether or not the emission from the bright Orion $\mathrm{BN} / \mathrm{KL}$ region contributes to our detected signal, we compared the $1 \mathrm{~mm}$ spectrum of the Orion Bar with that of Orion BN/KL (located at $\sim 2^{\prime}$ north of the Bar, e.g. Tercero et al. 2010). Figure A. 1 shows several $\mathrm{H}_{2} \mathrm{CS}$ and $\mathrm{CH}_{3} \mathrm{OH}$ lines observed towards the Bar (black histogram) and Orion BN/KL (red histogram; see Tercero et al. 2010, 2015). We note that the amplitude of Orion $\mathrm{BN} / \mathrm{KL}$ spectra are divided by a given value to match the line intensities from the Bar. This comparison shows that while the line emission from the Orion Bar peaks at $v_{\text {LSR }} \simeq 10.7 \mathrm{~km} \mathrm{~s}^{-1}$, and can be fully attributed to gas in the PDR (Goicoechea et al. 2016), the blue-shifted shoulder emission seen in some lines at $\sim 8 \mathrm{~km} \mathrm{~s}^{-1}$ is likely produced by the intense emission from Orion BN/KL, and perhaps by the extended Orion cloud component (for the low-excitation lines). This emission is detected through the telescope extended side lobes and results in a blue-shifted emission shoulder in some spectra towards the Bar. For the IRAM $30 \mathrm{~m}$ telescope, the contribution of the secondary lobes increases with frequency (Greve et al. 1998). Given the specific emission velocity and narrow line widths of the emission from the Bar, and the fact that this effect is stronger at $\sim 1 \mathrm{~mm}$, we conclude that our line assignments and line intensity extraction in the PDR is correct.
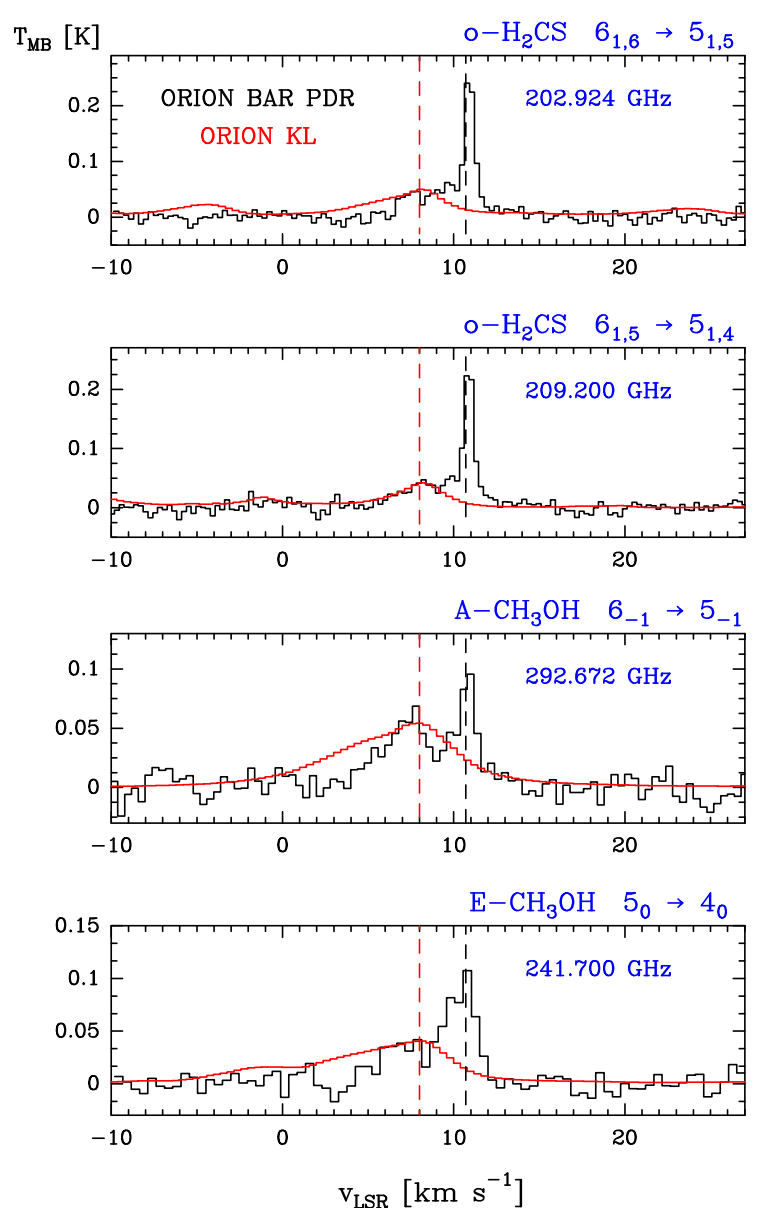

Fig. A.1. Orion Bar spectra (black) at different frequencies in the $1 \mathrm{~mm}$ range. For each line, the spectrum towards Orion $\mathrm{BN} / \mathrm{KL}$ is also shown in red (Tercero et al. 2010, 2015). The $\mathrm{CH}_{3} \mathrm{OH}$ spectra towards Orion BN/KL have been divided by $\sim 400$, and the $\mathrm{H}_{2} \mathrm{CS}$ spectra by $\sim 200$. The black and red dashed lines indicate the LSR velocity of the Orion Bar PDR $\left(10.7 \mathrm{~km} \mathrm{~s}^{-1}\right)$ and Orion extended ridge and/or south hot core $\left(\sim 8 \mathrm{~km} \mathrm{~s}^{-1}\right.$, see e.g. Cernicharo et al. 2016), respectively. 
Appendix B: Identified lines of complex organic molecules

A summary of the main line spectroscopic parameters is presented in Tables B.1-B.11. Line frequency (in MHz), energy of the upper level of each transition $\left(E_{\mathrm{u}} / k\right.$ in $\left.\mathrm{K}\right)$, Einstein coefficient for spontaneous emission $\left(A_{\mathrm{ul}}\right.$ in s $\left.{ }^{-1}\right)$, intrinsic line strength $\left(S_{\mathrm{ul}}\right)$, and the level degeneracy $\left(g_{\mathrm{u}}\right)$ from MADEX spectral catalogue, and JPL and CDMS molecular databases are shown. The velocity-integrated line intensity $\left(\int T_{\mathrm{MB}} \mathrm{d} v\right.$ in $\left.\mathrm{mK} \mathrm{km} \mathrm{s}{ }^{-1}\right)$, LSR velocity $\left(v_{\mathrm{LSR}}\right.$ in $\left.\mathrm{km} \mathrm{s}^{-1}\right)$, FWHM line width $\left(\Delta v\right.$ in $\left.\mathrm{km} \mathrm{s}^{-1}\right)$, and the line peak temperature $\left(T_{\mathrm{MB}}\right.$ in $\left.\mathrm{mK}\right)$ were obtained from Gaussian fits. Parentheses indicate the uncertainty. When two or more transitions were found to overlap, the total profile was fitted. Fully overlapping transitions are marked with connecting symbols in the tables.

Table B.1. Line parameters of HCO.

\begin{tabular}{|c|c|c|c|c|c|c|c|c|c|c|}
\hline Transition & Frequency & $E_{\mathrm{u}} / k$ & $A_{\mathrm{ul}}$ & $S_{\mathrm{ul}}$ & $g_{\mathrm{u}}$ & $T_{\mathrm{MB}} \mathrm{d} v$ & $v_{\mathrm{LSR}}$ & $\Delta v$ & $T_{\mathrm{MB}}$ & $S / N$ \\
\hline$\left(N_{K_{\mathrm{a}}, K_{\mathrm{c}}}, J, F\right)_{\mathrm{u}} \rightarrow\left(N_{K_{\mathrm{a}}, K_{\mathrm{c}}}, J, F\right)_{1}$ & {$[\mathrm{MHz}]$} & {$[\mathrm{K}]$} & {$\left[\mathrm{s}^{-1}\right]$} & & & {$\left[\mathrm{mK} \mathrm{km} \mathrm{s}^{-1}\right]$} & {$\left[\mathrm{km} \mathrm{s}^{-1}\right]$} & {$\left[\mathrm{km} \mathrm{s}^{-1}\right]$} & {$[\mathrm{mK}]$} & \\
\hline $1_{0,1}, 3 / 2,2 \rightarrow 0_{0,0}, 1 / 2,1$ & $86670.760^{F}$ & 4.2 & $4.68 \times 10^{-6}$ & 1.66 & 5 & $497(12)$ & $10.5(<0.1)$ & $3.1(0.1)$ & 149 & 52 \\
\hline $1_{0,1}, 3 / 2,1 \rightarrow 0_{0,0}, 1 / 2,0$ & $86708.360^{F}$ & 4.2 & $4.59 \times 10^{-6}$ & 0.98 & 3 & $286(7)$ & $10.5(<0.1)$ & $2.8(0.1)$ & 95 & 33 \\
\hline $1_{0,1}, 1 / 2,1 \rightarrow 0_{0,0}, 1 / 2,1$ & $86777.460^{F}$ & 4.2 & $4.60 \times 10^{-6}$ & 0.98 & 3 & 294(7) & $10.5(<0.1)$ & $3.0(0.1)$ & 92 & 32 \\
\hline $1_{0,1}, 1 / 2,0 \rightarrow 0_{0,0}, 1 / 2,1$ & $86805.780^{F}$ & 4.2 & $4.71 \times 10^{-6}$ & 0.33 & 1 & $75(6)$ & $10.5(0.1)$ & $2.3(0.2)$ & 31 & 10 \\
\hline $2_{0,2}, 5 / 2,3 \rightarrow 1_{0,1}, 3 / 2,2$ & $173377.377^{W}$ & 12.5 & $4.50 \times 10^{-5}$ & 2.80 & 7 & $683(86)$ & - & - & - & 8 \\
\hline $2_{0,2}, 5 / 2,2 \rightarrow 1_{0,1}, 3 / 2,1$ & $173406.082^{W}$ & 12.5 & $4.42 \times 10^{-5}$ & 1.96 & 5 & $346(70)$ & - & - & - & 6 \\
\hline $2_{0,2}, 3 / 2,2 \rightarrow 1_{0,1}, 1 / 2,1$ & $173443.065^{W}$ & 12.5 & $3.38 \times 10^{-5}$ & 1.50 & 5 & $409(94)$ & - & - & - & 5 \\
\hline $2_{0,2}, 3 / 2,1 \rightarrow 1_{0,1}, 1 / 2,0$ & $173474.400^{W}$ & 12.5 & $2.50 \times 10^{-5}$ & 0.66 & 3 & $185(79)$ & - & - & - & 4 \\
\hline $3_{0,3}, 7 / 2,4 \rightarrow 2_{0,2}, 5 / 2,3$ & $260060.329^{F}$ & 25.0 & $1.63 \times 10^{-4}$ & 3.85 & 9 & $576(15)$ & $10.5(<0.1)$ & $2.0(0.1)$ & 275 & 23 \\
\hline $3_{0,3}, 7 / 2,3 \rightarrow 2_{0,2}, 5 / 2,2$ & $260082.192^{F}$ & 25.0 & $1.60 \times 10^{-4}$ & 2.95 & 7 & $446(15)$ & $10.5(<0.1)$ & $2.0(0.1)$ & 209 & 16 \\
\hline $3_{0,3}, 5 / 2,3 \rightarrow 2_{0,2}, 3 / 2,2$ & $260133.586^{F}$ & 25.0 & $1.45 \times 10^{-4}$ & 2.67 & 7 & $347(17)$ & $10.6(<0.1)$ & $1.7(0.4)$ & 195 & 15 \\
\hline $3_{0,3}, 5 / 2,2 \rightarrow 2_{0,2}, 3 / 2,1$ & $260155.769^{W}$ & 25.0 & $1.37 \times 10^{-4}$ & 1.80 & 5 & $382(25)$ & - & - & - & 19 \\
\hline $4_{0,4}, 9 / 2,5 \rightarrow 3_{0,3}, 7 / 2,4$ & $346708.493^{F}$ & 41.6 & $3.99 \times 10^{-4}$ & 4.88 & 11 & $437(38)$ & $10.6(0.1)$ & $2.6(0.3)$ & 156 & 7 \\
\hline $4_{0,4}, 9 / 2,4 \rightarrow 3_{0,3}, 7 / 2,3$ & $346725.172^{F}$ & 41.6 & $3.95 \times 10^{-4}$ & 3.95 & 9 & $308(36)$ & $10.6(0.1)$ & $2.0(0.3)$ & 142 & 7 \\
\hline $4_{0,4}, 7 / 2,4 \rightarrow 3_{0,3}, 5 / 2,3$ & $346787.898^{F}$ & 41.6 & $3.76 \times 10^{-4}$ & 3.76 & 9 & $362(41)$ & $10.5(0.2)$ & $3.0(0.5)$ & 112 & 6 \\
\hline $4_{0,4}, 7 / 2,3 \rightarrow 3_{0,3}, 5 / 2,2$ & $346804.597^{F}$ & 41.6 & $3.67 \times 10^{-4}$ & 2.85 & 7 & $223(29)$ & $10.6(0.1)$ & $1.6(0.3)$ & 127 & 7 \\
\hline
\end{tabular}

Notes. Frequencies, $E_{\mathrm{u}} / k, A_{\mathrm{ul}}, S_{\mathrm{ul}}$, and $g_{\mathrm{u}}$ from JPL catalogue. Labels: ${ }^{(F)}$ Detected with FTS backend. ${ }^{(W)}$ The lines detected with WILMA backend just give information about the integrated line intensity (see Cuadrado et al. 2015). ${ }^{(*)}$ Symmetry (ortho-para or E-A). 
Table B.2. Line parameters of $\mathrm{H}_{2} \mathrm{CO}$.

\begin{tabular}{|c|c|c|c|c|c|c|c|c|c|c|c|}
\hline Transition & Sym.* & Frequency & $E_{\mathrm{u}} / k$ & $A_{\mathrm{ul}}$ & $S_{\mathrm{ul}}$ & $g_{\mathrm{u}}$ & $T_{\mathrm{MB}} \mathrm{d} v$ & $v_{\mathrm{LSR}}$ & $\Delta v$ & $T_{\mathrm{MB}}$ & $S / N$ \\
\hline$\left(J_{K_{\mathrm{a}}, K_{\mathrm{c}}}\right)_{\mathrm{u}} \rightarrow\left(J_{K_{\mathrm{a}}, K_{\mathrm{c}}}\right)_{1}$ & & {$[\mathrm{MHz}]$} & {$[\mathrm{K}]$} & {$\left[\mathrm{s}^{-1}\right]$} & & & {$\left[\mathrm{mK} \mathrm{km} \mathrm{s}^{-1}\right]$} & {$\left[\mathrm{km} \mathrm{s}^{-1}\right]$} & {$\left[\mathrm{km} \mathrm{s}^{-1}\right]$} & {$[\mathrm{mK}]$} & \\
\hline $2_{1,2} \rightarrow 1_{1,1}$ & ortho & $140839.516^{W}$ & 6.8 & $5.30 \times 10^{-5}$ & 1.5 & 5 & $13488(28)$ & - & - & - & 423 \\
\hline $2_{0,2} \rightarrow 1_{0,1}$ & para & $145602.951^{W}$ & 10.5 & $7.80 \times 10^{-5}$ & 2.0 & 5 & $5611(67)$ & - & - & - & 95 \\
\hline $2_{1,1} \rightarrow 1_{1,0}$ & ortho & $150498.335^{W}$ & 7.5 & $6.46 \times 10^{-5}$ & 1.5 & 5 & $10850(97)$ & - & - & - & 208 \\
\hline $3_{1,3} \rightarrow 2_{1,2}$ & ortho & $211211.449^{F}$ & 16.9 & $2.27 \times 10^{-4}$ & 2.7 & 7 & $13732(26)$ & $10.6(0.1)$ & $2.3(0.1)$ & 5519 & 338 \\
\hline $3_{0,3} \rightarrow 2_{0,2}$ & para & $218222.187^{F}$ & 21.0 & $2.81 \times 10^{-4}$ & 3.0 & 7 & $6567(22)$ & $10.6(0.1)$ & $2.2(0.1)$ & 2771 & 311 \\
\hline $3_{2,2} \rightarrow 2_{2,1}$ & para & $218475.634^{F}$ & 68.1 & $1.57 \times 10^{-4}$ & 1.7 & 7 & $2600(9)$ & $10.7(0.1)$ & $2.1(0.1)$ & 1148 & 175 \\
\hline $3_{2,1} \rightarrow 2_{2,0}$ & para & $218760.062^{F}$ & 68.1 & $1.58 \times 10^{-4}$ & 1.7 & 7 & $2582(12)$ & $10.7(0.1)$ & $2.1(0.1)$ & 1145 & 151 \\
\hline $3_{1,2} \rightarrow 2_{1,1}$ & ortho & $225697.772^{F}$ & 18.3 & $2.77 \times 10^{-4}$ & 2.7 & 7 & $11382(39)$ & $10.6(0.1)$ & $2.4(0.1)$ & 4537 & 269 \\
\hline $4_{1,4} \rightarrow 3_{1,3}$ & ortho & $281526.919^{F}$ & 30.4 & $5.87 \times 10^{-4}$ & 3.8 & 9 & $15275(49)$ & $10.5(0.1)$ & $2.4(0.1)$ & 6032 & 409 \\
\hline $4_{2,3} \rightarrow 3_{2,2}$ & para & $291237.765^{F}$ & 82.1 & $5.20 \times 10^{-4}$ & 3.0 & 9 & 2870(19) & $10.6(0.1)$ & $2.1(0.1)$ & 1266 & 100 \\
\hline $4_{3,2} \rightarrow 3_{3,1}$ & ortho & $291380.441^{F}$ & 125.8 & $3.04 \times 10^{-4}$ & 1.8 & 9 & $3815(19)$ & $10.6(0.1)$ & $2.0(0.1)$ & 1755 & 138 \\
\hline $4_{3,1} \rightarrow 3_{3,0}$ & ortho & $291384.360^{F}$ & 125.8 & $3.04 \times 10^{-4}$ & 1.8 & 9 & $4282(21)$ & $10.7(0.1)$ & $2.3(0.1)$ & 1744 & 138 \\
\hline $4_{2,2} \rightarrow 3_{2,1}$ & para & $291948.066^{F}$ & 82.1 & $5.24 \times 10^{-4}$ & 3.0 & 9 & 2863(19) & $10.6(0.1)$ & $2.2(0.1)$ & 1244 & 101 \\
\hline $4_{1,3} \rightarrow 3_{1,2}$ & ortho & $300836.630^{F}$ & 32.7 & $7.17 \times 10^{-4}$ & 3.8 & 9 & $9897(49)$ & $10.7(0.1)$ & $2.5(0.1)$ & 3668 & 135 \\
\hline $5_{1,5} \rightarrow 4_{1,4}$ & ortho & $351768.637^{F}$ & 47.3 & $1.20 \times 10^{-3}$ & 4.8 & 11 & $8551(88)$ & $10.7(0.1)$ & $2.4(0.1)$ & 3294 & 61 \\
\hline
\end{tabular}

Notes. Frequencies, $E_{\mathrm{u}} / k, A_{\mathrm{ul}}, S_{\mathrm{ul}}$, and $g_{\mathrm{u}}$ from MADEX code, that fit to all rotational lines reported by Bocquet et al. (1996), Brünken et al. (2003), and Eliet et al. (2012).

Table B.3. Line parameters of $\mathrm{H}_{2}^{13} \mathrm{CO}$.

\begin{tabular}{|c|c|c|c|c|c|c|c|c|c|c|c|}
\hline Transition & Sym.* & & $E_{\mathrm{u}} / k$ & $A_{\mathrm{ul}}$ & $S_{\mathrm{ul}}$ & $g_{\mathrm{u}}$ & $T_{\mathrm{MB}} \mathrm{d} v$ & $v_{\text {LSR }}$ & $\Delta v$ & $T_{\mathrm{MB}}$ & $S / N$ \\
\hline$\left(J_{K_{\mathrm{a}}, K_{\mathrm{c}}}\right)_{\mathrm{u}} \rightarrow\left(J_{K_{\mathrm{a}}, K_{\mathrm{c}}}\right)_{1}$ & & {$[\mathrm{MHz}]$} & {$[\mathrm{K}]$} & {$\left[\mathrm{s}^{-1}\right]$} & & & {$\left[\mathrm{mK} \mathrm{km} \mathrm{s}^{-1}\right]$} & {$\left[\mathrm{km} \mathrm{s}^{-1}\right]$} & {$\left[\mathrm{km} \mathrm{s}^{-1}\right]$} & {$[\mathrm{mK}]$} & \\
\hline $2_{1,2} \rightarrow 1_{1,1}$ & ortho & $137449.954^{W}$ & 6.6 & $4.92 \times 10^{-5}$ & 1.5 & 5 & $298(53)$ & - & - & - & 7 \\
\hline $2_{1,1} \rightarrow 1_{1,0}$ & ortho & $146635.669^{W}$ & 7.3 & $5.98 \times 10^{-5}$ & 1.5 & 5 & $73(29)$ & - & - & - & 5 \\
\hline $3_{1,3} \rightarrow 2_{1,2}$ & ortho & $206131.619^{F}$ & 16.5 & $2.11 \times 10^{-4}$ & 2.6 & 7 & $251(12)$ & $10.5(0.1)$ & $2.4(0.1)$ & 97 & 11 \\
\hline $3_{0,3} \rightarrow 2_{0,2}$ & para & $212811.190^{F}$ & 20.4 & $2.61 \times 10^{-4}$ & 3.0 & 7 & $84(13)$ & $10.3(0.1)$ & $2.1(0.4)$ & 37 & 4 \\
\hline $3_{1,2} \rightarrow 2_{1,1}$ & ortho & $219908.481^{F}$ & 17.8 & $2.56 \times 10^{-4}$ & 2.7 & 7 & $151(12)$ & $10.7(0.1)$ & $2.0(0.2)$ & 70 & 7 \\
\hline $4_{1,4} \rightarrow 3_{1,3}$ & ortho & $274762.103^{F}$ & 29.7 & $5.46 \times 10^{-4}$ & 3.8 & 9 & $180(16)$ & $10.8(0.1)$ & $2.3(0.3)$ & 74 & 6 \\
\hline $4_{0,4} \rightarrow 3_{0,3}$ & para & $283441.868^{F}$ & 34.0 & $6.39 \times 10^{-4}$ & 4.0 & 9 & $32(13)$ & $10.7(0.2)$ & $0.9(0.5)$ & 33 & 4 \\
\hline $4_{1,3} \rightarrow 3_{1,2}$ & ortho & $293126.495^{F}$ & 31.9 & $6.63 \times 10^{-4}$ & 3.8 & 9 & $140(13)$ & $10.5(0.1)$ & $2.3(0.3)$ & 58 & 6 \\
\hline
\end{tabular}

Notes. Frequencies, $E_{\mathrm{u}} / k, A_{\mathrm{ul}}, S_{\mathrm{ul}}$, and $g_{\mathrm{u}}$ from MADEX code, that fit to all rotational lines reported by Müller et al. (2000). 
Table B.4. Line parameters of $\mathrm{H}_{2} \mathrm{CS}$.

\begin{tabular}{|c|c|c|c|c|c|c|c|c|c|c|c|}
\hline $\begin{array}{c}\text { Transition } \\
\left(J_{K_{\mathrm{a}}, K_{\mathrm{c}}}\right)_{\mathrm{u}} \rightarrow\left(J_{K_{\mathrm{a}}, K_{\mathrm{c}}}\right)_{1} \\
\end{array}$ & m.* & $\begin{array}{c}\text { Frequency } \\
{[\mathrm{MHz}]} \\
\end{array}$ & $\begin{array}{r}E_{\mathrm{u}} / k \\
{[\mathrm{~K}]}\end{array}$ & $\begin{array}{c}A_{\mathrm{ul}} \\
{\left[\mathrm{s}^{-1}\right]}\end{array}$ & $S_{\mathrm{ul}}$ & $g_{\mathrm{u}}$ & $\underset{\left[\mathrm{mK} \mathrm{km} \mathrm{s}^{-1}\right]}{T_{\mathrm{MB}} \mathrm{d} v}$ & $\begin{array}{c}v_{\mathrm{LSR}} \\
{\left[\mathrm{km} \mathrm{s}^{-1}\right]}\end{array}$ & $\begin{array}{c}\Delta v \\
{\left[\mathrm{~km} \mathrm{~s}^{-1}\right]}\end{array}$ & $\begin{array}{c}T_{\mathrm{MB}} \\
{[\mathrm{mK}]}\end{array}$ & $S / N$ \\
\hline $3_{1,3} \rightarrow 2_{1,2}$ & ortho & $101477.810^{F}$ & 8.1 & $1.26 \times 10^{-5}$ & 2.67 & 7 & $79(8)$ & $10.8(0.1)$ & $1.1(0.1)$ & 68 & 10 \\
\hline $3_{2,2} \rightarrow 2_{2,1}$ & para & $103039.907^{F}$ & 62.6 & $8.25 \times 10^{-6}$ & 1.67 & 7 & & & & & 9 \\
\hline $3_{0,3} \rightarrow 2_{0,2}$ & para & $103040.452^{F}$ & 9.9 & $1.48 \times 10^{-5}$ & 3.00 & 7 & & & & & \\
\hline $3_{2,1} \rightarrow 2_{2,0}$ & para & $103051.847^{F}$ & 62.6 & $8.25 \times 10^{-6}$ & 1.67 & 7 & 19(7) & $10.5(0.3)$ & $1.5(1.3)$ & 10 & 3 \\
\hline $3_{1,2} \rightarrow 2_{1,1}$ & ortho & $104617.040^{F}$ & 8.4 & $1.38 \times 10^{-5}$ & 2.67 & 7 & $85(5)$ & $.7(<0.1)$ & $1.3(0.1)$ & 59 & 14 \\
\hline $4_{0,4} \rightarrow 3_{0,3}$ & para & $137371.210^{W}$ & 16.5 & $3.65 \times 10^{-5}$ & 4.00 & 9 & 182(18) & - & - & - & 2 \\
\hline $4_{1,3} \rightarrow 3_{1,2}$ & ortho & $139483.682^{W}$ & 15.1 & $58 \times 10^{-5}$ & 75 & 9 & $149(22)$ & - & - & - & 4 \\
\hline $5_{1,5} \rightarrow 4_{1,4}$ & ortho & $169114.079^{W}$ & 22.7 & $6.68 \times 10^{-5}$ & 4.80 & 11 & $229(35)$ & - & - & - & 10 \\
\hline $5_{0,5} \rightarrow 4_{0,4}$ & para & 17168 & 24.7 & $7.28 \times 10^{-5}$ & 5.00 & 11 & $1447(217)$ & - & - & - & 9 \\
\hline $5_{1,4} \rightarrow 4_{1,3}$ & ortho & $174345.223^{W}$ & 23.5 & $7.32 \times 10^{-5}$ & 4.80 & 11 & $300(106)$ & - & - & - & 3 \\
\hline $6_{1,6} \rightarrow 5_{1,5}$ & ortho & $202924.054^{F}$ & 32.5 & $19 \times 10^{-4}$ & 5.83 & 13 & $206(10)$ & $10.9(<0.1)$ & $0.8(0.1)$ & 245 & 18 \\
\hline $6_{0,6} \rightarrow 5_{0,5}$ & para & $205987.858^{F}$ & 34.6 & $1.28 \times 10^{-4}$ & 6.00 & 13 & 75( & $<0.1)$ & $0.1)$ & 104 & 10 \\
\hline $6_{3,4} \rightarrow 5_{3,3}$ & ortho & 2060 & 138.3 & $59 \times 10^{-5}$ & 4.50 & 13 & & & & 55 & 5 \\
\hline $6_{3,3} \rightarrow 5_{3,2}$ & ortho & $206052.602^{F}$ & 138.3 & $9.59 \times 10^{-5}$ & 4.50 & 13 & & & & & \\
\hline $6_{2,4} \rightarrow 5_{2,3}$ & para & $206158.602^{F}$ & 87.3 & $1.14 \times 10^{-4}$ & 5.33 & 13 & $48(7)$ & $10.9(0.1)$ & $1.0(0.1)$ & 47 & 5 \\
\hline $6_{1,5} \rightarrow 5_{1,4}$ & ortho & $209200.620^{F}$ & 33.5 & $1.30 \times 10^{-4}$ & 5.83 & (1) & $190(9)$ & $10.9(<0.1)$ & $0.8(0.1)$ & 231 & 17 \\
\hline $7_{1,7} \rightarrow 6_{1,6}$ & ortho & $236727.020^{F}$ & 43.8 & $1.92 \times 10^{-4}$ & 6.86 & 15 & $105(14)$ & $10.9(<0.1)$ & $0.5(0.1)$ & 185 & 7 \\
\hline $7_{0,7} \rightarrow 6_{0,6}$ & para & $240266.872^{F}$ & 46.1 & & 7.00 & 15 & 107(13) & $10.8(<0.1)$ & $0.9(0.1)$ & 116 & 8 \\
\hline $7_{2,6} \rightarrow 6_{2,5}$ & para & $240382.051^{F}$ & 98.8 & $1.88 \times 10^{-4}$ & 6.43 & 15 & $24(6)$ & $10.8(0.1)$ & $0.3(0.2)$ & 76 & 3 \\
\hline $7_{3,5} \rightarrow 6_{3,4}$ & ortho & $240393.037^{F}$ & 149.8 & $1.68 \times 10^{-4}$ & 5.71 & 15 & $122(14)$ & & & 72 & 6 \\
\hline $7_{3,4} \rightarrow 6_{3,3}$ & ortho & $240393.762^{F}$ & 149.8 & $1.68 \times 10^{-4}$ & 5.71 & 15 & & & & & \\
\hline $7_{2,5} \rightarrow 6_{2,4}$ & para & $240549.066^{F}$ & 98.8 & $1.89 \times 10^{-4}$ & 6.43 & 15 & $62(11)$ & $10.7(0.1)$ & $1.5(0.2)$ & 54 & 5 \\
\hline $7_{1,6} \rightarrow 6_{1,5}$ & ortho & $244048.504^{F}$ & 45.2 & $2.10 \times 10^{-4}$ & 6.86 & 15 & $185(11)$ & $10.9(<0.1)$ & $0.8(0.1)$ & 260 & 14 \\
\hline $8_{1,8} \rightarrow 7_{1,7}$ & ortho & $270521.931^{F}$ & 56.8 & $2.90 \times 10^{-4}$ & 7.88 & 17 & $128(16)$ & $10.8(0.1)$ & $0.9(0.2)$ & 139 & 6 \\
\hline $8_{0,8} \rightarrow 7_{0,7}$ & para & $274521.931^{F}$ & 59.3 & $3.08 \times 10^{-4}$ & 8.00 & 17 & $60(9)$ & $11.1(0.1)$ & $0.7(0.1)$ & 77 & 5 \\
\hline $8_{2,6} \rightarrow 7_{2,5}$ & para & $274953.744^{F}$ & 112.0 & $2.90 \times 10^{-4}$ & 7.50 & 17 & $36(9)$ & $11.0(0.1)$ & $0.9(0.2)$ & 39 & 3 \\
\hline $8_{1,7} \rightarrow 7_{1,6}$ & ortho & $278887.661^{F}$ & 58.6 & $3.18 \times 10^{-4}$ & 7.87 & 17 & 195(13) & $10.9(<0.1)$ & $0.7(0.1)$ & 245 & 14 \\
\hline $9_{1,9} \rightarrow 8_{1,8}$ & ortho & $304307.709^{F}$ & 71.4 & $4.17 \times 10^{-4}$ & 8.89 & 19 & $75(8)$ & $10.7(0.1)$ & $0.7(0.1)$ & 101 & 5 \\
\hline $10_{1,10} \rightarrow 9_{1,9}$ & ortho & $338083.195^{F}$ & 87.6 & $5.77 \times 10^{-4}$ & 9.90 & 21 & $108(30)$ & $10.6(0.1)$ & $0.9(0.3)$ & 113 & 3 \\
\hline
\end{tabular}

Notes. Frequencies, $E_{\mathrm{u}} / k, A_{\mathrm{ul}}, S_{\mathrm{ul}}$, and $g_{\mathrm{u}}$ from CDMS catalogue.

Table B.5. Line parameters of HNCO.

\begin{tabular}{|c|c|c|c|c|c|c|c|c|c|c|}
\hline Transition & Frequency & $E_{\mathrm{u}} / k$ & $A_{\mathrm{ul}}$ & $S_{\text {ul }}$ & $g_{\mathrm{u}}$ & $T_{\mathrm{MB}} \mathrm{d} v$ & $v_{\mathrm{LSR}}$ & $\Delta v$ & $T_{\mathrm{MB}}$ & $S / N$ \\
\hline$\left(J_{K_{\mathrm{a}}, K_{\mathrm{c}}}\right)_{\mathrm{u}} \rightarrow\left(J_{K_{\mathrm{a}}, K_{\mathrm{c}}}\right)_{1}$ & [MHz] & {$[\mathrm{K}]$} & {$\left[\mathrm{s}^{-1}\right]$} & & & {$\left[\mathrm{mK} \mathrm{km} \mathrm{s}^{-1}\right]$} & {$\left[\mathrm{km} \mathrm{s}^{-1}\right]$} & {$\left[\mathrm{km} \mathrm{s}^{-1}\right]$} & {$[\mathrm{mK}]$} & \\
\hline $4_{0,4} \rightarrow 3_{0,3}$ & $87925.237^{F}$ & 10.5 & $9.03 \times 10^{-6}$ & 4.0 & 9 & $49(6)$ & $10.8(0.1)$ & $1.7(0.2)$ & 27 & 8 \\
\hline $5_{0,5} \rightarrow 4_{0,4}$ & $109905.749^{F}$ & 15.8 & $1.80 \times 10^{-5}$ & 5.0 & 11 & $110(9)$ & $10.6(0.1)$ & $1.9(0.2)$ & 54 & 10 \\
\hline $7_{0,7} \rightarrow 6_{0,6}$ & $153865.086^{W}$ & 29.5 & $5.08 \times 10^{-5}$ & 7.0 & 15 & $125(39)$ & - & - & - & 3 \\
\hline $10_{0,10} \rightarrow 9_{0,9}$ & $219798.274^{F}$ & 58.0 & $1.51 \times 10^{-4}$ & 10.0 & 21 & $154(16)$ & $10.6(0.2)$ & $3.3(0.4)$ & 44 & 6 \\
\hline $11_{0,11} \rightarrow 10_{0,10}$ & $241774.032^{F}$ & 69.6 & $2.02 \times 10^{-4}$ & 11.0 & 23 & $118(21)$ & $10.7(0.1)$ & $1.6(0.3)$ & 69 & 5 \\
\hline $13_{0,13} \rightarrow 12_{0,12}$ & $285721.951^{F}$ & 96.0 & $3.36 \times 10^{-4}$ & 13.0 & 27 & $129(26)$ & $10.4(0.3)$ & $2.8(0.7)$ & 43 & 5 \\
\hline
\end{tabular}

Notes. Frequencies, $E_{\mathrm{u}} / k, A_{\mathrm{ul}}, S_{\mathrm{ul}}$, and $g_{\mathrm{u}}$ from CDMS catalogue. 
Table B.6. Line parameters of $\mathrm{CH}_{2} \mathrm{NH}$.

\begin{tabular}{|c|c|c|c|c|c|c|c|c|c|c|}
\hline$\frac{\text { Transition }}{\left(J_{K_{\mathrm{a}}, K_{\mathrm{c}}}\right)_{\mathrm{u}} \rightarrow\left(J_{K_{\mathrm{a}}, K_{\mathrm{c}}}\right)_{1}}$ & $\begin{array}{c}\text { Frequency } \\
{[\mathrm{MHz}]}\end{array}$ & $\begin{array}{r}E_{\mathrm{u}} / k \\
{[\mathrm{~K}]}\end{array}$ & $\begin{array}{c}A_{\mathrm{ul}} \\
{\left[\mathrm{s}^{-1}\right]}\end{array}$ & $S_{\text {ul }}$ & $g_{\mathrm{u}}$ & $\underset{\left[\mathrm{mK} \mathrm{km} \mathrm{s}^{-1}\right]}{\int_{\mathrm{MB}} \mathrm{d} v}$ & $\begin{array}{c}v_{\mathrm{LSR}} \\
{\left[\mathrm{km} \mathrm{s}^{-1}\right]}\end{array}$ & $\begin{array}{c}\Delta v \\
{\left[\mathrm{~km} \mathrm{~s}^{-1}\right]}\end{array}$ & $\begin{array}{c}T_{\mathrm{MB}} \\
{[\mathrm{mK}]}\end{array}$ & $S / N$ \\
\hline $4_{0,4} \rightarrow 3_{1,3}$ & $105794.062^{F}$ & 30.6 & $1.62 \times 10^{-5}$ & 5.0 & 9 & $55(13)$ & $11.3(0.5)$ & $4.2(1.3)$ & 12 & 3 \\
\hline $1_{1,1} \rightarrow 0_{0,0}$ & $225554.609^{F}$ & 10.8 & $2.79 \times 10^{-4}$ & 3.0 & 3 & $120(26)$ & $10.5(0.2)$ & $2.9(0.9)$ & 39 & 4 \\
\hline $4_{1,4} \rightarrow 3_{1,3}$ & $245125.866^{F}$ & 37.3 & $3.85 \times 10^{-4}$ & 11.2 & 9 & $106(14)$ & $11.1(0.1)$ & $2.3(0.4)$ & 43 & 4 \\
\hline $6_{0,6} \rightarrow 5_{1,5}$ & $251421.265^{F}$ & 64.1 & $2.73 \times 10^{-4}$ & 9.2 & 13 & $72(13)$ & $11.0(0.3)$ & $3.1(0.6)$ & 22 & 4 \\
\hline $4_{0,4} \rightarrow 3_{0,3}$ & $254685.137^{F}$ & 30.6 & $4.60 \times 10^{-4}$ & 12.0 & 9 & $314(12)$ & $10.8(0.1)$ & $2.0(0.1)$ & 147 & 14 \\
\hline $4_{1,3} \rightarrow 3_{1,2}$ & $266270.024^{F}$ & 39.8 & $4.93 \times 10^{-4}$ & 11.2 & 9 & $117(12)$ & $10.9(0.1)$ & $2.0(0.2)$ & 54 & 5 \\
\hline
\end{tabular}

Notes. Frequencies, $E_{\mathrm{u}} / k, A_{\mathrm{ul}}, S_{\mathrm{ul}}$, and $g_{\mathrm{u}}$ from CDMS catalogue. 
Table B.7. Line parameters of $\mathrm{H}_{2} \mathrm{CCO}$.

\begin{tabular}{|c|c|c|c|c|c|c|c|c|c|c|c|}
\hline$\frac{\text { Transition }}{\left(J_{K_{\mathrm{a}}, K_{\mathrm{c}}}\right)_{\mathrm{u}} \rightarrow\left(J_{K_{\mathrm{a}}, K_{\mathrm{c}}}\right)_{1}}$ & Sym. ${ }^{*}$ & $\begin{array}{c}\text { Frequency } \\
{[\mathrm{MHz}]}\end{array}$ & $\begin{array}{r}E_{\mathrm{u}} / k \\
{[\mathrm{~K}]}\end{array}$ & $\begin{array}{c}A_{\mathrm{ul}} \\
{\left[\mathrm{s}^{-1}\right]}\end{array}$ & $S_{\mathrm{ul}}$ & $g_{\mathrm{u}}$ & $\underset{\left[\mathrm{mKKm} \mathrm{s}^{-1}\right]}{\int T_{\mathrm{MB}} \mathrm{d} v}$ & $\begin{array}{c}v_{\text {LSR }} \\
{\left[\mathrm{km} \mathrm{s}^{-1}\right]}\end{array}$ & $\begin{array}{c}\Delta v \\
{\left[\mathrm{~km} \mathrm{~s}^{-1}\right]}\end{array}$ & $\begin{array}{c}T_{\mathrm{MB}} \\
{[\mathrm{mK}]}\end{array}$ & $S / N$ \\
\hline $4_{2,3} \rightarrow 3_{2,2}$ & para & $80820.400^{F}$ & 61.9 & $4.14 \times 10^{-6}$ & 3.0 & 9 & 13(9) & $10.9(0.7)$ & $1.6(0.7)$ & 8 & 2 \\
\hline $4_{1,3} \rightarrow 3_{1,2}$ & ortho & $81586.239^{F}$ & 8.8 & $5.33 \times 10^{-6}$ & 3.8 & 9 & $44(8)$ & $11.0(0.3)$ & $2.5(0.6)$ & 13 & 4 \\
\hline $5_{1,5} \rightarrow 4_{1,4}$ & ortho & $100094.511^{F}$ & 13.5 & $1.03 \times 10^{-5}$ & 4.8 & 11 & $61(6)$ & $10.4(0.2)$ & $1.9(0.5)$ & 30 & 3 \\
\hline $5_{3,3} \rightarrow 4_{3,2}$ & ortho & $101002.349^{F}$ & 117.9 & $7.06 \times 10^{-6}$ & 3.2 & 11 & $25(8)$ & 10 & 3) & 25 & 3 \\
\hline $5_{3,2} \rightarrow 4_{3,1}$ & ortho & $101002.354^{F}$ & 117.9 & $7.06 \times 10^{-6}$ & 3.2 & 11 & & & ग) & & \\
\hline $5_{2,4} \rightarrow 4_{2,3}$ & para & $101024.430^{F}$ & 66.7 & $9.27 \times 10^{-6}$ & 4.2 & 11 & $24(6)$ & $10.2(0.2)$ & $1.7(0.8)$ & 15 & 2 \\
\hline $5_{1,4} \rightarrow 4_{1,3}$ & ortho & $101981.442^{F}$ & 13.7 & $1.09 \times 10^{-5}$ & 4.8 & 11 & $58(6)$ & $10.9(0.1)$ & $2.3(0.3)$ & 24 & 7 \\
\hline $7_{1,7} \rightarrow 6_{1,6}$ & ortho & $140127.471^{W}$ & 25.9 & $2.96 \times 10^{-5}$ & 6.9 & 15 & $107(43)$ & - & - & - & 5 \\
\hline $7_{3,5} \rightarrow 6_{3,4}$ & ortho & $141402.460^{W}$ & 130.5 & $2.54 \times 10^{-5}$ & 5.7 & 15 & $71(32)$ & - & - & - & 4 \\
\hline $7_{3,4} \rightarrow 6_{3,3}$ & ortho & $141402.491^{W}$ & 130.5 & $2.54 \times 10^{-5}$ & 5.7 & 15 & & & & & \\
\hline $8_{1,7} \rightarrow 7_{1,6}$ & ortho & $163160.893^{W}$ & 34.3 & $4.74 \times 10^{-5}$ & 7.9 & 17 & $114(22)$ & - & - & - & 5 \\
\hline $11_{1,11} \rightarrow 10_{1,10}$ & ortho & $220177.558^{F}$ & 62.4 & $1.19 \times 10^{-4}$ & 10.9 & 23 & $128(13)$ & $10.8(0.1)$ & $2.6(0.3)$ & 47 & 5 \\
\hline $11_{3,9} \rightarrow 10_{3,8}$ & ortho & $222199.879^{F}$ & 167.4 & $1.14 \times 10^{-4}$ & 10.2 & 23 & $120(13)$ & $10.5(0.1)$ & $19(0.5)$ & 59 & 8 \\
\hline $11_{3,8} \rightarrow 10_{3,7}$ & ortho & $222200.199^{F}$ & 167.4 & $1.14 \times 10^{-4}$ & 10.2 & 23 & & & & & \\
\hline $11_{2,10} \rightarrow 10_{2,9}$ & para & $222228.629^{F}$ & 116.2 & $1.20 \times 10^{-4}$ & 10.6 & 23 & $54(15)$ & $10.7(0.1)$ & $2.0(0.8)$ & 25 & 4 \\
\hline $11_{1,10} \rightarrow 10_{1,9}$ & ortho & $224327.246^{F}$ & 63.6 & $1.26 \times 10^{-4}$ & 10.9 & 23 & $125(11)$ & $10.8(0.1)$ & $2.5(0.2)$ & 47 & 7 \\
\hline $12_{1,12} \rightarrow 11_{1,11}$ & ortho & $240185.798^{F}$ & 74.0 & $1.56 \times 10^{-4}$ & 11.9 & 25 & $123(19)$ & $10.9(0.2)$ & $2.6(0.6)$ & 45 & 5 \\
\hline $12_{0,12} \rightarrow 11_{0,11}$ & para & $242375.721^{F}$ & 75.6 & $1.61 \times 10^{-4}$ & 12.0 & 25 & $38(11)$ & $10.5(0.1)$ & $0.8(0.2)$ & 46 & 2 \\
\hline $12_{1,11} \rightarrow 11_{1,10}$ & ortho & $244712.254^{F}$ & 75.4 & $1.64 \times 10^{-4}$ & 11.9 & 25 & $123(13)$ & $10.8(0.1)$ & $1.7(0.1)$ & 69 & 5 \\
\hline $13_{1,13} \rightarrow 12_{1,12}$ & ortho & $260191.993^{W}$ & 86.5 & $1.99 \times 10^{-4}$ & 12.9 & 27 & $100(19)$ & - & - & - & 7 \\
\hline $13_{0,13} \rightarrow 12_{0,12}$ & para & $262548.202^{F}$ & 88.2 & $2.05 \times 10^{-4}$ & 13.0 & 27 & $35(9)$ & $10.8(0.1)$ & $1.2(0.2)$ & 28 & 3 \\
\hline $13_{3,11} \rightarrow 12_{3,10}$ & ortho & $262596.638^{F}$ & 191.6 & $1.94 \times 10^{-4}$ & 12.3 & 27 & $108(17)$ & $107(01)$ & $21(0.3)$ & 46 & 5 \\
\hline $13_{3,10} \rightarrow 12_{3,9}$ & ortho & $262597.384^{F}$ & 191.6 & $1.94 \times 10^{-4}$ & 12.3 & 27 & & & & & \\
\hline $13_{2,12} \rightarrow 12_{2,11}$ & para & $262618.994^{F}$ & 140.4 & $2.00 \times 10^{-4}$ & 12.7 & 27 & $43(9)$ & $10.7(0.2)$ & $1.5(0.2)$ & 27 & 3 \\
\hline $13_{2,11} \rightarrow 12_{2,10}$ & para & $262760.857^{F}$ & 140.5 & $2.01 \times 10^{-4}$ & 12.7 & 27 & $38(15)$ & $10.3(0.3)$ & $1.8(0.8)$ & 20 & 3 \\
\hline $13_{1,12} \rightarrow 12_{1,11}$ & ortho & $265095.061^{F}$ & 88.1 & $2.10 \times 10^{-4}$ & 13.0 & 27 & $99(10)$ & $10.7(0.1)$ & $1.5(0.1)$ & 63 & 6 \\
\hline $14_{1,14} \rightarrow 13_{1,13}$ & ortho & $280195.979^{F}$ & 99.9 & $2.49 \times 10^{-4}$ & 13.9 & 29 & $128(13)$ & $10.6(0.1)$ & $2.0(0.2)$ & 61 & 6 \\
\hline $14_{0,14} \rightarrow 13_{0,13}$ & para & $282714.584^{F}$ & 101.8 & $2.57 \times 10^{-4}$ & 14.0 & 29 & $33(15)$ & $10.8(0.3)$ & $1.0(0.3)$ & 31 & 3 \\
\hline $14_{3,12} \rightarrow 13_{3,11}$ & ortho & $282794.399^{F}$ & 205.2 & $2.45 \times 10^{-4}$ & 13.4 & 29 & $131(15)$ & $10.5(0.1)$ & $.0(0.2)$ & 62 & 6 \\
\hline $14_{3,11} \rightarrow 13_{3,10}$ & ortho & $282795.485^{F}$ & 205.2 & $2.45 \times 10^{-4}$ & 13.4 & 29 & & & & & \\
\hline $14_{2,13} \rightarrow 13_{2,12}$ & para & $282811.466^{F}$ & 154.0 & $2.52 \times 10^{-4}$ & 13.7 & 29 & $39(13)$ & $10.5(0.1)$ & $0.9(0.3)$ & 45 & 4 \\
\hline $14_{2,12} \rightarrow 13_{2,11}$ & para & $282988.739^{F}$ & 154.0 & $2.52 \times 10^{-4}$ & 13.7 & 29 & $34(7)$ & $10.7(0.1)$ & $1.0(0.2)$ & 34 & 4 \\
\hline $14_{1,13} \rightarrow 13_{1,12}$ & ortho & $285475.477^{F}$ & 101.8 & $2.63 \times 10^{-4}$ & 13.9 & 29 & $107(18)$ & $10.5(0.2)$ & $1.8(0.3)$ & 54 & 4 \\
\hline $15_{1,15} \rightarrow 14_{1,14}$ & ortho & $300197.596^{F}$ & 114.3 & $3.07 \times 10^{-4}$ & 14.9 & 31 & $89(39)$ & $10.7(0.4)$ & $1.9(0.5)$ & 44 & 2 \\
\hline $15_{3,13} \rightarrow 14_{3,12}$ & ortho & $302991.695^{F}$ & 219.7 & $3.04 \times 10^{-4}$ & 14.4 & 31 & & & & 49 & 2 \\
\hline $15_{3,12} \rightarrow 14_{3,11}$ & ortho & $302993.234^{F}$ & 219.7 & $3.04 \times 10^{-4}$ & 14.4 & 31 & & & & & \\
\hline
\end{tabular}

Notes. Frequencies, $E_{\mathrm{u}} / k, A_{\mathrm{ul}}, S_{\mathrm{ul}}$, and $g_{\mathrm{u}}$ from MADEX code, that fit to all rotational lines reported in the CDMS database. 
Table B.8. Line parameters of $\mathrm{HC}_{3} \mathrm{~N}$.

\begin{tabular}{|c|c|c|c|c|c|c|c|c|c|c|}
\hline Transition & Frequency & $E_{\mathrm{u}} / k$ & $A_{\mathrm{ul}}$ & $S_{\mathrm{ul}}$ & $g_{\mathrm{u}}$ & $T_{\mathrm{MB}} \mathrm{d} v$ & $v_{\mathrm{LSR}}$ & $\Delta v$ & $T_{\mathrm{MB}}$ & $S / N$ \\
\hline$J_{\mathrm{u}} \rightarrow J_{1}$ & [MIRZ] & {$[\mathrm{K}]$} & {$\left[\mathrm{s}^{-1}\right]$} & & & {$\left[\mathrm{mK} \mathrm{km} \mathrm{s}^{-1}\right]$} & {$\left[\mathrm{km} \mathrm{s}^{-1}\right]$} & {$\left[\mathrm{km} \mathrm{s}^{-1}\right]$} & {$[\mathrm{mK}]$} & \\
\hline $9 \rightarrow 8$ & $81881.462^{F}$ & 19.6 & $4.22 \times 10^{-5}$ & 9.0 & 19 & $50(19)$ & $10.8(0.2)$ & $2.1(0.6)$ & $23(\mathrm{~s})$ & 6 \\
\hline $10 \rightarrow 9$ & $90978.989^{F}$ & 24.0 & $5.81 \times 10^{-5}$ & 10.0 & 21 & $86(1$ & & 2.9 & 28 & 6 \\
\hline $11 \rightarrow 10$ & $100076.385^{F}$ & 28.8 & $7.77 \times 10^{-5}$ & 11.0 & 23 & $80(14)$ & $10.5(0.2)$ & 1.8( & 42 & 6 \\
\hline $12 \rightarrow 11$ & 109173.63 & 34.1 & $1.01 \times 10^{-4}$ & 2.0 & 25 & $76(\varepsilon$ & $10.7(0.1)$ & $2.0(0.2)$ & 37 & 10 \\
\hline $15 \rightarrow 14$ & $136464.402^{W}$ & 52.4 & $1.99 \times 10^{-4}$ & 15.0 & 31 & $164(59)$ & - & - & - & 3 \\
\hline $16 \rightarrow 15$ & $145560.949^{W}$ & 59.4 & $2.42 \times 10^{-4}$ & 16.0 & 33 & $95(59)$ & - & - & - & 4 \\
\hline $17 \rightarrow 16$ & $154657.288^{W}$ & 66.8 & $2.91 \times 10^{-4}$ & 17.0 & 35 & $162(36)$ & - & - & - & 5 \\
\hline $18 \rightarrow 17$ & $163753.404^{W}$ & 74.7 & $3.46 \times 10^{-4}$ & 18.0 & 37 & $162(20)$ & - & - & - & 8 \\
\hline $19 \rightarrow 18$ & $172849.285^{W}$ & 83.0 & $4.08 \times 10^{-4}$ & 19.0 & 39 & $169(17)$ & - & - & - & 2 \\
\hline $23 \rightarrow 22$ & $209230.199^{F}$ & 120.5 & $7.27 \times 10^{-4}$ & 23.0 & 47 & $54(16)$ & $10.8(0.2)$ & $1.7(0.6)$ & 30 & 5 \\
\hline $24 \rightarrow 23$ & $218324.709^{F}$ & 131.0 & $8.26 \times 10^{-4}$ & 24.0 & 49 & $16(4)$ & $10.9(0.1)$ & $0.6(0.2)$ & 24 & 4 \\
\hline
\end{tabular}

Notes. Frequencies, $E_{\mathrm{u}} / k, A_{\mathrm{ul}}, S_{\mathrm{ul}}$, and $g_{\mathrm{u}}$ from MADEX code, that fit to all rotational lines reported by de Zafra (1971), Mbosei et al. (2000), Creswell et al. (1977), Chen et al. (1991), Yamada et al. (1995), Thorwirth et al. (2000).

Table B.9. Line parameters of $\mathrm{CH}_{3} \mathrm{CN}$.

\begin{tabular}{|c|c|c|c|c|c|c|c|c|c|c|c|}
\hline Transition & ym.* & Frequency & $E_{\mathrm{u}} / k$ & $A_{\mathrm{ul}}$ & $S_{\mathrm{ul}}$ & $g_{\mathrm{u}}$ & $T_{\mathrm{MB}} \mathrm{d} v$ & $v_{\mathrm{LSR}}$ & $\Delta v$ & $T_{\mathrm{MB}}$ & $S / N$ \\
\hline$\left(J_{\mathrm{K}}\right)_{\mathrm{u}} \rightarrow\left(J_{\mathrm{K}}\right)_{1}$ & & {$[\mathrm{MHz}]$} & {$[\mathrm{K}]$} & {$\left[\mathrm{s}^{-1}\right]$} & & & {$\left[\mathrm{mK} \mathrm{km} \mathrm{s}^{-1}\right]$} & {$\left[\mathrm{km} \mathrm{s}^{-1}\right]$} & {$\left[\mathrm{km} \mathrm{s}^{-1}\right]$} & {$[\mathrm{mK}]$} & \\
\hline $5_{4} \rightarrow 4_{4}$ & $\mathrm{E}$ & $91958.726^{F}$ & 119.5 & $2.28 \times 10^{-5}$ & 1.8 & 11 & $26(13)$ & $12.5(0.5)$ & $2.0(1.0)$ & 13 & 3 \\
\hline $5_{3} \rightarrow 4_{3}$ & A & $91971.130^{F}$ & 77.5 & $4.06 \times 10^{-5}$ & 6.4 & 22 & 103(9) & $10.2(0.2)$ & $4.0(0.4)$ & 24 & 6 \\
\hline $5_{2} \rightarrow 4_{2}$ & E & $91979.993^{F}$ & 33.8 & $5.33 \times 10^{-5}$ & 4.2 & 11 & $84(16)$ & $10.6(0.3)$ & $3.0(0.7)$ & 26 & 6 \\
\hline $5_{1} \rightarrow 4_{1}$ & E & $91985.313^{F}$ & 12.4 & $6.09 \times 10^{-5}$ & 4.8 & 11 & $114(12)$ & $10.5(0.1)$ & $2.6(0.4)$ & 40 & 9 \\
\hline $5_{0} \rightarrow 4_{0}$ & A & $91987.087^{F}$ & 13.2 & $6.35 \times 10^{-5}$ & 5.0 & 11 & $138(13)$ & $10.9(0.1)$ & $2.8(0.4)$ & 46 & 11 \\
\hline $6_{3} \rightarrow 5_{3}$ & A & $110364.353^{F}$ & 82.8 & $8.35 \times 10^{-5}$ & 9.0 & 26 & 151(11) & $10.8(0.1)$ & $2.7(0.2)$ & 53 & 8 \\
\hline $6_{2} \rightarrow 5_{2}$ & E & $110374.988^{F}$ & 39.1 & $9.89 \times 10^{-5}$ & 5.3 & 13 & $87(10)$ & $10.7(0.1)$ & $2.0(0.3)$ & 40 & 7 \\
\hline $6_{1} \rightarrow 5_{1}$ & $\mathrm{E}$ & $110381.371^{F}$ & 17.7 & $1.08 \times 10^{-4}$ & 5.8 & 13 & $144(10)$ & $10.8(0.1)$ & $2.1(0.2)$ & 65 & 10 \\
\hline $6_{0} \rightarrow 5_{0}$ & A & $110383.499^{F}$ & 18.5 & $1.11 \times 10^{-4}$ & 6.0 & 13 & $137(10)$ & $10.8(0.1)$ & $2.1(0.2)$ & 62 & 11 \\
\hline $7_{4} \rightarrow 6_{4}$ & E & $128739.669^{W}$ & 131.0 & $1.20 \times 10^{-4}$ & 4.7 & 15 & $75(49)$ & - & - & - & 2 \\
\hline $7_{3} \rightarrow 6_{3}$ & A & $128757.029^{W}$ & 89.0 & $1.46 \times 10^{-4}$ & 11.4 & 30 & 181(59) & - & - & - & 3 \\
\hline $7_{2} \rightarrow 6_{2}$ & $\mathrm{E}$ & $128769.435^{W}$ & 45.3 & $1.64 \times 10^{-4}$ & 6.4 & 15 & $112(62)$ & - & - & - & 4 \\
\hline $7_{1} \rightarrow 6_{1}$ & $\mathrm{E}$ & $128776.880^{W}$ & 23.8 & $1.75 \times 10^{-4}$ & 6.8 & 15 & & & & & \\
\hline $7_{0} \rightarrow 6_{0}$ & A & $128779.363^{W}$ & 24.7 & $1.79 \times 10^{-4}$ & 7.0 & 15 & & - & - & - & 0 \\
\hline $8_{3} \rightarrow 7_{3}$ & A & $147149.068^{W}$ & 96.1 & $2.31 \times 10^{-4}$ & 13.8 & 34 & $149(31)$ & - & - & - & 4 \\
\hline $8_{2} \rightarrow 7_{2}$ & $\mathrm{E}$ & $147163.243^{W}$ & 52.3 & $2.52 \times 10^{-4}$ & 7.5 & 17 & $98(33)$ & - & - & - & 2 \\
\hline $8_{1} \rightarrow 7_{1}$ & E & $147171.751^{W}$ & 30.9 & $2.65 \times 10^{-4}$ & 7.9 & 17 & $385(41)$ & - & - & - & 8 \\
\hline $8_{0} \rightarrow 7_{0}$ & A & $147174.587^{W}$ & 31.8 & $2.69 \times 10^{-4}$ & 8.0 & 17 & $30(4+1)$ & - & - & - & 0 \\
\hline $9_{4} \rightarrow 8_{4}$ & $\mathrm{E}$ & $165518.064^{W}$ & 146.0 & $3.09 \times 10^{-4}$ & 7.2 & 19 & $85(23)$ & - & - & - & 3 \\
\hline $9_{3} \rightarrow 8_{3}$ & A & $165540.376^{W}$ & 104.0 & $3.43 \times 10^{-4}$ & 16.0 & 38 & $177(20)$ & - & - & - & 9 \\
\hline
\end{tabular}


Table B.9. continued

\begin{tabular}{|c|c|c|c|c|c|c|c|c|c|c|c|}
\hline$\frac{\text { Transition }}{\left(J_{\mathrm{K}}\right)_{\mathrm{u}} \rightarrow\left(J_{\mathrm{K}}\right)_{1}}$ &.$^{*}$ & $\begin{array}{c}\text { Frequency } \\
{[\mathrm{MHz}]}\end{array}$ & $\begin{array}{r}E_{\mathrm{u}} / k \\
{[\mathrm{~K}]}\end{array}$ & $\begin{array}{c}A_{\mathrm{ul}} \\
{\left[\mathrm{s}^{-1}\right]}\end{array}$ & $S_{\mathrm{ul}}$ & $g_{\mathrm{u}}$ & $\underset{\left[\mathrm{mKKm} \mathrm{s}^{-1}\right]}{\int T_{\mathrm{MB}} \mathrm{d} v}$ & $\begin{array}{c}v_{\mathrm{LSR}} \\
{\left[\mathrm{km} \mathrm{s}^{-1}\right]}\end{array}$ & $\begin{array}{c}\Delta v \\
{\left[\mathrm{~km} \mathrm{~s}^{-1}\right]}\end{array}$ & $\begin{array}{c}T_{\mathrm{MB}} \\
{[\mathrm{mK}]}\end{array}$ & $/ N$ \\
\hline $9_{2} \rightarrow 8_{2}$ & $\mathrm{E}$ & $165556.321^{W}$ & 60.3 & $3.66 \times 10^{-4}$ & 8.6 & 19 & 108(19) & - & - & 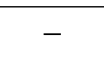 & 7 \\
\hline $9_{1} \rightarrow 8_{1}$ & $\mathrm{E}$ & $5565.890^{W}$ & 38.8 & $3.81 \times 10^{-4}$ & 8.9 & 19 & & & & & \\
\hline $9_{0} \rightarrow 8_{0}$ & A & $165569.080^{W}$ & 39.7 & $3.86 \times 10^{-4}$ & 9.0 & 19 & & & & & \\
\hline $11_{3} \rightarrow 10_{3}$ & 19 & $202320.442^{F}$ & 122.6 & $6.58 \times 10^{-4}$ & 20.3 & 46 & $140(11)$ & $10.7(0.1)$ & $2.0(0.2)$ & 6 & 8 \\
\hline $11_{2} \rightarrow 10_{2}$ & $\mathrm{E}$ & 2 & 78.8 & & 10.6 & 23 & $78(9$ & 1) & & 49 & 6 \\
\hline $11_{1} \rightarrow 10_{1}$ & E & 202351.6 & 57.4 & $7.05 \times 10^{-4}$ & 10.9 & 23 & $103(13$ & $10.7(0.2)$ & $2.9(0.4)$ & 33 & 5 \\
\hline $11_{0} \rightarrow 10_{0}$ & A & $2355.507^{F}$ & 58.3 & $7.11 \times 10^{-4}$ & 11.0 & 23 & $135(11)$ & & & & 7 \\
\hline $12_{4} \rightarrow 11_{4}$ & E & $220679.287^{F}$ & 175.1 & $8.22 \times 10^{-4}$ & 10.7 & 25 & $44(12)$ & $10.9(0.3)$ & 1.8 & 23 & 4 \\
\hline $12_{3} \rightarrow 11_{3}$ & A & & 33.2 & & 22.5 & 50 & $100(15)$ & $10.7(0.1)$ & 1.8 & & 8 \\
\hline $12_{2} \rightarrow 11_{2}$ & E & $220730.259^{F}$ & 89.4 & $9.00 \times 10^{-4}$ & 11.7 & 25 & $61(15)$ & $10.6(0.3)$ & 1.7 & & 6 \\
\hline $12_{1} \rightarrow 11_{1}$ & E & $220743.009^{F}$ & 68.0 & $9.20 \times 10^{-4}$ & 11.9 & 25 & $122(15)$ & $10.4(0.1)$ & $1.7(0.2)$ & 1 & 11 \\
\hline $12_{0} \rightarrow 11_{0}$ & A & $220747.259^{F}$ & 68.9 & $9.26 \times 10^{-4}$ & 12.0 & 25 & 69( & & & & 6 \\
\hline $13_{3} \rightarrow 12$ & A & $239096.495^{F}$ & 144.6 & $1.12 \times 10^{-3}$ & 24.6 & 54 & $94(16)$ & 10 & 1.9 & 46 & 7 \\
\hline $13_{2} \rightarrow 12_{2}$ & E & $239119.503^{F}$ & 100.9 & $1.15 \times 10^{-3}$ & 12.7 & 27 & $20(11)$ & 10.6 & 1.0 & & 3 \\
\hline $13_{0} \rightarrow 12_{0}$ & A & $239137.914^{F}$ & 80.3 & $1.18 \times 10^{-3}$ & 13.0 & 27 & 9) & $0.5(0.2)$ & 1.3 & 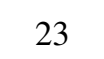 & 3 \\
\hline $14_{4} \rightarrow$ & 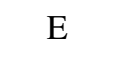 & & 199.0 & & 12.9 & 29 & $29(10)$ & 10.6 & 1.5 & 9 & 3 \\
\hline $14_{3} \rightarrow 13_{3}$ & A & & 157.0 & & 26.7 & 58 & 5 & & & & 5 \\
\hline $14_{2}-$ & $\mathrm{E}$ & & 113.3 & & 13.7 & 29 & & & & 0 & 6 \\
\hline $14_{1} \rightarrow 13_{1}$ & $\Gamma$ & $257522.425^{F}$ & 91.8 & $1.47 \times 10^{-3}$ & 13.9 & 29 & $53(11)$ & $10.8(0.3)$ & $2.0(C$ & & 4 \\
\hline $14_{0} \rightarrow 13_{0}$ & A & $257527.381^{F}$ & 92.7 & $1.48 \times 10^{-3}$ & 14.0 & 29 & $42(8)$ & $10.9(0.1)$ & $1.0(0.2)$ & 8 & 5 \\
\hline $15_{3} \rightarrow 14_{3}$ & 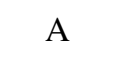 & $275867.809^{F}$ & 170.2 & $1.75 \times 10^{-3}$ & 28.8 & 62 & 61(14) & $10.5(0.2)$ & $1.5(C$ & 50 & 4 \\
\hline$\rightarrow 14_{2}$ & 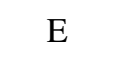 & $275894.339^{F}$ & 126.5 & $1.79 \times 10^{-3}$ & 14.7 & 31 & $31(9)$ & $10.3(0.1)$ & $0.7(0.3)$ & 40 & 2 \\
\hline $15_{1} \rightarrow 14_{1}$ & $\mathrm{E}$ & $275910.261^{F}$ & 105.1 & $1.81 \times 10^{-3}$ & 14.9 & 31 & $30(12)$ & $10.7(0.2)$ & $0.7(0.2)$ & 40 & 2 \\
\hline $16_{3} \rightarrow 15_{3}$ & 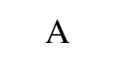 & $294251.460^{F}$ & 184.4 & $2.14 \times 10^{-3}$ & 30.9 & 66 & $55(13)$ & $10.1(0.2)$ & $1.2(0.2)$ & 43 & 4 \\
\hline $16_{2} \rightarrow 15_{2}$ & $\mathrm{E}$ & $294279.748^{F}$ & 140.6 & $2.18 \times 10^{-3}$ & 15.7 & 33 & $33(15)$ & $10.4(0.2)$ & $0.9(0.3)$ & 34 & 4 \\
\hline $16 . \rightarrow 15$ & E & $294296.726^{F}$ & 119.2 & $2.21 \times 10^{-3}$ & 15.9 & 33 & $34(9)$ & $10.2(0.1)$ & $1.0(0.2)$ & 32 & 4 \\
\hline $16_{0} \rightarrow 15_{0}$ & 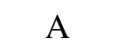 & $294302.386^{F}$ & 120.1 & $2.22 \times 10^{-3}$ & 16.0 & 33 & 27(9) & $10.9(0.2)$ & $0.8(0.2)$ & 32 & 2 \\
\hline
\end{tabular}

Notes. Frequencies, $E_{\mathrm{u}} / k, A_{\mathrm{ul}}, S_{\mathrm{ul}}$, and $g_{\mathrm{u}}$ from MADEX code, that fit to all rotational lines reported by Kukolich et al. (1973), Boucher et al. (1977), Kukolich (1982), Pavone et al. (1990), Cazzoli \& Puzzarini (2006), Šimečková et al. (2004), Müller et al. (2009). 
Table B.10. Line parameters of $\mathrm{CH}_{3} \mathrm{OH}$.

\begin{tabular}{|c|c|c|c|c|c|c|c|c|c|c|c|}
\hline$\frac{\text { Transition }}{\left(J_{\mathrm{K}}\right)_{\mathrm{u}} \rightarrow\left(J_{\mathrm{K}}\right)_{1}}$ & Sym.* & $\begin{array}{c}\text { Frequency } \\
{[\mathrm{MHz}]}\end{array}$ & $\begin{array}{r}E_{\mathrm{u}} / k \\
{[\mathrm{~K}]} \\
\end{array}$ & $\begin{array}{c}A_{\mathrm{ul}} \\
{\left[\mathrm{s}^{-1}\right]}\end{array}$ & $S_{\mathrm{ul}}$ & $g_{\mathrm{u}}$ & $\underset{\left[\mathrm{mK} \mathrm{km} \mathrm{s}^{-1}\right]}{\int T_{\mathrm{MB}} \mathrm{d} v}$ & $\begin{array}{c}v_{\mathrm{LSR}} \\
{\left[\mathrm{km} \mathrm{s}^{-1}\right]}\end{array}$ & $\begin{array}{c}\Delta v \\
{\left[\mathrm{~km} \mathrm{~s}^{-1}\right]}\end{array}$ & $\begin{array}{c}T_{\mathrm{MB}} \\
{[\mathrm{mK}]}\end{array}$ & $S / N$ \\
\hline $5_{-1} \rightarrow 4_{0}$ & $\mathrm{E}$ & $84521.172^{F}$ & 32.5 & $1.97 \times 10^{-6}$ & 1.5 & 11 & $149(8)$ & $10.6(0.1)$ & $1.6(0.1)$ & 86 & 18 \\
\hline $8_{0} \rightarrow 7_{1}$ & A & $95169.391^{F}$ & 83.5 & $2.13 \times 10^{-6}$ & 1.8 & 17 & $59(6)$ & $10.4(0.1)$ & $1.5(0.1)$ & 54 & 14 \\
\hline $2_{1} \rightarrow 1_{1}$ & A & $95914.310^{F}$ & 21.4 & $2.49 \times 10^{-6}$ & 1.5 & 5 & $28(12)$ & $10.8(0.3)$ & $1.7(0.7)$ & 15 & 2 \\
\hline $2_{-1} \rightarrow 1_{-1}$ & $\mathrm{E}$ & $96739.358^{F}$ & 4.6 & $2.56 \times 10^{-6}$ & 1.5 & 5 & $107(9)$ & $10.7(0.1)$ & $1.5(0.1)$ & 67 & 9 \\
\hline $2_{0} \rightarrow 1_{0}$ & A & $96741.371^{F}$ & 7.0 & $3.41 \times 10^{-6}$ & 2.0 & 5 & $206(9)$ & $10.8(0.1)$ & $1.7(0.2)$ & 114 & 16 \\
\hline $2_{0} \rightarrow 1_{0}$ & $\mathrm{E}$ & $96744.545^{F}$ & 12.2 & $3.41 \times 10^{-6}$ & 2.0 & 5 & $95(12)$ & $10.7(0.1)$ & $1.9(0.3)$ & 44 & 6 \\
\hline $2_{1} \rightarrow 1_{1}$ & $\mathrm{E}$ & $96755.501^{F}$ & 20.1 & $2.62 \times 10^{-6}$ & 1.5 & 5 & $66(13)$ & $10.8(0.2)$ & $2.0(0.5)$ & 27 & 4 \\
\hline $2_{-1} \rightarrow 1_{-1}$ & A & $97582.798^{F}$ & 21.6 & $2.63 \times 10^{-6}$ & 1.5 & 5 & $32(12)$ & $10.5(0.2)$ & $1.7(0.6)$ & 18 & 4 \\
\hline $3_{1} \rightarrow 4_{0}$ & A & $107013.831^{F}$ & 28.3 & $3.07 \times 10^{-6}$ & 0.7 & 7 & $30(12)$ & $9.7(0.4)$ & $2.2(0.2)$ & 13 & 3 \\
\hline $0_{0} \rightarrow 1_{-1}$ & $\mathrm{E}$ & $108893.945^{F}$ & 5.2 & $1.47 \times 10^{-5}$ & 0.5 & 1 & $45(6)$ & $10.7(0.1)$ & $1.6(0.2)$ & 26 & 7 \\
\hline $6_{-1} \rightarrow 5_{0}$ & $\mathrm{E}$ & $132890.759^{W}$ & 46.4 & $7.75 \times 10^{-6}$ & 1.8 & 13 & 191(31) & - & - & - & 5 \\
\hline $3_{1} \rightarrow 2_{1}$ & A & $143865.795^{W}$ & 28.3 & $1.07 \times 10^{-5}$ & 2.7 & 7 & $74(28)$ & - & - & - & 3 \\
\hline $3_{-1} \rightarrow 2_{-1}$ & $\mathrm{E}$ & $145097.435^{W}$ & 11.6 & $1.10 \times 10^{-5}$ & 2.7 & 7 & $269(28)$ & - & - & - & 10 \\
\hline $3_{0} \rightarrow 2_{0}$ & A & $145103.185^{W}$ & 13.9 & $1.23 \times 10^{-5}$ & 3.0 & 7 & $384(83)$ & - & - & - & 12 \\
\hline $3_{-2} \rightarrow 2_{-2}$ & A & $145124.332^{W}$ & 51.6 & $6.89 \times 10^{-6}$ & 1.7 & 7 & & & & & \\
\hline $3_{2} \rightarrow 2_{2}$ & $\mathrm{E}$ & $145126.191^{W}$ & 28.3 & $6.77 \times 10^{-6}$ & 1.7 & 7 & $103(23)$ & - & - & - & 4 \\
\hline $3_{-2} \rightarrow 2_{-2}$ & $\mathrm{E}$ & $145126.386^{W}$ & 31.9 & $6.86 \times 10^{-6}$ & 1.7 & 7 & & & & & \\
\hline $3_{1} \rightarrow 2_{1}$ & $\mathrm{E}$ & $145131.864^{W}$ & 27.1 & $1.13 \times 10^{-5}$ & 2.8 & 7 & 13 & - & - & - & 5 \\
\hline $3_{2} \rightarrow 2_{2}$ & A & $145133.415^{W}$ & 51.6 & $6.89 \times 10^{-6}$ & 1.7 & 7 & & & & & \\
\hline $3_{-1} \rightarrow 2_{-1}$ & A & $146368.328^{W}$ & 28.6 & $1.13 \times 10^{-5}$ & 2.7 & 7 & $74(41)$ & - & - & - & 3 \\
\hline $9_{0} \rightarrow 8_{1}$ & A & $146618.697^{W}$ & 104.4 & $8.04 \times 10^{-6}$ & 2.1 & 19 & $92(26)$ & - & - & - & 3 \\
\hline $6_{2} \rightarrow 7_{1}$ & A & $156127.544^{W}$ & 86.5 & $6.74 \times 10^{-6}$ & 1.0 & 13 & $82(30)$ & - & - & - & 3 \\
\hline $2_{1} \rightarrow 3_{0}$ & A & $156602.395^{W}$ & 21.4 & $8.93 \times 10^{-6}$ & 0.5 & 5 & $149(35)$ & - & - & - & 4 \\
\hline $7_{0} \rightarrow 7_{-1}$ & $\mathrm{E}$ & $156828.517^{W}$ & 70.2 & $1.88 \times 10^{-5}$ & 3.1 & 15 & $61(17)$ & - & - & - & 2 \\
\hline $6_{0} \rightarrow 6_{-1}$ & $\mathrm{E}$ & $157048.617^{W}$ & 54.0 & $1.96 \times 10^{-5}$ & 2.8 & 13 & $82(27)$ & - & - & - & 3 \\
\hline $1_{0} \rightarrow 1_{-1}$ & $\mathrm{E}$ & $157270.832^{W}$ & 7.5 & $2.21 \times 10^{-5}$ & 0.7 & 3 & & & & & \\
\hline $3_{0} \rightarrow 3_{-1}$ & $\mathrm{E}$ & $157272.338^{W}$ & 19.2 & $2.15 \times 10^{-5}$ & 1.7 & 7 & $355(53)$ & - & - & - & 8 \\
\hline $2_{0} \rightarrow 2_{-1}$ & $\mathrm{E}$ & $157276.019^{W}$ & 12.2 & $2.18 \times 10^{-5}$ & 1.2 & 5 & & & & & \\
\hline $1_{1} \rightarrow 1_{0}$ & $\mathrm{E}$ & $165050.175^{W}$ & 15.5 & $2.35 \times 10^{-5}$ & 0.7 & 3 & $56(22)$ & - & - & - & 2 \\
\hline $2_{1} \rightarrow 2_{0}$ & $\mathrm{E}$ & $165061.130^{W}$ & 20.1 & $2.34 \times 10^{-5}$ & 1.1 & 5 & $232(38)$ & - & - & - & 4 \\
\hline $3_{1} \rightarrow 3_{0}$ & $\mathrm{E}$ & $165099.240^{W}$ & 27.1 & $2.33 \times 10^{-5}$ & 1.6 & 7 & $170(28)$ & - & - & - & 6 \\
\hline $4_{1} \rightarrow 4_{0}$ & $\mathrm{E}$ & $165190.475^{W}$ & 36.4 & $2.32 \times 10^{-5}$ & 2.0 & 9 & $178(70)$ & - & - & - & 6 \\
\hline $5_{1} \rightarrow 5_{0}$ & $\mathrm{E}$ & $165369.341^{W}$ & 48.0 & $2.31 \times 10^{-5}$ & 2.4 & 11 & $127(25)$ & - & - & - & 4 \\
\hline $6_{1} \rightarrow 6_{0}$ & $\mathrm{E}$ & $165678.649^{W}$ & 61.9 & $2.29 \times 10^{-5}$ & 2.8 & 13 & $312(31)$ & - & - & - & 6 \\
\hline $7_{1} \rightarrow 7_{0}$ & $\mathrm{E}$ & $166169.098^{W}$ & 78.2 & $2.28 \times 10^{-5}$ & 3.2 & 15 & $102(23)$ & - & - & - & 4 \\
\hline $3_{2} \rightarrow 2_{1}$ & $\mathrm{E}$ & $170060.592^{W}$ & 28.3 & $2.55 \times 10^{-5}$ & 1.6 & 7 & $275(53)$ & - & - & - & 7 \\
\hline $1_{1} \rightarrow 2_{0}$ & A & $205791.270^{F}$ & 16.8 & $6.28 \times 10^{-5}$ & 0.9 & 3 & $47(16)$ & $10.3(0.4)$ & $2.5(0.7)$ & 18 & 2 \\
\hline $4_{2} \rightarrow 3_{1}$ & $\mathrm{E}$ & $218440.063^{F}$ & 37.6 & $4.69 \times 10^{-5}$ & 1.7 & 9 & $180(10)$ & $10.7(0.1)$ & $1.5(0.1)$ & 113 & 15 \\
\hline $8_{-1} \rightarrow 7_{0}$ & $\mathrm{E}$ & $229758.756^{F}$ & 81.2 & $4.19 \times 10^{-5}$ & 2.5 & 17 & $110(14)$ & $10.7(0.1)$ & $1.5(0.1)$ & 69 & 5 \\
\hline $5_{1} \rightarrow 4_{1}$ & A & $239746.219^{F}$ & 49.1 & $5.66 \times 10^{-5}$ & 4.8 & 11 & $74(14)$ & $10.4(0.1)$ & $1.4(0.1)$ & 53 & 3 \\
\hline $5_{0} \rightarrow 4_{0}$ & $\mathrm{E}$ & $241700.159^{F}$ & 40.0 & $6.04 \times 10^{-5}$ & 5.0 & 11 & 251(21) & $10.8(0.1)$ & $2.6(0.3)$ & 90 & 7 \\
\hline $5_{-1} \rightarrow 4_{-1}$ & $\mathrm{E}$ & $241767.234^{F}$ & 32.5 & $5.81 \times 10^{-5}$ & 4.8 & 11 & $357(33)$ & $10.4(0.2)$ & $1.9(0.1)$ & 224 & 15 \\
\hline
\end{tabular}


Table B.10. continued.

\begin{tabular}{|c|c|c|c|c|c|c|c|c|c|c|c|}
\hline$\frac{\text { Transition }}{\left(J_{\mathrm{K}}\right)_{\mathrm{u}} \rightarrow\left(J_{\mathrm{K}}\right)_{1}}$ & Sym.* & $\begin{array}{c}\text { Frequency } \\
{[\mathrm{MHz}]}\end{array}$ & $\begin{array}{r}E_{\mathrm{u}} / k \\
{[\mathrm{~K}]}\end{array}$ & $\begin{array}{c}A_{\mathrm{ul}} \\
{\left[\mathrm{s}^{-1}\right]}\end{array}$ & $S_{\text {ul }}$ & $g_{\mathrm{u}}$ & $\underset{\left[\mathrm{mK} \mathrm{km} \mathrm{s}^{-1}\right]}{\int T_{\mathrm{MB}} \mathrm{d} v}$ & $\begin{array}{c}v_{\mathrm{LSR}} \\
{\left[\mathrm{km} \mathrm{s}^{-1}\right]}\end{array}$ & $\begin{array}{c}\Delta v \\
{\left[\mathrm{~km} \mathrm{~s}^{-1}\right]}\end{array}$ & $\begin{array}{c}T_{\mathrm{MB}} \\
{[\mathrm{mK}]}\end{array}$ & $S / N$ \\
\hline $5_{0} \rightarrow 4_{0}$ & A & $241791.352^{F}$ & 34.8 & $6.05 \times 10^{-5}$ & 5.0 & 11 & $646(43)$ & $10.5(0.2)$ & $2.2(0.2)$ & 273 & 27 \\
\hline $5_{-4} \rightarrow 4_{-4}$ & $\mathrm{E}$ & $241813.255^{F}$ & 114.8 & $2.18 \times 10^{-5}$ & 1.8 & 11 & $38(13)$ & $10.7(0.2)$ & $1.2(0.6)$ & 28 & 2 \\
\hline $5_{1} \rightarrow 4_{1}$ & $\mathrm{E}$ & $241879.025^{F}$ & 48.0 & $5.96 \times 10^{-5}$ & 5.0 & 11 & 205 & .3) & $3.3(0.6)$ & 56 & 7 \\
\hline $5_{-2} \rightarrow 4_{-2}$ & E & $241904.147^{F}$ & 52.8 & $5.09 \times 10^{-5}$ & 4.2 & 11 & & & & & 7 \\
\hline $5_{2} \rightarrow 4_{2}$ & E & $241904.643^{F}$ & 49.2 & $5.03 \times 10^{-5}$ & 4.2 & 11 & & & & & \\
\hline $5_{-1} \rightarrow 4_{-1}$ & A & $243915.788^{F}$ & 49.7 & $5.97 \times 10^{-5}$ & 4.8 & 11 & $72(13)$ & $10.8(0.1)$ & $0.7(0.2)$ & 99 & 7 \\
\hline $2_{1} \rightarrow 1_{0}$ & E & $261805.675^{F}$ & 20.1 & $5.57 \times 10^{-5}$ & 0.7 & 5 & $143(10)$ & $10.7(0.1)$ & $1.5(0.1)$ & 89 & 7 \\
\hline $5_{2} \rightarrow 4_{1}$ & E & $266838.148^{F}$ & 49.2 & $7.74 \times 10^{-5}$ & 1.9 & 11 & $225(12)$ & $10.7(0.1)$ & $1.7(0.1)$ & 124 & 10 \\
\hline $9_{-1} \rightarrow 8_{0}$ & E & $278304.512^{F}$ & 102.1 & $7.69 \times 10^{-5}$ & 2.9 & 19 & $96(9)$ & $10.7(0.1)$ & $0.9(0.2)$ & 100 & 10 \\
\hline $6_{1} \rightarrow 5_{1}$ & A & $287670.767^{F}$ & 62.9 & $1.01 \times 10^{-4}$ & 5.9 & 13 & $80(9)$ & $10.8(0.2)$ & $1.8(0.1)$ & 42 & 3 \\
\hline $6_{-1} \rightarrow 5_{-1}$ & A & $292672.889^{F}$ & 63.7 & $1.06 \times 10^{-4}$ & 5.9 & 13 & $82(23)$ & $10.8(0.1)$ & $0.9(0.2)$ & 90 & 10 \\
\hline $3_{0} \rightarrow 2_{-1}$ & E & $302369.773^{F}$ & 19.2 & $4.66 \times 10^{-5}$ & 0.5 & 7 & $34(14)$ & $10.0(0.1)$ & $0.4(0.2)$ & 84 & 3 \\
\hline $1_{-1} \rightarrow 1_{0}$ & A & $303366.921^{F}$ & 16.9 & $2.26 \times 10^{-4}$ & 1.0 & 3 & 171(14) & $10.5(0.1)$ & $1.8(0.1)$ & 89 & 5 \\
\hline $2_{-1} \rightarrow 2_{0}$ & A & $304208.348^{F}$ & 21.6 & $2.12 \times 10^{-4}$ & 1.6 & 5 & $228(14)$ & $10.3(0.1)$ & $1.6(0.1)$ & 134 & 7 \\
\hline $7_{0} \rightarrow 6_{0}$ & E & $338124.488^{F}$ & 70.2 & $1.70 \times 10^{-4}$ & 7.0 & 15 & $174(53)$ & $10.5(0.2)$ & $1.6(0.6)$ & 101 & 3 \\
\hline $7_{-1} \rightarrow 6_{-1}$ & E & $338344.588^{F}$ & 62.7 & $1.67 \times 10^{-4}$ & 6.9 & 15 & $260(64)$ & $10.7(0.1)$ & $1.5(0.2)$ & 235 & 11 \\
\hline $7_{0} \rightarrow 6_{0}$ & A & $338408.698^{F}$ & 65.0 & $1.70 \times 10^{-4}$ & 7.0 & 15 & $440(69)$ & $10.7(0.1)$ & $1.6(0.1)$ & 259 & 12 \\
\hline $7_{3} \rightarrow 6_{3}$ & E & $338583.216^{F}$ & 104.8 & $1.39 \times 10^{-4}$ & 5.8 & 15 & $59(20)$ & $11.0(0.1)$ & $0.4(0.1)$ & 133 & 3 \\
\hline $7_{2} \rightarrow 6_{2}$ & E & $338721.693^{F}$ & 79.4 & $1.55 \times 10^{-4}$ & 6.4 & 15 & 2 2) & $10.5(0.1)$ & $1.3(0.1)$ & 1 & 3 \\
\hline $7_{-2} \rightarrow 6_{-2}$ & $\mathrm{E}$ & $338722.898^{F}$ & 83.0 & $1.57 \times 10^{-4}$ & 6.5 & 15 & (2L) & $10.0(0.1)$ & $1.5(0.1)$ & 111 & 3 \\
\hline
\end{tabular}

Notes. Frequencies, $E_{\mathrm{u}} / k, A_{\mathrm{ul}}, S_{\mathrm{ul}}$, and $g_{\mathrm{u}}$ from JPL catalogue.

Table B.11. Line parameters of $\mathrm{CH}_{3} \mathrm{CHO}$.

\begin{tabular}{|c|c|c|c|c|c|c|c|c|c|c|c|}
\hline Transition & Sym.* & Frequency & $E_{\mathrm{u}} / k$ & $A_{\mathrm{ul}}$ & $S_{\mathrm{ul}}$ & $g_{\mathrm{u}}$ & $T_{\mathrm{MB}} \mathrm{d} v$ & $v_{\mathrm{LSR}}$ & $\Delta v$ & $T_{\mathrm{MB}}$ & $S / N$ \\
\hline$\left(J_{K_{\mathrm{a}}, K_{\mathrm{c}}}\right)_{\mathrm{u}} \rightarrow\left(J_{K_{\mathrm{a}}, K_{\mathrm{c}}}\right)_{1}$ & & {$[\mathrm{MHz}]$} & {$[\mathrm{K}]$} & {$\left[\mathrm{s}^{-1}\right]$} & & & {$\left[\mathrm{mK} \mathrm{km} \mathrm{s}^{-1}\right]$} & {$\left[\mathrm{km} \mathrm{s}^{-1}\right]$} & {$\left[\mathrm{km} \mathrm{s}^{-1}\right]$} & {$[\mathrm{mK}]$} & \\
\hline $5_{1,5} \rightarrow 4_{1,4}$ & A & $93580.909^{F}$ & 15.7 & $2.63 \times 10^{-5}$ & 5.2 & 11 & $60(6)$ & $10.4(0.1)$ & $2.7(0.3)$ & 21 & 6 \\
\hline $5_{1,5} \rightarrow 4_{1,4}$ & $\mathrm{E}$ & $93595.235^{F}$ & 15.7 & $2.63 \times 10^{-5}$ & 5.2 & 11 & $51(7)$ & $10.8(0.2)$ & $2.3(0.4)$ & 21 & 6 \\
\hline $5_{0,5} \rightarrow 4_{0,4}$ & $\mathrm{E}$ & $95947.437^{F}$ & 13.8 & $2.96 \times 10^{-5}$ & 5.4 & 11 & $29(6)$ & $10.7(0.3)$ & $2.0(0.4)$ & 13 & 3 \\
\hline $5_{0,5} \rightarrow 4_{0,4}$ & A & $95963.459^{F}$ & 13.8 & $2.95 \times 10^{-5}$ & 5.4 & 11 & $54(13)$ & $10.7(0.2)$ & $2.0(0.5)$ & 25 & 3 \\
\hline $5_{1,4} \rightarrow 4_{1,3}$ & E & $98863.314^{F}$ & 16.5 & $3.10 \times 10^{-5}$ & 5.2 & 11 & $79(6)$ & $11.1(0.3)$ & $2.9(0.5)$ & 26 & 3 \\
\hline $5_{1,4} \rightarrow 4_{1,3}$ & A & $98900.944^{F}$ & 16.5 & $3.11 \times 10^{-5}$ & 5.2 & 11 & $63(10)$ & $11.1(0.1)$ & $1.6(0.3)$ & 38 & 7 \\
\hline $6_{1,6} \rightarrow 5_{1,5}$ & A & $112248.716^{F}$ & 21.1 & $4.67 \times 10^{-5}$ & 6.3 & 13 & $57(10)$ & $10.7(0.2)$ & $2.0(0.3)$ & 27 & 5 \\
\hline $6_{1,6} \rightarrow 5_{1,5}$ & $\mathrm{E}$ & $112254.508^{F}$ & 21.1 & $4.67 \times 10^{-5}$ & 6.3 & 13 & $46(11)$ & $11.2(0.2)$ & $1.9(0.5)$ & 23 & 4 \\
\hline $6_{0,6} \rightarrow 5_{0,5}$ & E & $114940.175^{F}$ & 19.4 & $5.16 \times 10^{-5}$ & 6.5 & 13 & $95(18)$ & $11.0(0.2)$ & $2.2(0.5)$ & 40 & 4 \\
\hline $6_{0,6} \rightarrow 5_{0,5}$ & A & $114959.902^{F}$ & 19.4 & $5.15 \times 10^{-5}$ & 6.5 & 13 & $106(15)$ & $10.6(0.1)$ & $2.0(0.3)$ & 49 & 5 \\
\hline $7_{1,7} \rightarrow 6_{1,6}$ & A & $130891.821^{W}$ & 27.4 & $7.54 \times 10^{-5}$ & 7.4 & 15 & & - & t & - & 4 \\
\hline $7_{1,7} \rightarrow 6_{1,6}$ & $\mathrm{E}$ & $130892.749^{W}$ & 27.4 & $7.55 \times 10^{-5}$ & 7.4 & 15 & & & & & \\
\hline
\end{tabular}


Table B.11. continued.

\begin{tabular}{|c|c|c|c|c|c|c|c|c|c|c|c|}
\hline Transition & Sym.* & Frequency & $E_{\mathrm{u}} / k$ & $A_{\mathrm{ul}}$ & $S_{\mathrm{ul}}$ & $g_{\mathrm{u}}$ & $T_{\mathrm{MB}} \mathrm{d} v$ & $v_{\mathrm{LSR}}$ & $\Delta v$ & $T_{\mathrm{MB}}$ & $S / N$ \\
\hline$\left(J_{K_{\mathrm{a}}, K_{\mathrm{c}}}\right)_{\mathrm{u}} \rightarrow\left(J_{K_{\mathrm{a}}, K_{\mathrm{c}}}\right)_{1}$ & & {$[\mathrm{MHz}]$} & {$[\mathrm{K}]$} & {$\left[\mathrm{s}^{-1}\right]$} & & & {$\left[\mathrm{mK} \mathrm{km} \mathrm{s}^{-1}\right]$} & {$\left[\mathrm{km} \mathrm{s}^{-1}\right]$} & {$\left[\mathrm{km} \mathrm{s}^{-1}\right]$} & {$[\mathrm{mK}]$} & \\
\hline $7_{1,6} \rightarrow 6_{1,5}$ & A & $138319.628^{W}$ & 28.8 & $8.90 \times 10^{-5}$ & 7.4 & 15 & $166(62)$ & - & - & - & 3 \\
\hline $8_{1,8} \rightarrow 7_{1,7}$ & $\mathrm{E}$ & $149505.128^{W}$ & 34.6 & $1.14 \times 10^{-4}$ & 8.5 & 17 & $193(96)$ & - & - & - & 2 \\
\hline $8_{1,8} \rightarrow 7_{1,7}$ & A & $149507.462^{W}$ & 34.6 & $1.14 \times 10^{-4}$ & 8.5 & 17 & & - & - & - & 2 \\
\hline $8_{0,8} \rightarrow 7_{0,7}$ & $\mathrm{E}$ & $152607.614^{W}$ & 33.1 & $1.23 \times 10^{-4}$ & 8.6 & 17 & $184(74)$ & - & - & - & 4 \\
\hline $8_{1,7} \rightarrow 7_{1,6}$ & E & $157937.697^{W}$ & 36.4 & $1.34 \times 10^{-4}$ & 8.5 & 17 & $86(21)$ & - & - & - & 4 \\
\hline $8_{1,7} \rightarrow 7_{1,6}$ & A & $157974.590^{W}$ & 36.4 & $1.34 \times 10^{-4}$ & 8.5 & 17 & $105(24)$ & - & - & - & 6 \\
\hline $9_{1,9} \rightarrow 8_{1,8}$ & $\mathrm{E}$ & $168088.618^{W}$ & 42.6 & $1.64 \times 10^{-4}$ & 9.6 & 19 & $98(36)$ & - & - & - & 3 \\
\hline $9_{1,9} \rightarrow 8_{1,8}$ & A & $168093.444^{W}$ & 42.7 & $1.64 \times 10^{-4}$ & 9.6 & 19 & & & & & \\
\hline $9_{0,9} \rightarrow 8_{0,8}$ & A & $171296.985^{W}$ & 41.3 & $1.75 \times 10^{-4}$ & 9.7 & 19 & $158(92)$ & - & - & - & 2 \\
\hline $11_{1,11} \rightarrow 10_{1,10}$ & $\mathrm{E}$ & $205161.898^{F}$ & 61.4 & $3.02 \times 10^{-4}$ & 11.7 & 23 & $74(10)$ & $10.6(0.2)$ & $2.4(0.3)$ & 29 & 4 \\
\hline $11_{1,11} \rightarrow 10_{1,10}$ & A & $205170.686^{F, B}$ & 61.5 & $3.01 \times 10^{-4}$ & 11.7 & 23 & - & - & - & - & - \\
\hline $11_{0,11} \rightarrow 10_{0,10}$ & A & $208267.045^{F}$ & 60.4 & $3.17 \times 10^{-4}$ & 11.8 & 23 & $62(9)$ & $10.6(0.1)$ & $1.8(0.3)$ & 33 & 5 \\
\hline $11_{1,10} \rightarrow 10_{1,9}$ & $\mathrm{E}$ & $216581.930^{F}$ & 64.8 & $3.55 \times 10^{-4}$ & 11.7 & 23 & $47(10)$ & $10.7(0.2)$ & $1.4(0.5)$ & 32 & 5 \\
\hline $11_{1,10} \rightarrow 10_{1,9}$ & A & $216630.234^{F}$ & 64.8 & $3.55 \times 10^{-4}$ & 11.7 & 23 & $53(7)$ & $10.7(0.1)$ & $1.5(0.2)$ & 33 & 5 \\
\hline $12_{1,12} \rightarrow 11_{1,11}$ & $\mathrm{E}$ & $223650.093^{F}$ & 72.2 & $3.92 \times 10^{-4}$ & 12.8 & 25 & $68(9)$ & $10.8(0.1)$ & $1.9(0.3)$ & 34 & 6 \\
\hline $12_{1,12} \rightarrow 11_{1,11}$ & A & $223660.603^{F}$ & 72.2 & $3.92 \times 10^{-4}$ & 12.8 & 25 & $58(11)$ & $10.7(0.2)$ & $2.2(0.5)$ & 24 & 4 \\
\hline $12_{0,12} \rightarrow 11_{0,11}$ & $\mathrm{E}$ & $226551.622^{F}$ & 71.3 & $4.10 \times 10^{-4}$ & 12.9 & 25 & $114(6)$ & $10.5(0.3)$ & $2.5(0.5)$ & 43 & 6 \\
\hline $12_{0,12} \rightarrow 11_{0,11}$ & A & $226592.725^{F}$ & 71.3 & $4.10 \times 10^{-4}$ & 12.9 & 25 & $54(15)$ & $11.4(0.1)$ & $1.0(0.4)$ & 50 & 4 \\
\hline $12_{1,11} \rightarrow 11_{1,10}$ & $\mathrm{E}$ & $235996.212^{F}$ & 76.1 & $4.61 \times 10^{-4}$ & 12.8 & 25 & $77(23)$ & $10.8(0.3)$ & $2.0(0.8)$ & 36 & 3 \\
\hline $12_{1,11} \rightarrow 11_{1,10}$ & A & $236049.131^{F}$ & 76.1 & $4.61 \times 10^{-4}$ & 12.8 & 25 & $39(15)$ & $10.8(0.2)$ & $1.0(0.5)$ & 38 & 3 \\
\hline $13_{1,13} \rightarrow 12_{1,12}$ & A & $242118.136^{F}$ & 83.8 & $5.00 \times 10^{-4}$ & 13.9 & 27 & $43(17)$ & $10.0(0.5)$ & $2.5(1.3)$ & 16 & 2 \\
\hline $13_{0,13} \rightarrow 12_{0,12}$ & A & $244832.176^{F}$ & 83.1 & $5.18 \times 10^{-4}$ & 13.9 & 27 & $48(10)$ & $11.5(0.1)$ & $1.2(0.3)$ & 39 & 3 \\
\hline $13_{1,12} \rightarrow 12_{1,11}$ & $\mathrm{E}$ & $255326.968^{F}$ & 88.4 & $5.86 \times 10^{-4}$ & 13.9 & 27 & $65(13)$ & $10.9(0.2)$ & $2.0(0.5)$ & 30 & 5 \\
\hline $13_{1,12} \rightarrow 12_{1,11}$ & A & $255384.754^{F}$ & 88.4 & $5.86 \times 10^{-4}$ & 13.9 & 27 & $67(10)$ & $10.6(0.1)$ & $1.8(0.3)$ & 34 & 6 \\
\hline $14_{0,14} \rightarrow 13_{0,13}$ & $\mathrm{E}$ & $262960.097^{F}$ & 95.7 & $6.44 \times 10^{-4}$ & 15.0 & 29 & $32(7)$ & $10.5(0.2)$ & $1.3(0.3)$ & 23 & 4 \\
\hline $14_{1,13} \rightarrow 13_{1,12}$ & $\mathrm{E}$ & $274563.412^{F}$ & 101.5 & $7.31 \times 10^{-4}$ & 15.0 & 29 & $38(11)$ & $10.9(0.2)$ & $1.0(0.3)$ & 35 & 2 \\
\hline $15_{1,15} \rightarrow 14_{1,14}$ & A & $278939.438^{F}$ & 109.7 & $7.69 \times 10^{-4}$ & 16.1 & 31 & $22(7)$ & $10.5(0.2)$ & $1.0(0.4)$ & 23 & 3 \\
\hline $15_{0,15} \rightarrow 14_{0,14}$ & A & $281126.944^{F}$ & 109.2 & $7.88 \times 10^{-4}$ & 16.1 & 31 & $29(11)$ & $10.7(0.3)$ & $1.4(0.5)$ & 19 & 2 \\
\hline
\end{tabular}

Notes. ${ }^{B}$ Blended with $\mathrm{CF}^{+} 2 \rightarrow 1$. Frequencies, $E_{\mathrm{u}} / k, A_{\mathrm{ul}}, S_{\mathrm{ul}}$, and $g_{\mathrm{u}}$ from JPL catalogue. 